\title{
Collection of experimental data on the behavior of TCM/PCM-materials to bench- mark numerical codes
}

Report A3.2 of the Working Group on Numerical Modelling

December 2012

Paul Gantenbein

Camilo Rindt

A report of the IEA Solar Heating and Cooling / Energy Conservation through Energy Storage programme - Task 42/Annex 24:

\section{Compact Thermal Energy Storage: Material Development for System Integration}
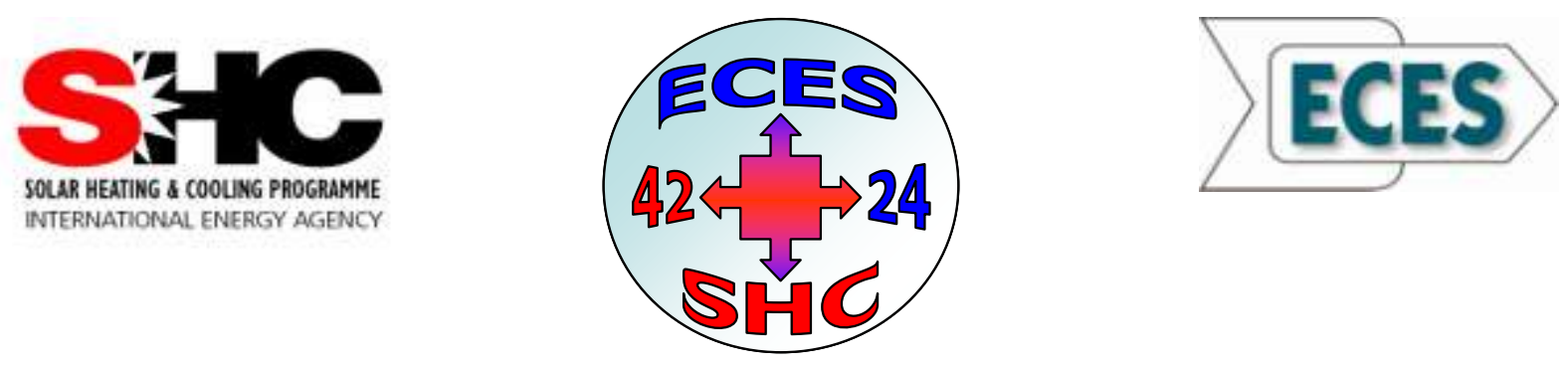


\section{Collection of experimental data on the behavior of TCM/PCM-materials to bench- mark numerical codes}

by

Paul Gantenbein, Camilo Rindt 


\section{Short description Working Group A3 Numerical Modelling}

\section{INTRODUCTION}

The activities in this working group are aimed at developing and testing numerical models that help to understand and optimise the material behaviour and the dynamic behaviour of compact thermal energy storage systems and components based on Phase Change Materials (PCM's) and Thermo Chemical Materials (TCM's). Ultimately, these numerical models could help to find ways to optimise the materials in combination with the system components. The activities in this working group help to lay the foundation for such models.

The Working Group includes the following activities:

- Micro-scale modelling

- Meso-scale modelling

- Macro-scale modelling

- Multi-scale approach

- Thermo-mechanical modelling

- Reactor models

Not all activities receive the same amount of attention in the Working Group and the distinction between the various scales is not always clear. The figure below presents an attempt to quantify the micro-, meso- and macro-scales in a time-length framework but it has to be realised that the definition of the scales is highly dependent on the problem at hand.

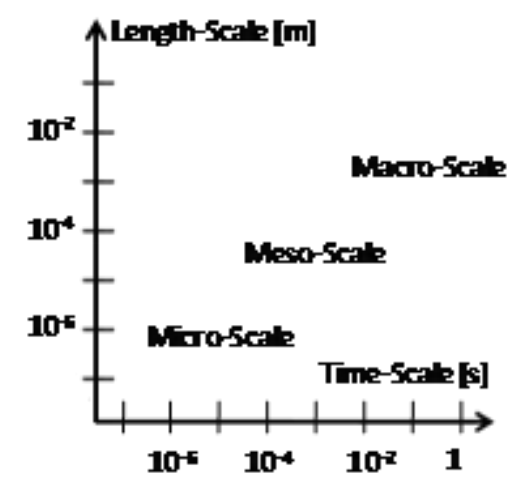

Figure 1: Definition of micro-, meso- and macro-scales in a time-length framework.

\section{DELIVERABLES}

The following deliverables are set.

\begin{tabular}{lll}
\hline \# & Deliverable & Month \\
\hline A3.1 & $\begin{array}{l}\text { Report on state-of-the-art modeling techniques of TCM/PCM- } \\
\text { materials on micro-, meso- and macro scales }\end{array}$ & 12 \\
A3.2 & $\begin{array}{l}\text { Collection of experimental data on the behavior of TCM/PCM- } \\
\text { materials which can be used to bench-mark numerical codes }\end{array}$ & 30 \\
A3.3 & $\begin{array}{l}\text { Overview of material properties required for increased storage } \\
\text { performance compared to conventional storage techniques }\end{array}$ & 48 \\
A3.4 & $\begin{array}{l}\text { Final report on the (validated) numerical models developed for } \\
\text { the micro-, meso-, macro and multi-scale }\end{array}$ & 48 \\
\hline
\end{tabular}




\section{Deliverable A3.2: collection of experimental data on the behavior of TCM/PCM-materials to validate numerical models}

\section{MOTIVATION}

In the developing process of a heat storage device experiments play a dominant role because in the prototype stadium a physical system has to be built to acquire measurement data for fine tuning of the pilot and market product. In this development process numerical modelling plays the role of reducing the number of time consuming and cost intensive experiments. And modelling should help to understand how the limiting parameters can or should be adapted for the assigned task.

In the former deliverable A3.1 it is shown that numerical models are being developed for all kind of length scales (and time scales), ranging from the molecular level, f.e. Molecular Dynamics simulations to gain insight into the hydration/dehydration kinetics, up to the reactor level, f.e. CFD-calculations to simulate the time-dependent heat and vapour flows in a fixed-bed reactor. For validation purposes all these models need to be confronted with results of detailed experiments and it is needless to say that this should be done on as many length scales as possible. Therefore, the contribution of experimental results from one group and the use of these results to validate numerical models developed in another group is appreciated.

This report contains a collection of various experiments. The focus is not only on the measuring results but the report also presents detailed descriptions of the experimental set-ups, the materials tested and their physical properties and the measuring procedures.

\section{OUTLINE}

The document is structured in two main parts focussing on PCM and TCM experiments. Each section describes a typical experiment and has a fixed outline:

1. introduction;

2. lay-out of the experimental set-up including dimensions and material properties;

3. detailed description of the measuring procedure;

4. results presented in graphical or table form;

5. closure containing contact details. 
Table of contents

SHORT DESCRIPTION WORKING GROUP A3 NUMERICAL

MODELLING ...............................................................................

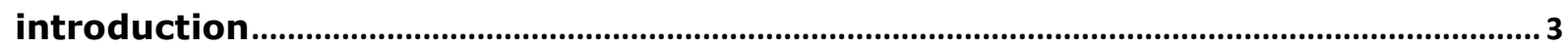

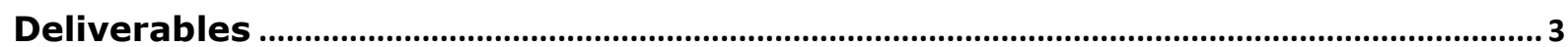

DELIVERABLE A3.2: COLLECTION OF EXPERIMENTAL DATA ON THE BEHAVIOR OF TCM/PCM-MATERIALS TO VALIDATE NUMERICAL

MODELS .................................................................................... 4

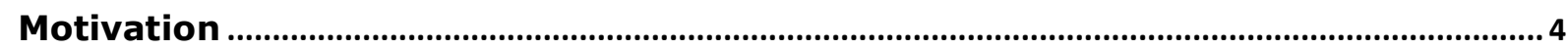

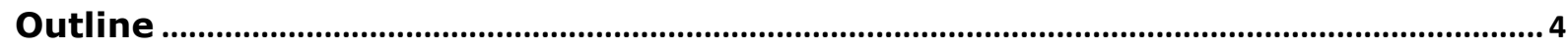

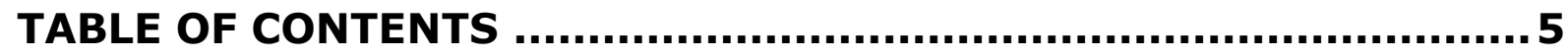

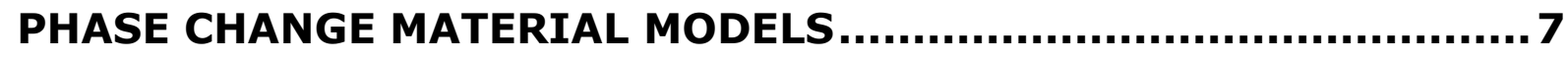

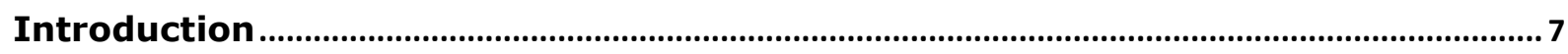

Detailed experimental results for PCM Melting and solidification in circular tubes and spherical shells.

Detailed Experimental Results for Submerged Finned Heat Exchanger in PCM

Based Thermal Energy Storage ............................................................................................. 12

Experimental results for PCM-Air heat exchangers: Melting and solidification in flat plates (CSM panels from rubitherm) .....................................................................................15

Heat storage system coupled with a photovoltaic panel.................................................. 21

THERMO-CHEMICAL MATERIAL MODELS ............................... 27

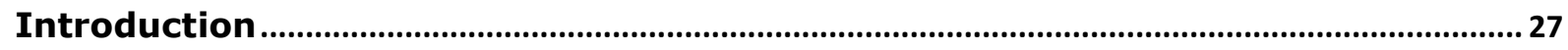

HYDRATION AND DESHYDRATION OF SORPTION MATERIALS: EXPERIMENTS IN

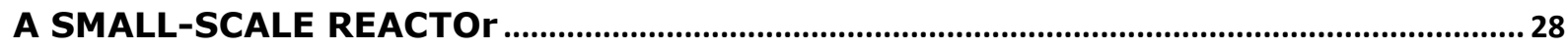

Adsorption heat storage: Dynamic properties........................................................................ 34

Fixed bed reactor for Hydration / dehydration or adsorption / desorption experiments.

Adsorption heat storage: EQUILIBRIUM properties DETERMINATION WITH COMPARISON TO MOLECULAR SIMULATIONS

Characterization OF the dehydration reaction OF SEVeral crystalline salt hydrates uNDER the condtions of the seasonal heat storage 


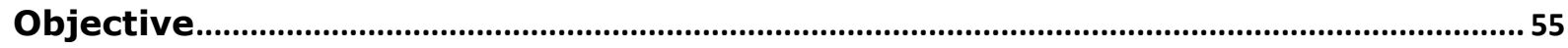

Scope

Structure

IEA SOLAR HEATING AND COOLING PROGRAMME $\ldots \ldots \ldots \ldots \ldots \ldots \ldots \ldots \ldots 7$

Appendix "Detailed Experimental Results for Submerged Finned Heat Exchanger in PCM Based Thermal Energy Storage" by NM. J. CHIU and V. MARTIN ..................61 


\section{Phase Change Material Models}

\section{INTRODUCTION}

Nowadays, thermal energy storage systems are essential for reducing dependency on fossil fuels and then contributing to a more efficient environmentally benign energy use.

Thermal energy storage can be accomplished either by using sensible heat storage or latent heat storage. Sensible heat storage has been used for centuries by builders to store/release passively thermal energy, but a much larger volume of material is required to store the same amount of energy in comparison to latent heat storage. The principle of the phase change material (PCM) use is simple. As the temperature increases, the material changes phase from solid to liquid. The reaction being endothermic, the PCM absorbs heat. Similarly, when the temperature decreases, the material changes phase from liquid to solid. The reaction being exothermic, the PCM desorbs heat.

The phase change materials used in applications can be either organic materials or inorganic materials. The organic PCM are paraffins, fatty acids and the polyethylene glycol (PEG). They present a congruent phase change, they are not dangerous, and they have a good nucleation rate.

The advantages of organic PCM are:

- availability in a large temperature range,

- freeze without much super cooling,

- ability to melt congruently,

- self nucleating properties,

- compatibility with conventional material of construction,

- no segregation,

- chemically stable,

- high heat of fusion,

- safe and non-reactive,

- recyclable.

The disadvantages of organic PCM are:

- low thermal conductivity,

- low volumetric latent heat storage capacity,

- flammable (depending on containment).

The inorganic PCM are salt hydrates.

The advantages of inorganic PCM are:

- high volumetric latent heat storage capacity,

- low cost and easy availability,

- sharp phase change,

- high thermal conductivity,

- non-flammable.

The disadvantages of inorganic PCM are:

- high volume change,

- super cooling,

- segregation.

PCM are used in systems for passive or active applications. The objective of numerical modeling is to predict the behavior of systems depending on the heat and/or mass transfers involved. 


\section{DETAILED EXPERIMENTAL RESULTS FOR PCM MELTING AND SOLIDIFICATION IN CIRCULAR TUBES AND SPHERICAL SHELLS}

G. ZISKIND, Heat Transfer Laboratory, Department of Mechanical Engineering, BenGurion University of the Negev, Beer-Sheva 84105, Israel

\section{INTRODUCTION}

Extensive experimental investigations are performed for circular vertical tubes and spherical shells containing paraffin-type PCMs. Visualization makes it possible to obtain melt fractions and patterns for various instants. Thus, a significant database is created for validation of the numerical codes, not only in terms of overall parameters but also concerning the details.

\section{LAY-OUT OF THE EXPERIMENTAL SET-UP}

The experimental set-up for melting is shown schematically in Figure 1. Experiments are performed in a transparent tank, filled with water. In order to keep a constant water temperature, an electric heater is used, and its power is adjusted using a variable voltage controller. In order to ensure uniform temperature of water inside the tank, a mechanical turbine-type stirrer is used. In a typical experiment, a transparent vertical tube/spherical shell filled with the solid PCM is placed into the water. The experiment continues until the PCM has melted completely.

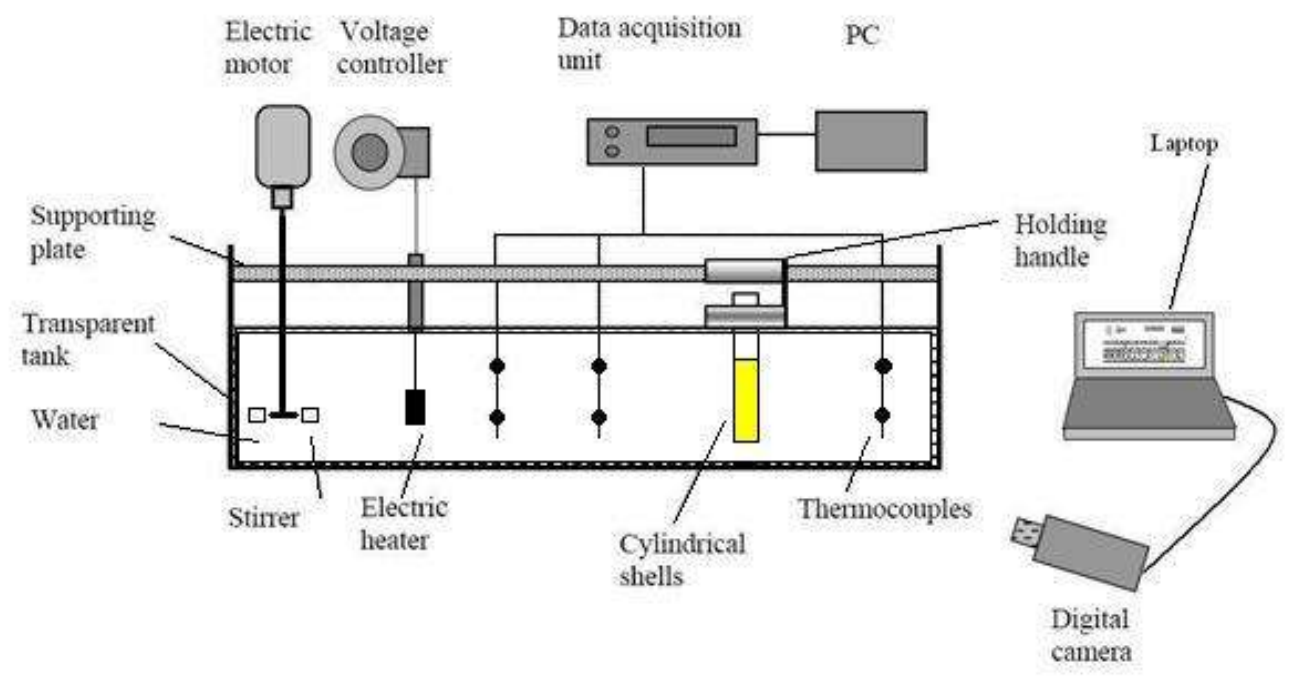

Figure 1: Schematic view of the experimental set-up.

Circular tubes of four different diameters are used, with the inner diameters of $0.9,1.93$, 3.14 , and $3.92 \mathrm{~cm}$. These tubes are referred to using their nominal diameters of $1,2,3$, and $4 \mathrm{~cm}$, respectively. The water level is set at $23.5 \mathrm{~cm}$ above the tank bottom. The height of the solid PCM inside the tube is 6,12 or $17 \mathrm{~cm}$. At its top, the tube is open to atmosphere, in order to allow free expansion of the melt liquid. From below, the tube is sealed by a cork made of an insulating material. In each tube the experiments are performed at the water bath temperatures 10,20 and $30^{\circ} \mathrm{C}$ above the melting point of the PCM. Thus, the four different diameters, three heights and three temperature differences bring the total number of cases explored in the present study to thirty-six. Similar experiments are performed for spherical shells and could be expanded to various diameters and temperature differences. Details of the shells are given in the references.

Solidification is studied using a Neslab RTE 7 circulating thermostatic bath, which maintains a desired temperature within $0.1^{\circ} \mathrm{C}$. The bath is kept typically at 10 or $20{ }^{\circ} \mathrm{C}$ below the mean solidification temperature. The shell is inserted in the bath when the PCM temperature is typically few degrees above its mean melting temperature. 
The material used in the experimental study is the RT27 paraffin wax (Rubitherm $\mathrm{GmbH}$ ), claimed to be suitable for heat-storage applications. Its properties, given in the references, are close to $n$-octadecane. Melting occurs at a temperature about $28^{\circ} \mathrm{C}$.

\section{DETAILED DESCRIPTION OF THE MEASURING PROCEDURE}

For melting, the initial shape of the solid PCM is cylindrical/spherical, with a flat top. In order to achieve a desired shape, the tube/shell is filled gradually with a liquid PCM allowing the latter to solidify at each stage. As a result, no void is formed close to the centerline/centerpoint of the tube/shell. Sample preparation is performed at a reduced ambient pressure, in order to prevent air entrapment in the PCM. Visualization has been chosen as the major method of investigation. Melting images are recorded by a digital camera at various stages of the process. Then, these images are analyzed and the experimental values of the melt fraction are calculated at various instants.

For solidification, thin plastic shells are used, which can be sawed with the PCM after the latter has solidified completely or on the intermediate stages of the process. Two series of the experiments are performed. The first series is conducted in shells of $30 \mathrm{~mm}$ and $70 \mathrm{~mm}$ in diameter up to complete solidification. The shells are then cut in halves, and the solid shape recorded. The second series is conducted in shells of $40 \mathrm{~mm}$ in diameter, where each shell is withdrawn from the bath at a prescribed time. The shell is cut in halves, the remaining liquid is removed and the solid shape is recorded.

\section{RESULTS}

The results for melting in circular tubes are summarized in Figure 2, in terms of the melt fraction versus time. The melt fraction is defined as the melted mass divided by the total mass of the sample.

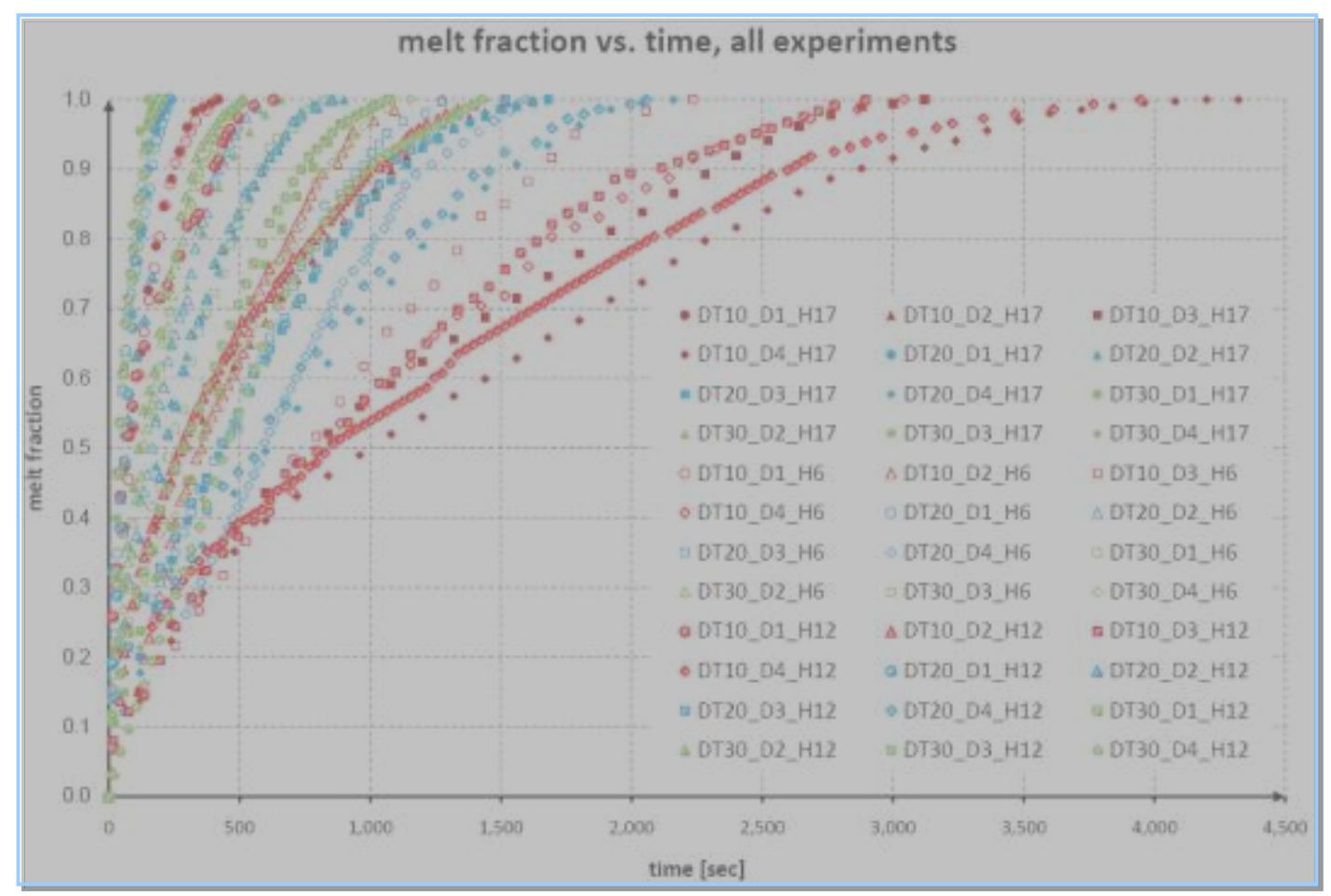

Figure 2: Experimental results for melting in circular tubes.

An example of the visualization results for solidification in a spherical shell is presented in Figure 3, along with its numerical simulation. 

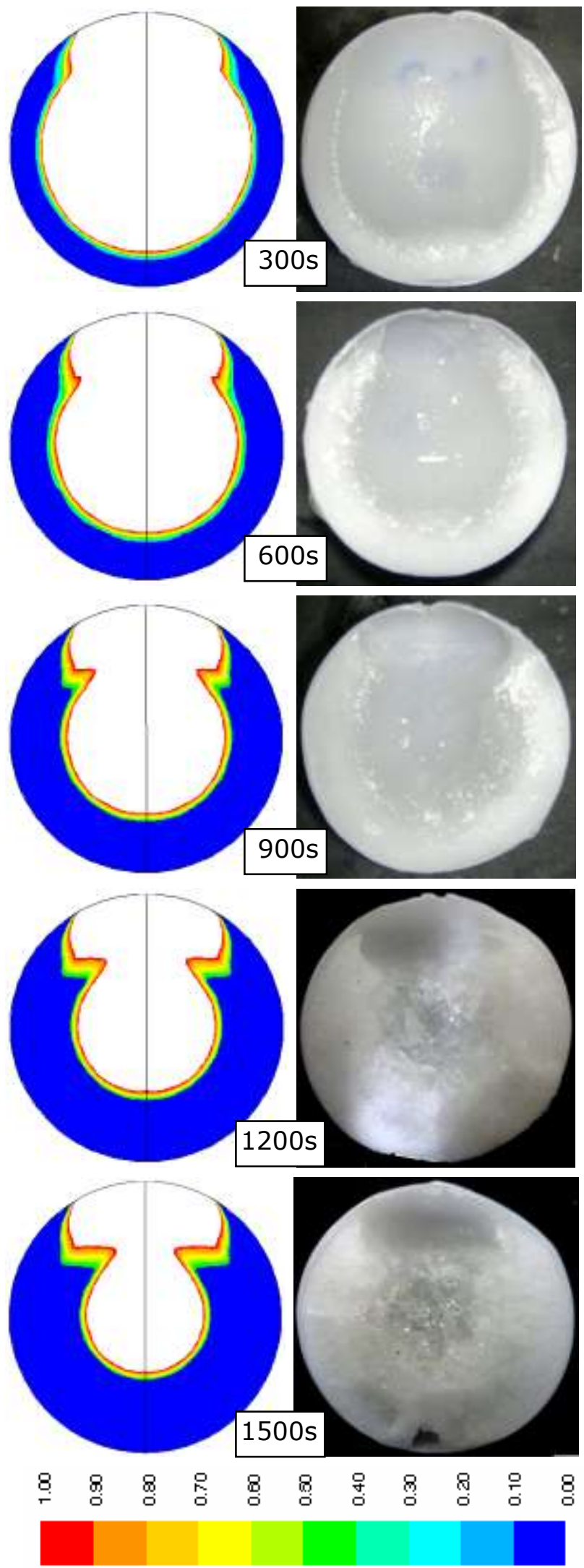
a. numerical
b. experimental

Figure 3: Example of the results for solidification in spherical shells $\left(D=40 \mathrm{~mm}, \Delta T=20^{\circ} \mathrm{C}\right)$. 
An extensive database has been created for melting and solidification of PCM in circular vertical tubes and spherical shell. The accumulated data includes also detailed melting/solidification patterns based on visualization. Thus, these data can be used for benchmarking. Further information is available (see the Bibliography or contact gziskind@bgu.ac.il).

\section{BIBLIOGRAPHY}

[1] E. Assis, L. Katsman, G. Ziskind, R. Letan (2007) Numerical and experimental study of melting in a spherical shell. Int. J. Heat Mass Transfer 50, 1790-1804.

[2] L. Fraiman, E. Benisti, G. Ziskind, R. Letan, Experimental investigation of melting in vertical circular tubes, Proceedings of the ASME Biennial ESDA Conference, Haifa, Israel, 7-9 July 2008.

[3] E. Assis, G. Ziskind, R. Letan (2009) Numerical and experimental study of solidification in a spherical shell. ASME Journal of Heat Transfer 131, 024502.

[4] H. Shmueli, G. Ziskind, R. Letan (2010) Melting in a vertical cylindrical tube: Numerical investigation and comparison with experiments. Int. J. Heat Mass Transfer 53, 4082-4091. 


\section{DETAILED EXPERIMENTAL RESULTS FOR SUBMERGED FINNED HEAT EXCHANGER IN PCM BASED THERMAL ENERGY STORAGE}

NW. J. CHIU* and V. MARTIN, Department of Energy Technology, Royal Institute of Technology, 10044 Stockholm, Sweden (*Justin.chiu@energy.kth.se)

\section{INTRODUCTION}

Various means have been investigated for the goal of overcoming the low thermal storage/extraction rate with use of phase change materials (PCMs) in active thermal energy storage systems (TESs). The most common means employed are surface extension techniques, such as encapsulation, heat-exchange-surface extension, and material thermal property enhancement, for instance with highly conductive additives/matrices. Numerous simulations predicting the effect of the enhancement are available $[1,2,3]$, however, only limited number of experiments are made available to serve as basis for model validation. This article, as part of the IEA Task 42/Annex 24 official report, aims at providing experimental data for use in validating and verifying gelled PCM-based TESs with submerged finned pipe heat exchanger. This work was carried out at Royal Institute of Technology, Sweden.

\section{DETAILED DESCRIPTION OF THE EXPERIMENTAL SET-UP}

The submerged finned pipe heat exchanger based latent heat TES is characterized by specifications listed in Table 1 . The water temperature is practically uniform, and the material is gelled. This means that at different fins the process is practically the same. However, to avoid any disturbance of temperature due to edge effect on the first and the last fin, 4 fins were mounted, and the temperature was taken from the center 2 fins. The insulation is attached to the shell of the unit. Water was utilized as the heat transfer fluid (HTF). The mass flow rate of the HTF was maintained at a sufficient level to assure uniform heat flux between the storage and the HTF in this experimental study. The HTF temperature variation from inlet to outlet was maintained below $0.1{ }^{\circ} \mathrm{C}$. Temperature sensors are thermocouples type $\mathrm{T}$, calibrated to $0.1{ }^{\circ} \mathrm{C}$ accuracy.

Table 1 Characteristics of the Thermal Energy Storage Unit and Experimental Parameters

\begin{tabular}{|c|c|c|c|}
\hline Parameter & 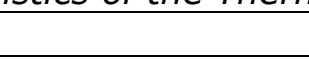 & Parameter & \\
\hline Fin spacing & $30 \mathrm{~mm}$ & Heat transfer fluid & Water \\
\hline Fin thickness & $1 \mathrm{~mm}$ & PCM & $\begin{array}{l}\text { Shape Stabilized Sodium } \\
\text { Sulfate Decahydrate }\end{array}$ \\
\hline Fin diameter & $68 \mathrm{~mm}$ & $\begin{array}{l}\text { Change in HTF } \\
\text { temperature }\end{array}$ & $<0.1^{\circ} \mathrm{C}$ \\
\hline Pipe diameter & $8 \mathrm{~mm}$ & Mass flow rate & $0.07 \mathrm{~L} / \mathrm{s}$ \\
\hline Pipe thickness & $0.8 \mathrm{~mm}$ & Tank insulation & $\begin{array}{l}10 \mathrm{~mm} \text { polyurethane with } \\
0.03 \mathrm{~W} / \mathrm{m} . \mathrm{K}\end{array}$ \\
\hline $\begin{array}{l}\text { Pipe and fin } \\
\text { material }\end{array}$ & Aluminum 6082 & Number of fins & 4 \\
\hline $\begin{array}{l}\text { Outer diameter } \\
\text { of shell }\end{array}$ & $80 \mathrm{~mm}$ & Thickness of shell & $3 \mathrm{~mm}$ \\
\hline $\begin{array}{l}\text { Total length of } \\
\text { the finned pipe }\end{array}$ & $160 \mathrm{~mm}$ & & \\
\hline
\end{tabular}

The PCM utilized is a commercially available gelled salt-hydrate product [4], the material properties of which were tested and characterized with an in-house built testing facility based on an improved T-History method described by Chiu et al. [5]. The specific heat of the material in melting and in congealing (freezing) is measured between $5^{\circ} \mathrm{C}$ and 40 ${ }^{\circ} \mathrm{C}$, as depicted in Figure 1 . The energy storage capacities measured in melting and congealing of the PCM are $52 \pm 1 \mathrm{Wh} / \mathrm{kg}(187 \pm 4 \mathrm{~kJ} / \mathrm{kg})$. A proposed numerical curve fit function with the use of Dirac approximation and proposed parameters is presented in eq. (1). It is shown that melting latent heat extends over a range of $8^{\circ} \mathrm{C}$ while the congealing $c_{p}$ covers a temperature range slightly less than $4{ }^{\circ} \mathrm{C}$. The use of correct material property data in modeling is essential in achieving representative results. 
$a=(T-T p c)$ ；

$$
c_{p}(T)=c_{p s}+h * \frac{e^{-\frac{a^{2}}{b^{2}}}}{(\sqrt{\pi} * b)}
$$

Melting

$\mathrm{Tpc}=23.5^{\circ} \mathrm{C}$;

$b=1.830559547$;

$\mathrm{c}_{\mathrm{ps}}=3600 \mathrm{~J} / \mathrm{kg} . \mathrm{K}$;

$\mathrm{h}=58800 \mathrm{~J} / \mathrm{kg}$;

\author{
Cooling \\ $\mathrm{Tpc}=20.5^{\circ} \mathrm{C}$; \\ $b=0.9152797733$; \\ $\mathrm{c}_{\mathrm{ps}}=3600 \mathrm{~J} / \mathrm{kg} . \mathrm{K}$; \\ $\mathrm{h}=64800 \mathrm{~J} / \mathrm{kg}$;
}

where " $a$ " and " $b$ " are cure fitting parameters that characterize the peak $c_{p}$ temperature and the phase change temperature range. " $\mathrm{T}_{\mathrm{pc}}$ " is the phase change temperature with the peak $c_{p} . c_{p s}$ corresponds to the sensible heat of the material; from the measurement, it is seen that the sensible heat is identical in both solid and liquid phases. " $h$ " is the latent heat of the material with sensible heat deducted, it also corresponds to the surface area of the lobe in Figure 1.
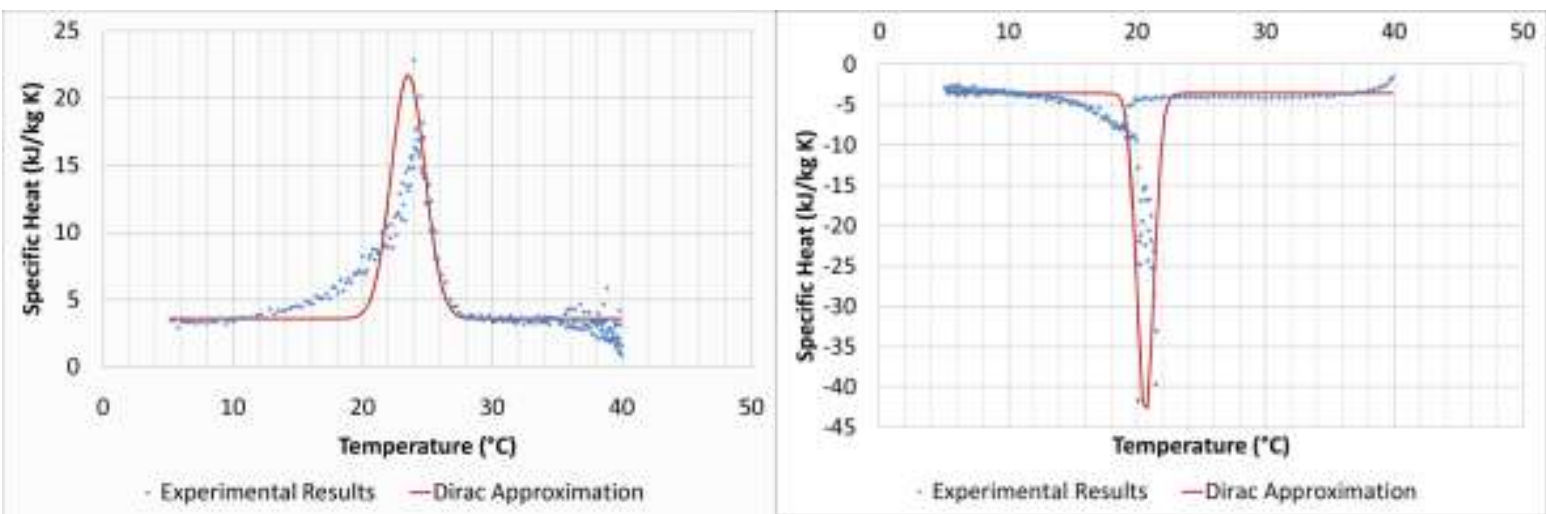

Figure 1 Thermal Property of PCM in Melting (left) and in Congealing (right) with Curve Fit Approximations

The schematic of the experimental setup is shown in Figure 2. Teflon insulated thermocouples are led out through the opening top of the TES unit. An $8 \mathrm{~L}$ water bath was served as the heat source and heat sink for charge and discharge of the TES unit. The experimental data were collected with a 16 bit multiplexer/ data logger and the data were recorded in a 32 bit computer. Temperature sensors are placed along the pipe, on the fins and in the center of the PCM, see Figure 2 (right).
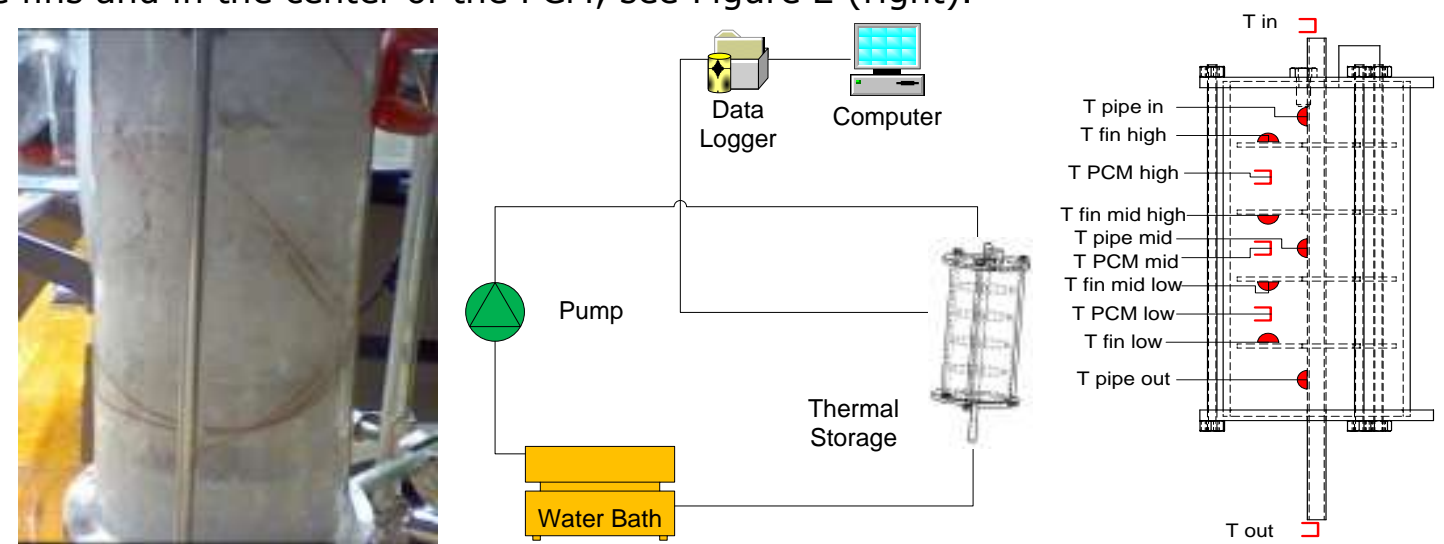

Figure 2 Submerged Finned Heat Exchanger (left); Schematic of the Setup (middle); Thermocouple Placement (right)

The charging of heat (melting process) was performed with initial temperature of $12{ }^{\circ} \mathrm{C}$ and HTF at $32{ }^{\circ} \mathrm{C}$; the discharging of heat (freezing process) was performed with initial temperature of $31^{\circ} \mathrm{C}$ and $\mathrm{HTF}$ at $11^{\circ} \mathrm{C}$. Data were recorded from $15^{\circ} \mathrm{C}$ to $29^{\circ} \mathrm{C}$ in the melting process and $29^{\circ} \mathrm{C}$ to $15^{\circ} \mathrm{C}$ in the congealing process. 


\section{RESULTS AND DISCUSSION}

Temperature readings obtained for the finned pipe heat exchanger submerged gelled PCM TES unit are appended to this article. The data are open for use to all for experimental comparisons and numerical validations by giving reference to this article. The fin temperature, PCM temperature, and pipe temperature presented in the appendices are the average fin temperatures, PCM temperatures and pipe temperatures measured. Averaging is possible due to the practically uniform HTF temperature throughout the heat exchanger tube and the symmetry of the storage.

The temperature profiles are presented in Figure 3 , the shown temperatures are fin temperatures and PCM temperatures in run A, run B and run C. It is shown here that the PCM heating temperatures deviate $5 \%$ in terms of melting time at the upper bound of the testing temperature range, while the congealing temperature curves have more consistent readings through the 3 test runs.
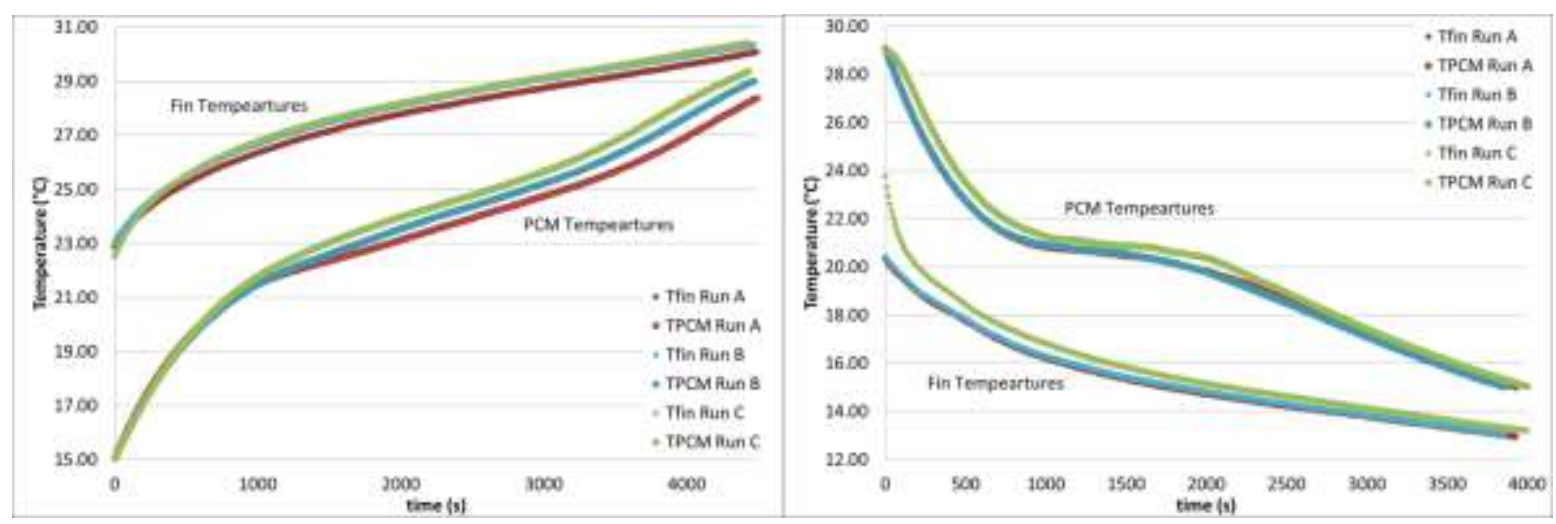

Figure 3 Temperature Profiles in Melting (left) and in Congealing (right)

\section{CLOSURE}

A compilation of experimental results for a gelled PCM based submerged finned pipe heat exchanger TES is made available in this report for numerical validation. The material enthalpy data measured with T-history method, the temperature profiles of the gelled PCM and of the fins are appended to this report. The data are open for access to all, and we welcome the use of the data with reference to this report.

\section{Acknowledgement}

The authors would like to acknowledge Swedish Energy Agency for providing funding for this project $31067-1$.

\section{BIBLIOGRAPHY}

[1] A. Castell, M. Belusko, F. Bruno and L.F. Cabeza, Maximisation of heat transfer in a coil tank PCM cold storage system, Applied Energy, 88, pp. 4120-4127, 2011.

[2] Li P.W. et al., "Similarity and generalized analysis of efficiencies of thermal energy storage systems," Renewable Energy, vol. 39, pp. 388-402, 2012.

[3] Ye W.B., Zhu D.S., and Wang N., "Numerical simulation on phase-change thermal storage/release in a plate-fin unit," Applied Thermal Engineering, vol. 31, pp. 3871-3884, 2011.

[4] Julin N. Climator. [Online]. www.climator.com/

[5] Chiu NWJ. and Martin V., "Submerged finned heat exchanger latent heat storage design and its experimental verification," Applied Energy, vol. 93, pp. 507-516, 2012. 


\section{EXPERIMENTAL RESULTS FOR PCM-AIR HEAT EXCHANGERS: MELTING AND SOLIDIFICATION IN FLAT PLATES (CSM PANELS FROM RUBITHERM)}

P. DOLADO, A. LÁZARO, J.M. MARÍN, B. ZALBA; GITSE-I3A, Department of Mechanical Engineering, EINA, University of Zaragoza, Spain.

\section{INTRODUCTION}

Experimental investigations are performed to test PCM-air heat exchange for macroencapsulated PCM in flat plates. The plates are commercially available as CSM panels from Rubitherm $\mathrm{GmbH}$, and filled with RT27 (paraffin wax from Rubitherm GmbH as well). The set up of the heat exchange is shown in Fig. 1. The plates are arranged in walls of plates, allowing an air gap to let the air go through. The air flows parallel to the plates from the inlet in the top to the outlet in the bottom, exchanging heat with the plates and melting/solidifying the PCM inside them.

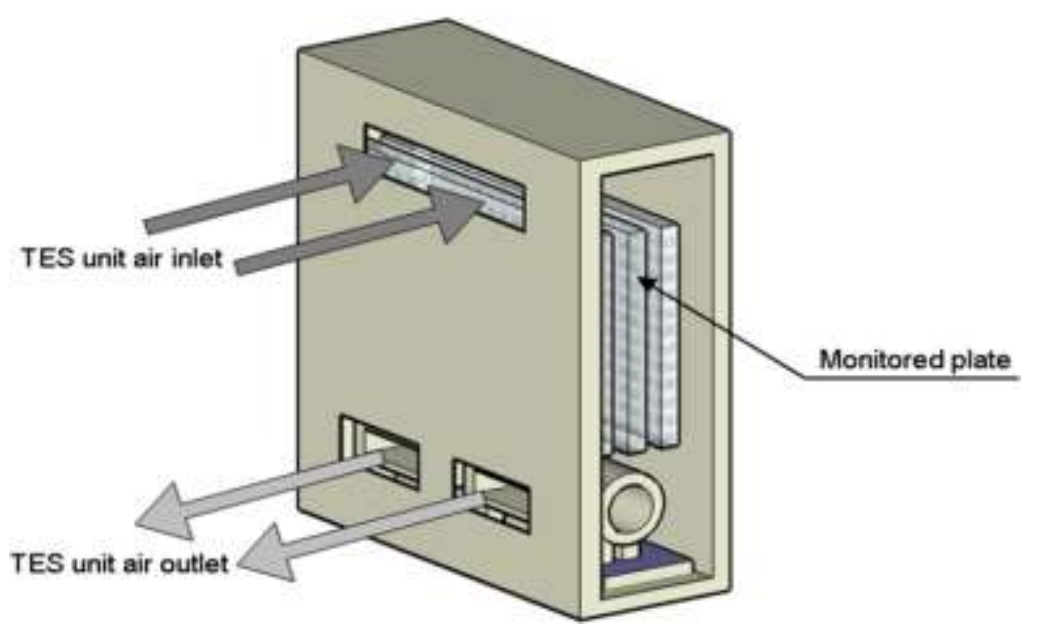

Figure 1: PCM-air heat exchanger set up

The experimental database involves:

- For the whole heat exchanger:

- temperatures of different points at the surface of the plates

- temperatures of the air in the air channels

- temperature difference between the inlet and the outlet (measured with a thermopile, that was constructed based on the ANSI-ASHRAE standard [1])

- pressure drop between the inlet and the outlet

- air temperature at the inlet and at the outlet

- relative humidity

- ambient temperature

- For one single plate (see Fig. 2; the reader can find experimental data for one single plate monitoring in the corresponding Appendix):

o temperature of three points at the surface of the plate

- temperature of the PCM at the corresponding points inside the plate

- temperature of the air at the inlet and the outlet of the corresponding air channel

The location of the sensors on the tested slab is shown in Figure 2. For the whole heat exchanger, 36 temperature sensors were distributed among air ducts and slab surfaces as shown in Figure 3. 

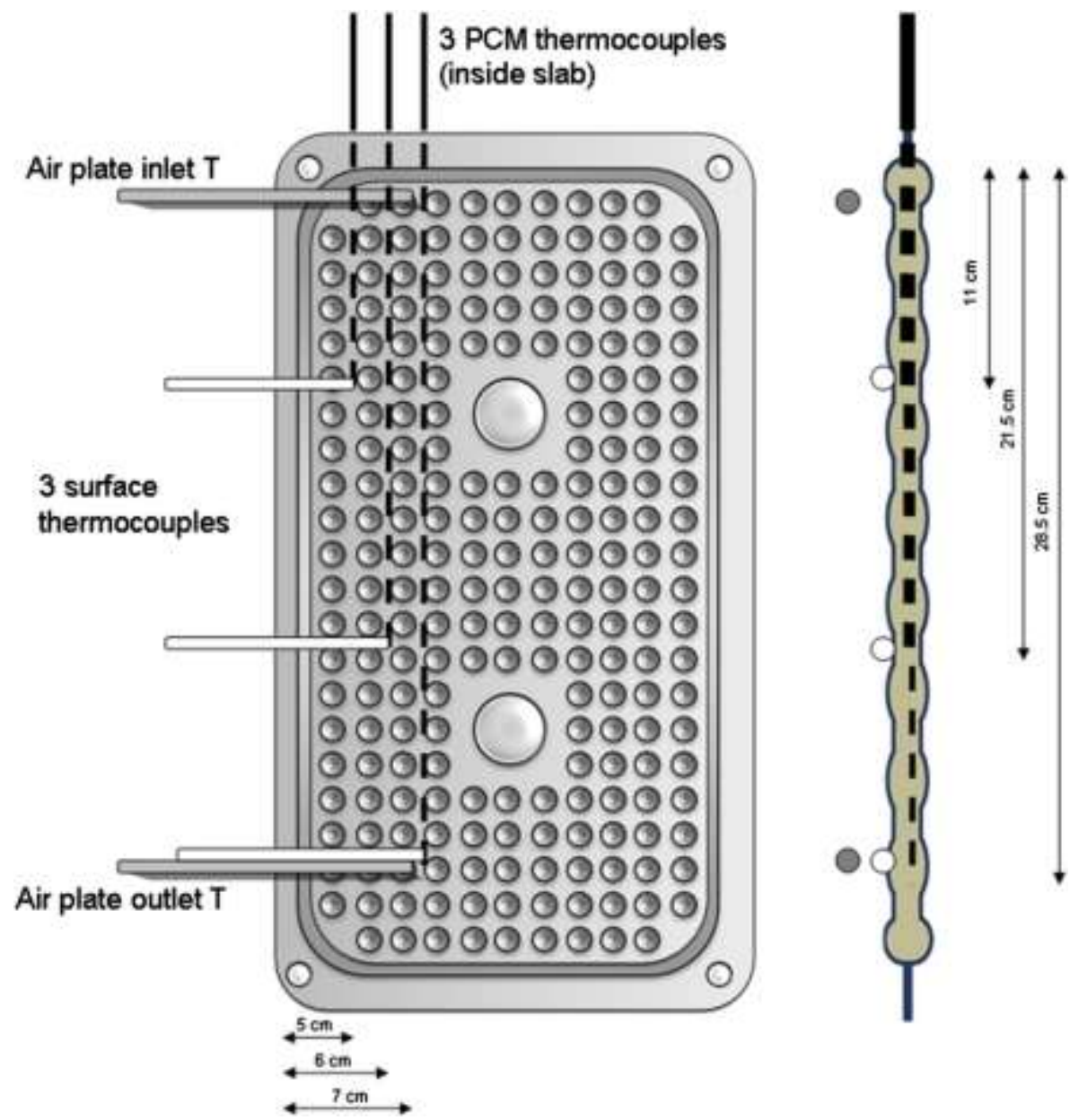

Figure 2: Compact Storage Modules by Rubitherm, layout of the T sensors over the plate

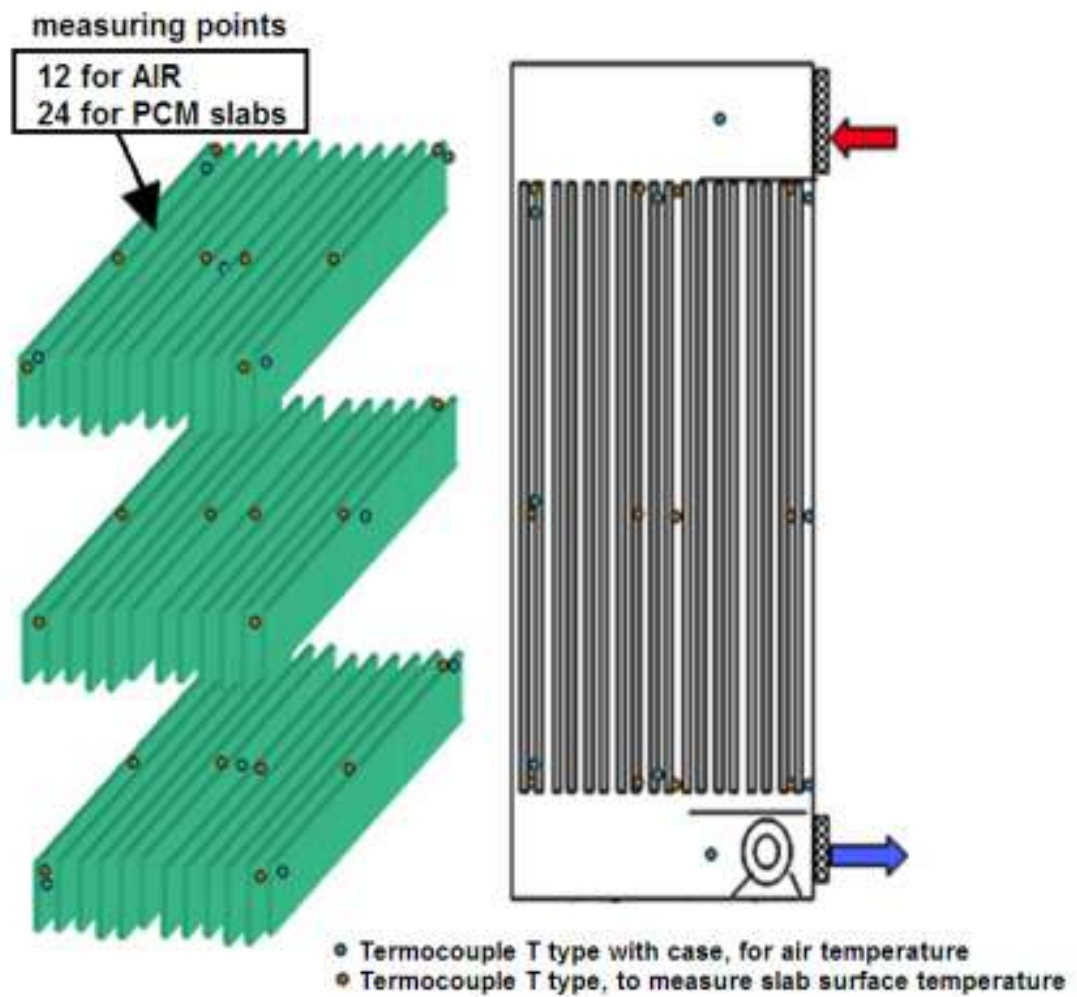

Figure 3: Temperature sensors distribution in the heat exchanger 
The experimental set-up is shown in Fig. 4.

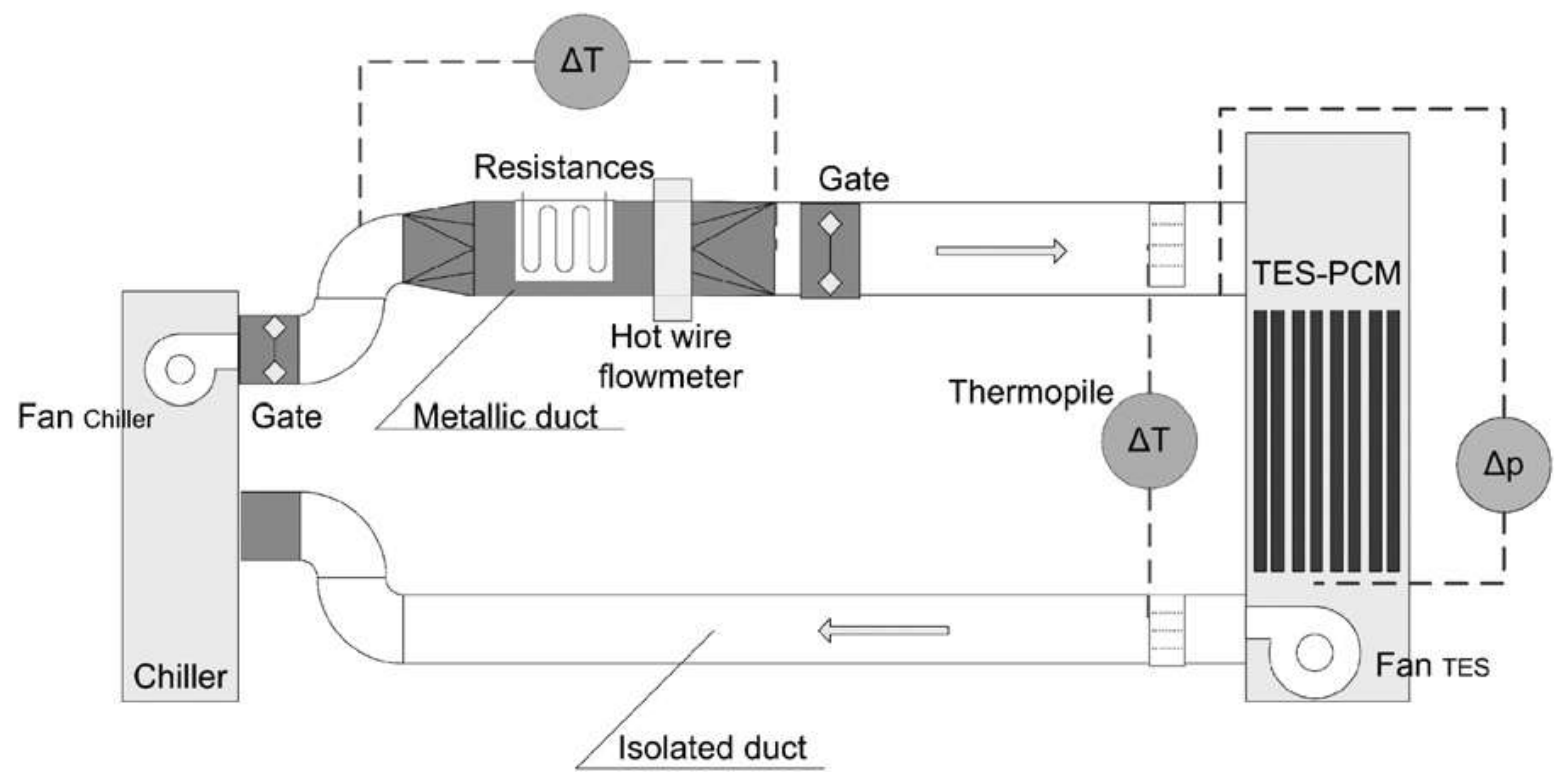

Figure 4: Experimental set-up

An experimental setup was designed to study different PCM-air heat exchangers. A closed air loop setup is used to simulate indoor conditions. Setup design was based on ANSI/ASHRAE STANDARD 94.1-2002 "Method of testing active latent-heat storage devices based on thermal performance" [1]. This setup is constituted of [2]:

- Inlet air conditioner allowing the simulation of different operating modes (5 kW air chiller and $4.4 \mathrm{~kW}$ electrical resistance)

- Air flow measurement

- Difference between inlet and outlet air temperatures measurement (thermopile)

- Inlet and outlet air temperature and humidity measurement

- PCM and air channels temperature measurement (over 20 thermocouples)

- Data logger and data screening

- Air ducts and gates

- PID controller

The total amount of PCM in TES is approximately $135 \mathrm{~kg}$, contained in 216 plates. The outer dimensions of the plate are $450 \mathrm{~mm}$ per $300 \mathrm{~mm}$, and $10 \mathrm{~mm}$ thick. The plates are arranged in walls of plates ( 3 plates high per 4 plates width). The 18 walls of plates are separated from each other by a $1 \mathrm{~cm}$ air gap. The chiller fan was single speed, while the TES unit fan had three speeds. In the energy balance the heat released by the fan is considered as a fixed quantity of watts, depending on the selected speed of the fan. Detailed information on the energy balance can be found in [6], section 3.3 (particularly page 69, Eq. 3.4). The air flow range varied from $675 \mathrm{~m}^{3} / \mathrm{h}$ to $1550 \mathrm{~m}^{3} / \mathrm{h}$. Depending on the stage of the thermal cycling (melting or solidification of the PCM), the working equipment will be the electrical resistances (to heat the inlet air) or the chiller (to cool down the inlet air).

\section{DESCRIPTION OF THE MEASURING PROCEDURE}

Measurements started after surface temperatures of the PCM slabs in the TES unit (average PCM temperature) had reached a stable value.

One of the main outputs of the PCM-air heat exchanger is the heat rate. This is determined applying an energy balance to the air between the inlet and the outlet of the heat exchanger. 
$\dot{Q}_{\mathrm{TES}}=\dot{m} \cdot c_{p} \cdot\left(T_{\text {inlet }}-T_{\text {outlet }}\right)=\dot{m} \cdot c_{p} \cdot \Delta T$

As the main parameters are the air flow and the air temperature difference between the inlet and the outlet, accuracy depends on the precision in measuring these parameters. The methods used are:

- Air temperature difference: Thermopile. There are three difficulties to solve in this measurement: a long period of time with small temperature difference, temperature distributions in air ducts because of its dimensions and accuracy is needed because it is a main parameter of evaluation. ANSI/ASHRAE standard recommends a thermopile to solve this problem. It was chosen because it solves these difficulties. Thermocouples are designed to measure direct temperature difference between two temperature junctions. Since a thermopile is constructed by using several junctions in series of calibrated thermocouple wire, the output signal is amplified by the number of junctions, so sensibility is increased. In this case, a six junction thermopile is used. In order to have representative measurements of air temperature difference, each junction is located at the centre of equal cross section areas. Therefore, the temperature difference is measured involving the complete sectional area. Precision is then $0.51{ }^{\circ} \mathrm{C}$, better than when using two Pt100 $\left(0.65^{\circ} \mathrm{C}\right)$ and also sensibility and temperature distribution evaluation are improved.

- Air flow: energy balance of electrical resistances. Air temperature changes during a test, therefore most of air flow measurements methods are not suitable for transitory measurements. Mass flow depends only on fan velocity; therefore it is measured by applying an energy balance on electrical resistance. The maximum power is set to electrical resistances. The energy consumption is measured with a $1 \%$ uncertainty and air temperature difference caused in the air by passing through the electrical resistances is measured by a thermopile with an accuracy of $0.51^{\circ} \mathrm{C}$.

- Air humidity: two sensors are used to measured air humidity at the inlet and the outlet. The maximum air humidity variation during a test was $0.006 \mathrm{~kg} / \mathrm{kg}_{\text {da }}$. It is lower than the $0.2 \%$ of total stored energy, therefore, it was confirmed that latent energy variation is negligible in energy balance of air for cooling power evaluation.

\section{RESULTS}

As an example, the experimental results of a test using constant setpoint air inlet temperature are shown in Figs. 5 and 6 . In these two plots different temperature measurements are shown, the first for the whole heat exchanger and the second for one single plate. 


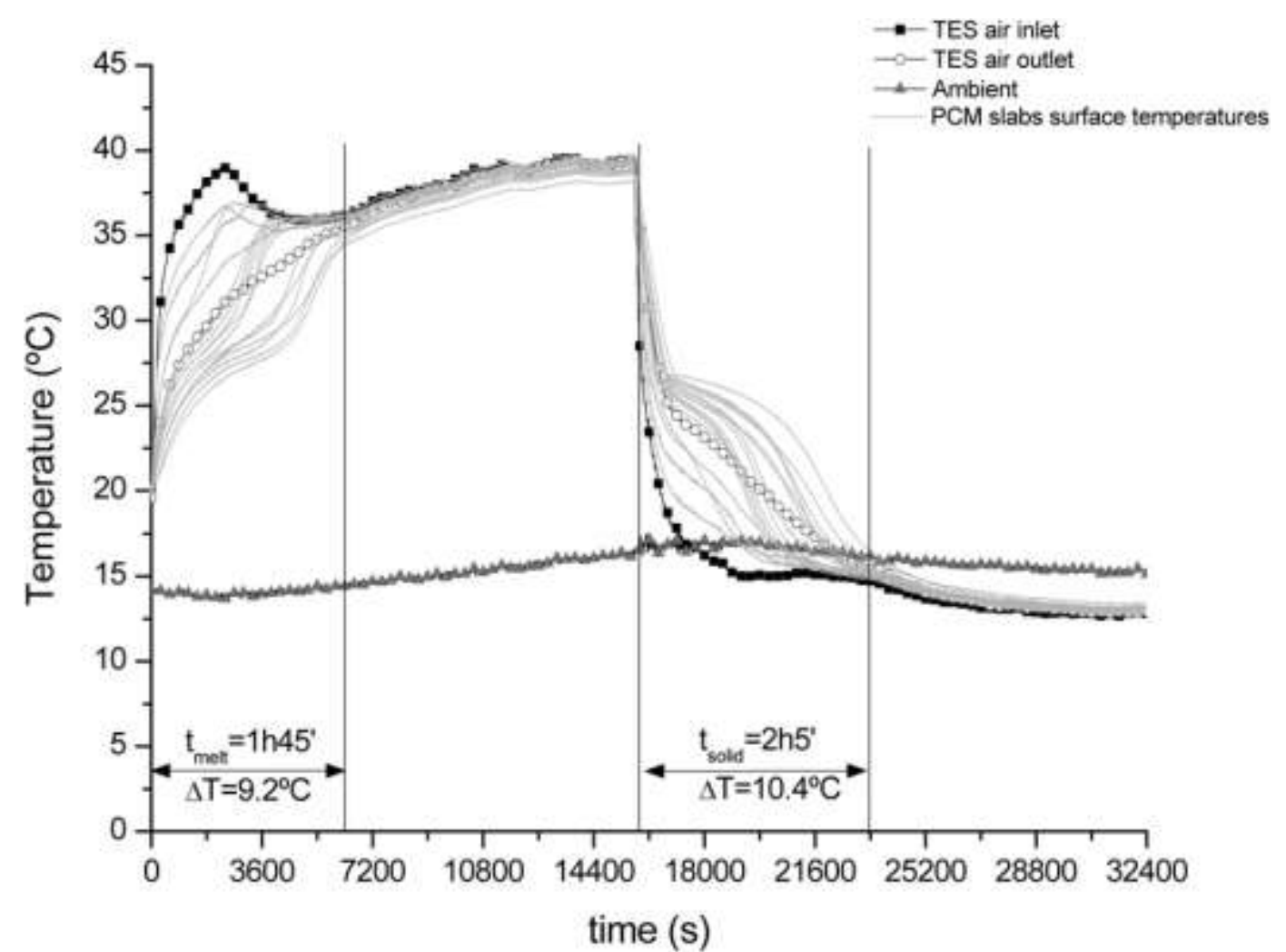

Figure 5: Experimental results for a full cycle: TES air inlet and outlet temperatures, ambient temperature, and surface temperature distribution of the plates inside TES

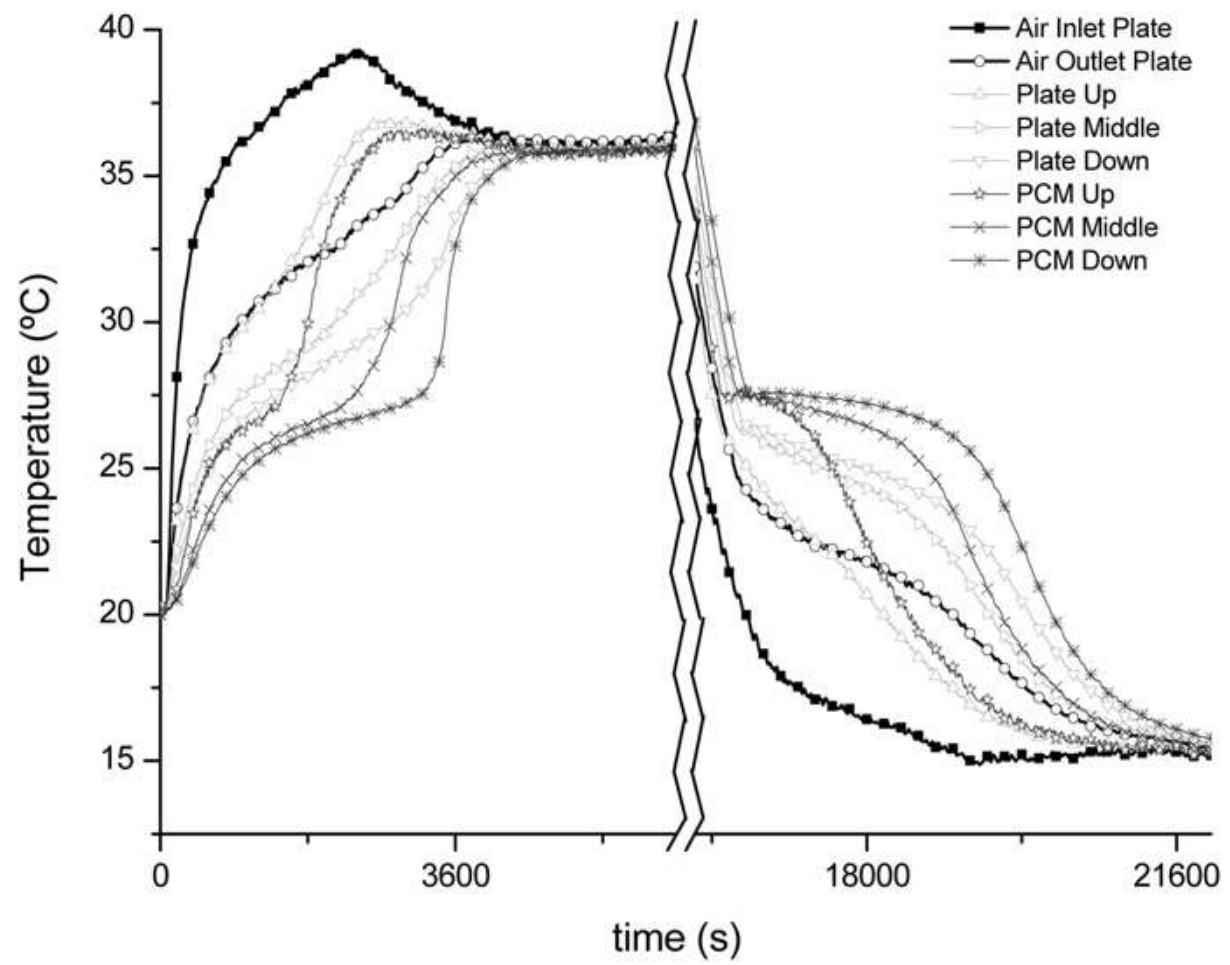

Figure 6: Experimental results for a full cycle, single-plate monitoring (air-plate surfacePCM temperatures)

In Fig. 7 the experimental heat rate (determined by means of the previous energy balance) is plotted as well as the total energy stored on each stage (melting or solidification). 


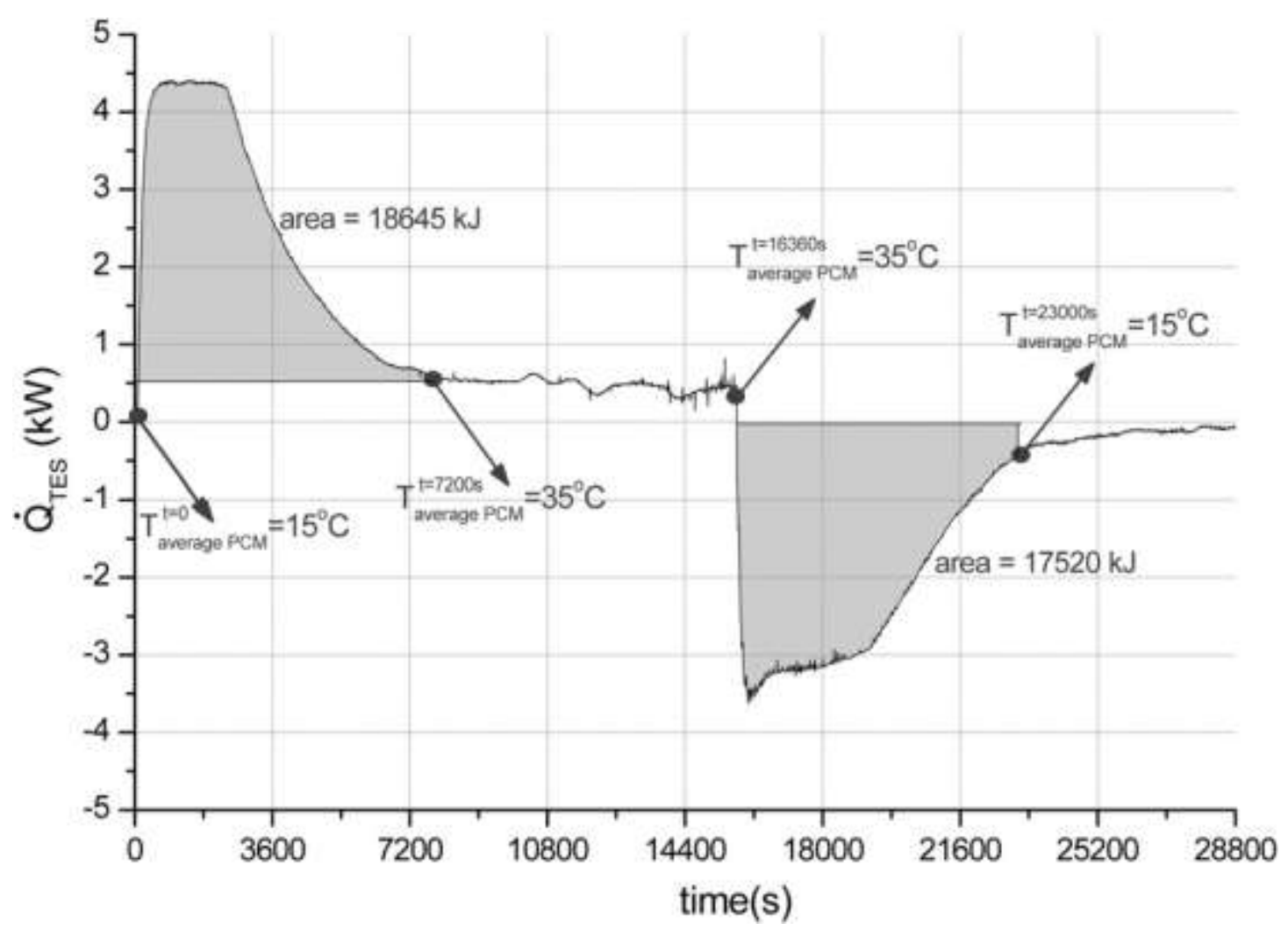

Figure 7: Heat rate curve and total energy exchanged

\section{CLOSURE}

An experimental database has been created for melting and solidification of PCM in CSM panels exchanging heat with air as heat transfer fluid in a PCM-air heat exchanger. Thus, these data can be used for benchmarking. Further information is available (see the Bibliography section or contact dolado@unizar.es).

\section{BIBLIOGRAPHY}

[1] ANSI/ASHRAE STANDARD 94.1-2002 (updated by 94.1-2010). Method of testing active latent-heat storage devices based on thermal performance.

[2] A. Lázaro, P. Dolado, J.M. Marín, B. Zalba, PCM-air heat exchangers for freecooling applications in buildings: Experimental results of two real-scale prototypes, Energy Conversion and Management, vol. 50 (2009), no. 3, pp. 439443.

[3] A. Lázaro, P. Dolado, J.M. Marín, B. Zalba, PCM-air heat exchangers for freecooling applications in buildings: Empirical model and application to design, Energy Conversion and Management, vol. 50 (2009), no. 3, pp. 444-449.

[4] P. Dolado, A. Lázaro, J.M. Marín, B. Zalba, Characterization of melting and solidification in a real-scale PCM-air heat exchanger: Numerical model and experimental validation, Energy Conversion and Management, vol. 52 (2011), pp. 1890-1907.

[5] P. Dolado, A. Lázaro, J.M. Marín, B. Zalba, Characterization of melting and solidification in a real scale PCM-air heat exchanger: Experimental results and empirical model, Renewable Energy, vol. 36 (2011), pp. 2096-2917.

[6] P. Dolado, Thermal Energy Storage with phase change. Design and modelling of storage equipment to exchange heat with air, Ph.D. Thesis, University of Zaragoza, Spain, 2011.; ISBN: 978-84-694-6103-7. Available online (Spanish only) at: http://zaguan.unizar.es/record/6153?ln=es. 


\section{HEAT STORAGE SYSTEM COUPLED WITH A PHOTOVOLTAIC PANEL}

V. LO BRANO, G. CIULLA, M. CELLURA; Department of Energy, University of Palermo, Italy.

\section{INTRODUCTION}

A key element of a wider dissemination of PV systems is represented by high power conversion efficiency. Concerning this point, the energy produced by a PV cell depends, apart materials, also on other two important parameters:

- the amount of the incident radiation;

- the temperature of the PV cell.

The performance of a PV panel in fact is defined by manufactures according to the "peak power", which identifies the maximum electric power supplied by the PV panel when it receives an insolation of $1 \mathrm{~kW} / \mathrm{m}^{2}$ and the cell temperature is maintained at $25{ }^{\circ} \mathrm{C}$. These conditions are nominal only because solar radiation has a variable intensity and the panel is subjected to significant temperature changes, with temperature values higher than 25 ${ }^{\circ} \mathrm{C}$. In real conditions performances of a PV panel are different from those declared under the nominal conditions and the conversion efficiency decreases when temperature of the cell increases.

Among other measures aimed to increase the energy conversion, we investigated the application of PCMs (Phase Change Materials).

The idea to couple the PCMs with the photovoltaic technology arises from features of these materials to absorb large amounts of heat (keeping almost constant the temperature) when the heat is not required. Indeed overheating causes a drop in efficiency of the photovoltaic cells. The absorbed heat should be then released to the surrounding air during the night when the panel does not produce electrical power. The application of PCM in PV systems has been experimentally and numerically studied by several authors [1-6].

\section{PV-PCM Model}

Considering a PV panel coupled with PCM system, the energy balance must take into account the presence of the phase-change material. Schematically, the energy exchanges in a PV-PCM system can be exemplified by the figure. Thanks to the presence of a simple geometry it was possible to choose a one-dimensional approach, considering only the heat flow orthogonal to the PV plane.

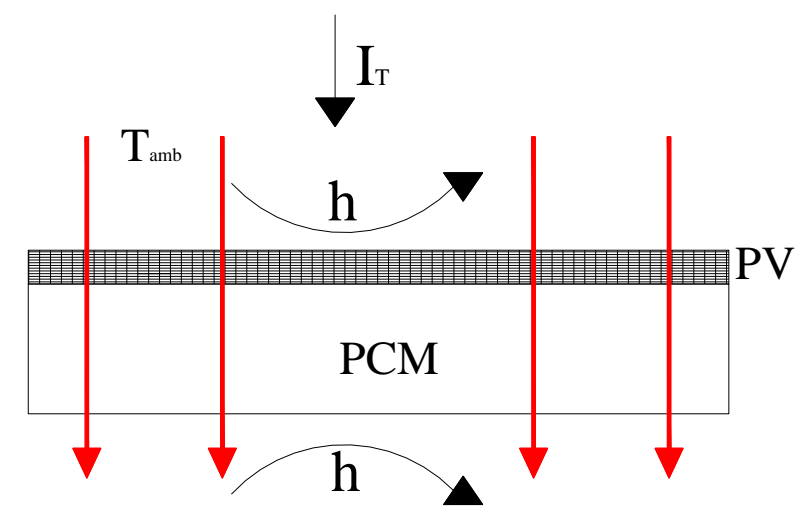

Figure 1: PV-PCM schema of the PV-PCM system

In detail, the system is composed by a:

- tempered glass sheet $(\lambda=1.3 \mathrm{~W} / \mathrm{mK})$ with a thickness of $3.2 \mathrm{~mm}$ (Glass layer);

- $1 \mathrm{~mm}$ of PET plastic panel $(\lambda=0.15 \mathrm{~W} / \mathrm{mK})$ on which are "printed" the silicon cells; the silicon cells are considered having negligible thickness (PET layer);

- an optional layer of air interposed between the panel and the heat storage system representing a possible imperfect contact (Air layer); a plastic layer ( $\lambda=0.15$ 
$\mathrm{W} / \mathrm{mK}$ ) that takes into account the bag that contains the PCM (bag layer); this is a vacuum plastic bag of $20 \mathrm{~cm} \times 30 \mathrm{~cm}$.

- the PCM layer;

Figure 2 represents a section of the geometry along the thickness of the PV-PCM system where it is possible to identify all the involved layers: the glass panel, the PET panel, the layer of air due to the imperfect contact of the envelope of PCM with the PV, the thickness of the envelope containing the PCM and the PCM layer itself.

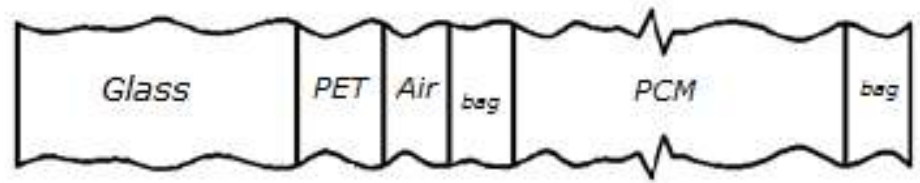

Figure 2: PV-PCM cross-section

The PV-PCM system is presented as a multi-layer plate invested by solar radiation and exchanging heat with the external environment by convection and radiation. Depending on the properties of the PCM and on the amount of energy captured from the panel, the layer of PCM can partially or totally melt during the maximum insolation, and returns that amount of energy, possibly solidifying again, during the night. The first hypothesis is that the phase change is isothermal. In case of non-isothermal transition, having the value of $c_{p}$ with temperature, the problem is reduced to a heat conduction case. The occurrence of a phase change that keeps the temperature at a given value is a more interesting case and implies the determination of the PCM liquid fraction.

In general terms, commercial PCMs have a thermal window; only pure substances show an isothermal phase change

The balance equations were written by finite difference model considering a onedimensional approach with constant thermo-physical properties and without internal heat generation. It was necessary to distinguish the energy balance of border nodes.

We developed an algorithm that can easily be implemented in a software procedure that uses a common programming language like VB.NET. Authors developed a software tool implementing the discussed algorithm shown in Fig. 3.

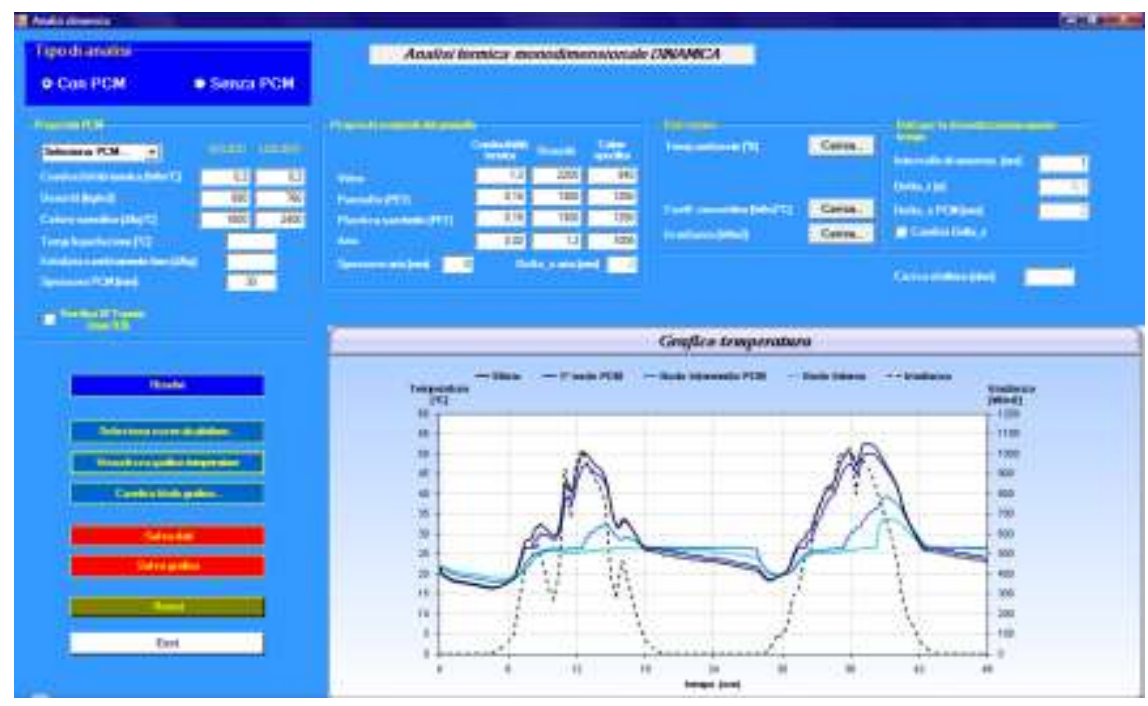

Figure 3: Front panel of the developed software

\section{EXPERIMENTAL SYSTEM}

To perform the measurements, an experimental system was made up and situated on the top of the Energy Department of University of Palermo, (38 $07^{\prime} \mathrm{N}, 13^{\circ} 22^{\prime} \mathrm{E}$ ). Two 
identical PV panels by Kyocera manufacturers' have been chosen (KC175GHT-2), one of which is coupled to PCM (Fig.4).

To secure a proper PV-PCM system configuration it was decided to install PCM in the bottom part of PV panel using a perforated metal mesh bolted into the frame of the panel. The silicon temperature was measured using thermocouples (type T, copperconstantan) installed into little holes made in the PET (Polyethylene Terephthalate) rear film of the panel, in order to improve the thermal contact with the cell silicon back face. To evaluate the real performance of PV panel, the electrical circuit has been linked to precision resistances (Vishay $\mathrm{RH} 250$ ) with a tolerance of $\pm 1 \%$ and a temperature coefficient of $\pm 50 \mathrm{ppm} /{ }^{\circ} \mathrm{C}$. To avoid that the presence of an ammeter altered the value of the electrical load connected to the panel, especially with the lowest values of electric resistances, the current was calculated on the basis of the measured voltage, accepting the error due to the precision resistances.

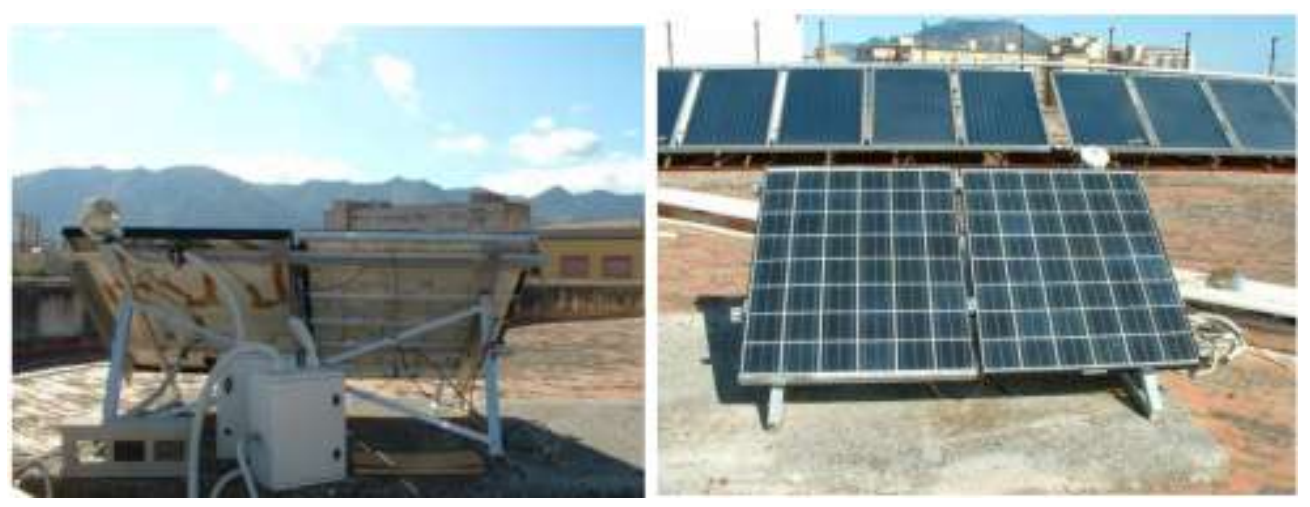

Figure 4: PV panel experimental system

\section{SIMULATION AND RESULTS}

To study the influence of PCM, as previously described, two identical PV panels were monitored, one of which was applied to the PCM. The field measurements were launched in the summer months as these are characterized by higher irradiance values.

The electrical load also has been changed frequently in order to observe the system response to load variations. Therefore, numerical simulations were performed on different days. The results were compared with measured data. In detail, the comparison was made between temperature and electrical power, measured and calculated.

In the following table, the thermo-physical characteristics of the PCMs used in this work are listed. The graphs below show some of the results that were obtained comparing the trends of the measured and simulated temperatures.

Table1: Thermo-physical characteristics of the RT27 PCM

\begin{tabular}{|l|l|l|}
\hline \multicolumn{2}{|c}{ PCM } & \\
\hline Transition phase & $25-28$ & ${ }^{\circ} \mathrm{C}$ \\
\hline Solid density & 0.88 & $\mathrm{~kg} / \mathrm{I}$ \\
\hline Liquid density & 0.76 & $\mathrm{~kg} / \mathrm{I}$ \\
\hline Specific enthalpy of phase change & 184 & $\mathrm{~kJ} / \mathrm{kg}$ \\
\hline Thermal Conductivity & 0.2 & $\mathrm{~W} / \mathrm{mK}$ \\
\hline Volumetric change & 16 & $\%$ \\
\hline
\end{tabular}




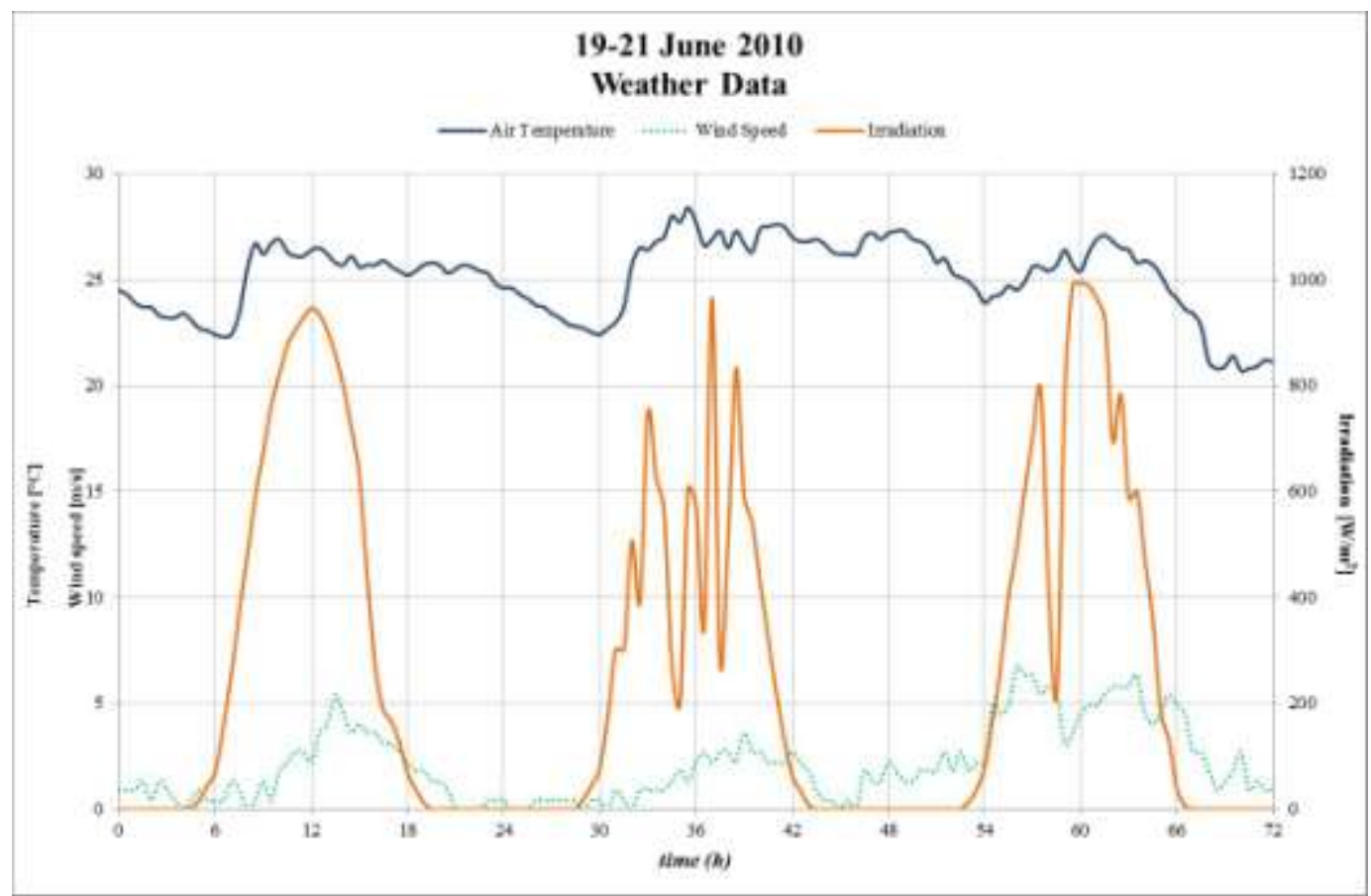

Figure 5: The figure represents the trends of climatic parameters in Palermo, June 19 to 21

Table 2: Climatic parameters in Palermo, June 19 to 21

\begin{tabular}{|l|l|l|}
\hline \multicolumn{3}{|c|}{ Mean value } \\
\hline Air Temperature & 25.14 & ${ }^{\circ} \mathrm{C}$ \\
\hline Irradiation & 264.75 & $\mathrm{~W} / \mathrm{m}^{2}$ \\
\hline Wind Speed & 2.1 & $\mathrm{~m} / \mathrm{s}$ \\
\hline
\end{tabular}

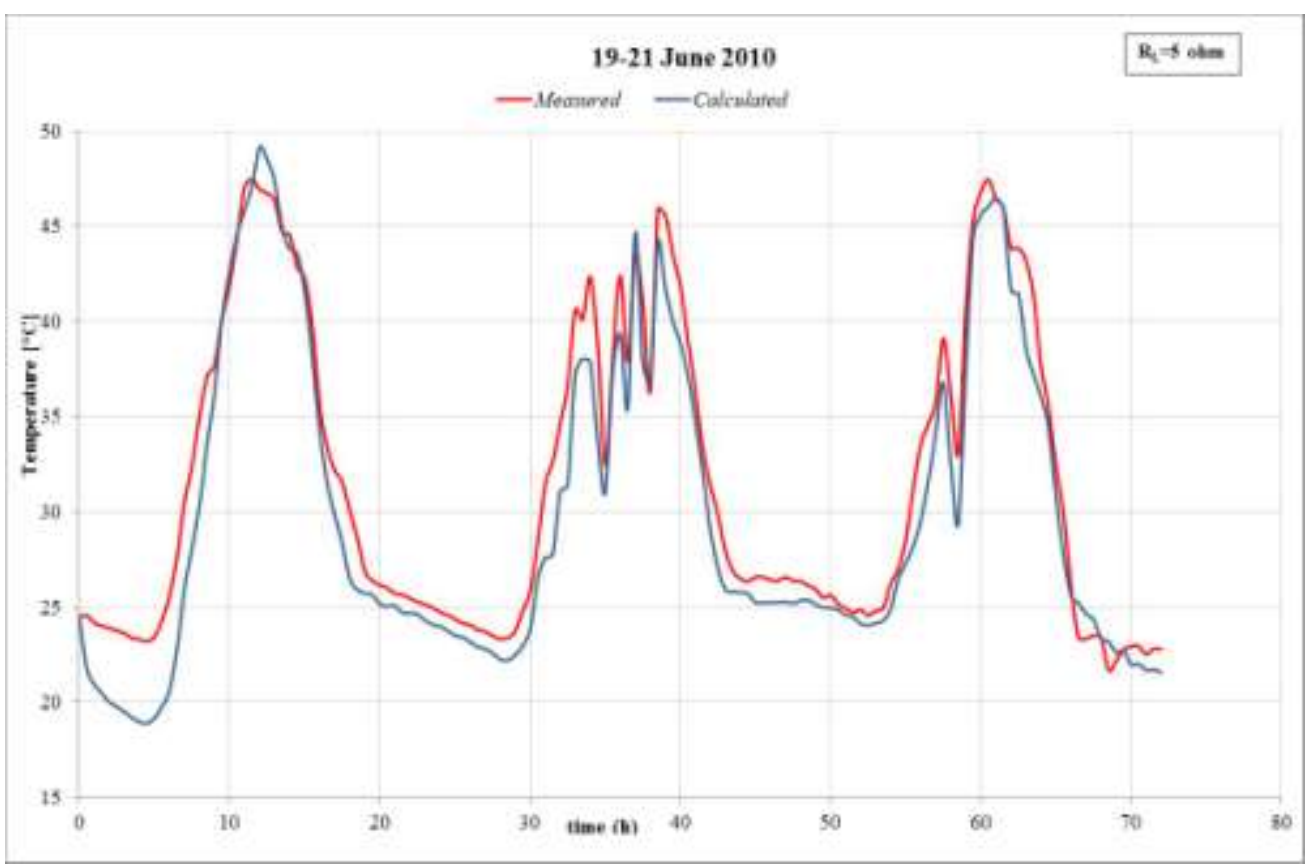

Figure 6: Temperature trend of the measured and simulated PV-PCM system, in Palermo, June 19 to 21 


\section{COMMENTS AND CONCLUSIONS}

Looking at the graphs represented before, it is possible to see as the calculated temperature trends are in good agreement with measured temperatures, validating the reliability of the calculation model.

The calculated temperatures at night are significantly lower than the comparable measured: this is an indication of an incorrect estimate irradiative heat exchange, which were estimated under the assumption of the sky always clear. Table 3 shows that the differences between the measured and calculated values are lower than $10 \%$ of average temperature. The comparison is based on the following definitions:

- Average gap: $\sum_{i=1}^{n} \frac{\left(T_{\text {mea }}-T_{c a l}\right)}{n}$

- Absolute average gap: $\sum_{i=1}^{n} \frac{\left|T_{\text {mea }}-T_{\text {cal }}\right|}{n}$

- Average Deviation: $\sum_{i=1}^{n} \frac{\left|T_{c a l}-T_{\text {mea }}\right|}{T_{\text {mea }}} / n$

- the maximum negative gap: $\min \sum_{i=1}^{n}\left(T_{\text {cal }}-T_{\text {mea }}\right)$;

- the maximum positive gap: $\max \sum_{i=1}^{n}\left(T_{c a l}-T_{\text {mea }}\right)$;

where $T_{\text {mea }}$ is the measured temperature $\left[{ }^{\circ} \mathrm{C}\right], T_{c a l}$ is the calculated temperature $\left[{ }^{\circ} \mathrm{C}\right]$ and $n$ in the number of samples.

Table 3: Comparison between measured and calculated temperatures

\begin{tabular}{|l|l|}
\hline \multicolumn{2}{|c|}{ PV panel } \\
\hline Average gap & $2.32\left[{ }^{\circ} \mathrm{C}\right]$ \\
\hline Absolute average gap & $2.48\left[{ }^{\circ} \mathrm{C}\right]$ \\
\hline Max negative gap & $-2.72\left[{ }^{\circ} \mathrm{C}\right]$ \\
\hline Max positive gap & $8.51\left[{ }^{\circ} \mathrm{C}\right]$ \\
\hline Average Deviation & $7.39 \%$ \\
\hline \multicolumn{1}{|c|}{$\mathbf{P C M}$} \\
\hline Average gap & $1.67\left[{ }^{\circ} \mathrm{C}\right]$ \\
\hline Absolute average gap & $1.87\left[{ }^{\circ} \mathrm{C}\right]$ \\
\hline Max negative gap & $-2.21\left[{ }^{\circ} \mathrm{C}\right]$ \\
\hline Max positive gap & $5.22\left[{ }^{\circ} \mathrm{C}\right]$ \\
\hline Average Deviation & $6.11 \%$ \\
\hline
\end{tabular}

The results show that the proposed model is valid and can be used to determine the thermal behaviour of a multilayer wall in which there is a phase change material. The model was validated by comparison with the analytical solution of the Voller and Cross problem and then by using an experimental setup with PV panel.

The good agreement between experimental measurements and numerical predictions have shown that the algorithm, although simplified and in one-dimensional geometry, can be used to determine the trend in temperature of a multilayer wall accompanied by a PCM 


\section{BIBLIOGRAPHY}

[1] Huang M.J., Eames P.C., Norton B., Thermal regulation of building-integrated photovoltaics using phase change materials, International Journal of Heat and Mass Transfer 47 (2004) 2715-2733.

[2] Huang M.J., Eames P.C., Norton B., An experimental study into the application of phase change materials to limit the temperature rise in build integrated photovoltaic systems, Proceedings of Renewable Energy in Maritime Island Climates, September, Belfast, UK, 2001, 143-150.

[3] Huang M.J., The application of CFD to predict the thermal performance of phase change materials for the control of photovoltaic cell temperature in buildings, Proceedings of VI World Renewable Energy Congress, July, Brighton, 2000, 2123-2126.

[4] Huang M.J., Eames P.C., Norton B., Phase change materials for limiting temperature rise in building integrated photovoltaics, Solar Energy 80 (2006) 1121-1130.

[5] Cellura M., Lo Brano V., Orioli A., et al., Miglioramento della resa energetica di un pannello fotovoltaico per mezzo di materiale a cambiamento di fase, ATI 2009, L'Aquila, Italy.

[6] Cellura M., Lo Brano V., Orioli A., et al., A Photovoltaic panel coupled with a phase changing material heat storage system in hot climates, DREAM University of Palermo, PLEA, Dublin, 2008.

[7] Frank P. Incropera, David P. DeWitt, Fundamentals of Heat Mass Transfer, $5^{\text {th }}$ edition, ISBN 0471386502.

[8] E V.R. Voller and M. Cross, Accurate Solutions of Moving Boundary Problems Using Enthalpy Method. Int. J. Heat Mass Transfer 24 (1981).

[9] L. Rubestein, The Stefan Problem, Transactions in Mathematics Monograph No. 27. American Mathematical Society, 1971 


\section{Thermo-Chemical Material Models}

\section{INTRODUCTION}

Households use a large amount of their energy consumption for space heating and domestic hot water. The energy consumption in the built environment can be reduced by energy saving measures (improved insulation, heat recovery, etc.). A substantial part of the remaining energy demand can be fulfilled by using renewable energy sources such as solar energy. During summer, the heat demand can be completely covered using solar heat, but in winter the heat demand exceeds the solar supply. To accommodate this lag between the solar energy surplus in summer and the energy demand in winter, a seasonal thermal storage is needed.

Traditionally, water is used for storing solar heat (for example, solar boiler) for short time periods. However, water-based long-term heat storage will require a large tank $\left(>50 \mathrm{~m}^{3}\right)$ that is often too large to be placed inside a building. As an alternative, it is possible to store energy by means of chemical processes, making use of the reversible reactions $C+$ heat $\Leftrightarrow A+B$.

In the charging mode during summer, solid $C$ dissociates under the influence of solar heat into components $A$ and $B$, which are stored separately. In the discharging mode during winter, the two components ( $A$ and $B$ ) react to form solid $C$ while releasing the stored solar heat. No reactions occur as long as the two components $A$ and $B$ are stored separately. Preliminary calculations show that sensible heat losses comprise approximately $10 \%$ of the total energy storage; this means that the remaining energy can be stored loss-free.

The Table below gives a list of candidate Thermo-Chemical Materials which can be used for long-term heat storage, see [1]. Dependent on their loading temperatures, energy densities, power densities and recyclability, TCM-materials can be used for (long-term) heat storage in the built environment and/or industry. To gain more insight into the heat and mass transfer processes taking place in these materials during charging and discharging, numerical modeling is needed ranging from the molecular- and micro-scale up to the macro- and reactor-scale. This insight can be used in a later stage to optimize specific properties of the storage materials with respect to their usage. The next chapters present an overview of the state-of-the-art modeling techniques on the various scales.

Candidate TCM-materials for long-term heat storage (from [1])

\begin{tabular}{|l|l|l|c|c|c|}
\hline $\mathrm{C}$ & $\mathrm{B}$ & $\mathrm{A}$ & $\mathrm{GJ} / \mathrm{m}^{3}$ & $\mathrm{~T} \rho \mathrm{C}$ ) & score \\
\hline $\mathrm{MgSO} 4 \cdot 7 \mathrm{H} 2 \mathrm{O}$ & $\mathrm{MgSO} 4$ & $7 \mathrm{H} 2 \mathrm{O}$ & 2.8 & 122 & $9.5 \%$ \\
\hline $\mathrm{SiO} 2$ & $\mathrm{Si}$ & $\mathrm{O} 2$ & 37.9 & 4065 & $9.0 \%$ \\
$\mathrm{FeCO} 3$ & $\mathrm{FeO}$ (wustite) & $\mathrm{CO} 2$ & 2.6 & 180 & $6.3 \%$ \\
$\mathrm{Fe}(\mathrm{OH}) 2$ & $\mathrm{FeO}$ & $\mathrm{H} 2 \mathrm{O}$ & 2.2 & 150 & $4.8 \%$ \\
\hline $\mathrm{CaSO} 4 \cdot 2 \mathrm{H} 2 \mathrm{O}$ & $\mathrm{CaSO} 4$ & $2 \mathrm{H} 2 \mathrm{O}$ & 1.4 & 89 & $4.3 \%$ \\
\hline $\mathrm{MgSO} 4 \cdot \mathrm{H} 2 \mathrm{O}$ & $\mathrm{MgSO} 4$ & $\mathrm{H} 2 \mathrm{O}$ & 1.3 & 216 & $2.7 \%$ \\
\hline $\mathrm{ZnCO} 3$ & $\mathrm{ZnO}$ & $\mathrm{CO} 2$ & 2.5 & 133 & $1.6 \%$ \\
\hline $\mathrm{CaCl} 2 \cdot 2 \mathrm{H} 2 \mathrm{O}$ & $\mathrm{CaCl} 2 \cdot 1 \mathrm{H} 2 \mathrm{O}$ & $\mathrm{H} 2 \mathrm{O}$ & 0.6 & 174 & $1.1 \%$ \\
\hline $\mathrm{MgSO} 4 \cdot 7 \mathrm{H} 2 \mathrm{O}$ & $\mathrm{MgSO} 4 \cdot 1 \mathrm{H} 2 \mathrm{O}$ & $\mathrm{H} 2 \mathrm{O}$ & 2.3 & 105 & $1.1 \%$ \\
\hline
\end{tabular}

[1] Visscher, K., Veldhuis, J. B. J., Oonk, H. A. J., van Ekeren, P. J., and Blok, J.G., 2004, "Compacte Chemische Seizoenopslag Van Zonnewarmte; Eindrapportage," ECN Report No. ECN-C-04-074. 


\section{HYDRATION AND DESHYDRATION OF SORPTION MATERIALS: EXPERIMENTS IN A SMALL-SCALE REACTOR}

Camilo RINDT and Hadi RAJAEI, Eindhoven University of Technology, Eindhoven, The Netherlands.

\section{INTRODUCTION}

In the present study a small-scale reactor is built in which controlled adsorption and desorption experiments are carried out. During the hydration and dehydration cycle temperature profiles are measured in the reactor to gain insight into the heat and mass transfer processes. Firstly a general description is given of the experimental set-up with special attention to the design of the reactor. Secondly some results are presented of adsorption and desorption experiments of zeolite 13X. Finally some conclusions are drawn and contact details are presented.

\section{LAY-OUT OF THE EXPERIMENTAL SET-UP}

\section{The setup}

The main components of the experimental device are the reactor, a heater and an evaporator. Figure 1 shows a lay-out of the experimental setup. At the left hand side, compressed air is delivered at a pressure of 7.5 bar and a relative humidity of $2.5 \%$ at $25^{\circ} \mathrm{C}$. The incoming dried air flow is measured and regulated by a gas flow controller (GFC). During a desorption experiment this air flows at the bottom side of the setup through the heater into the reactor. During a adsorption experiment water is pressed out of the water vessel by the pressurized airflow and measured by the liquid flow controller (LFC), resulting in a water-air stream into the controlled evaporator mixer (CEM). By giving set points for the air and water flow, the absolute humidity can be controlled. Then the humidified air flows into the reactor. A relative humidity/temperature sensor is used to measure the humidity and temperature at the outflow and a thermocouple data logger is used to readout the temperature profiles in the reactor. A more detailed description of the experimental device can be found in Rajaei [2012].

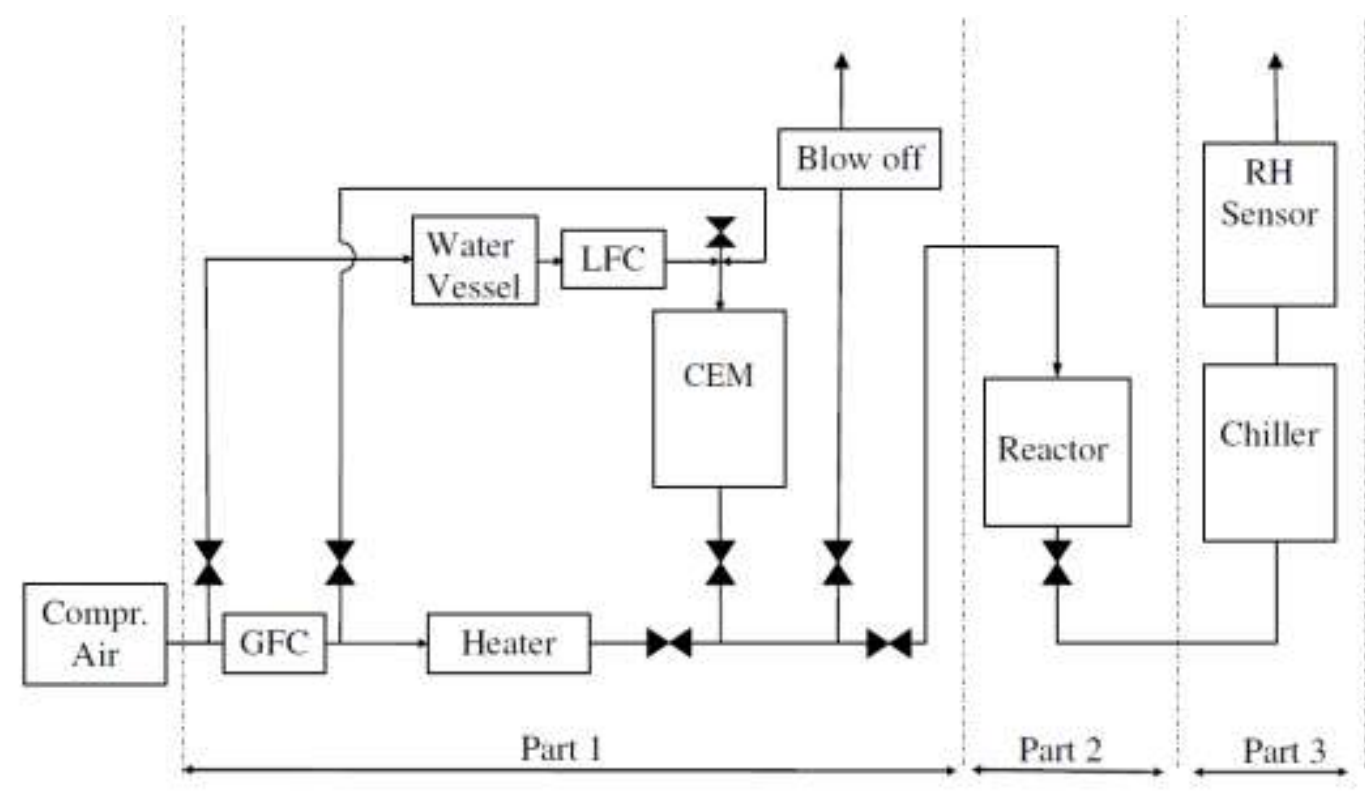

Figure 1: Lay-out of the experimental setup

Dimensions and design

Figure 2 shows a schematic view of the reactor and the positioning of the thermocouples and pressure gauges. The reactor is made of multiple materials. The inner shell is made of Teflon. The Teflon layer is used because of its low thermal conductivity characteristics, leading to large temperature differences over the wall, which are relatively easy to measure. The middle layer is made of stainless steel. A layer of insulation is applied at the outer part of the reactor. The outer side of the insulation is covered with a layer of 
tape. The air enters the reactor from the top side and leaves the reactor at the bottom, preventing the particles to go to a fluidized state. At the bottom of the reactor a filter is applied with a pore size is 40 micron. Table 1 shows all material characteristics of the reactor. Total mass of the reactor (including bolts, nuts and flanges) is around $4.7 \mathrm{~kg}$.
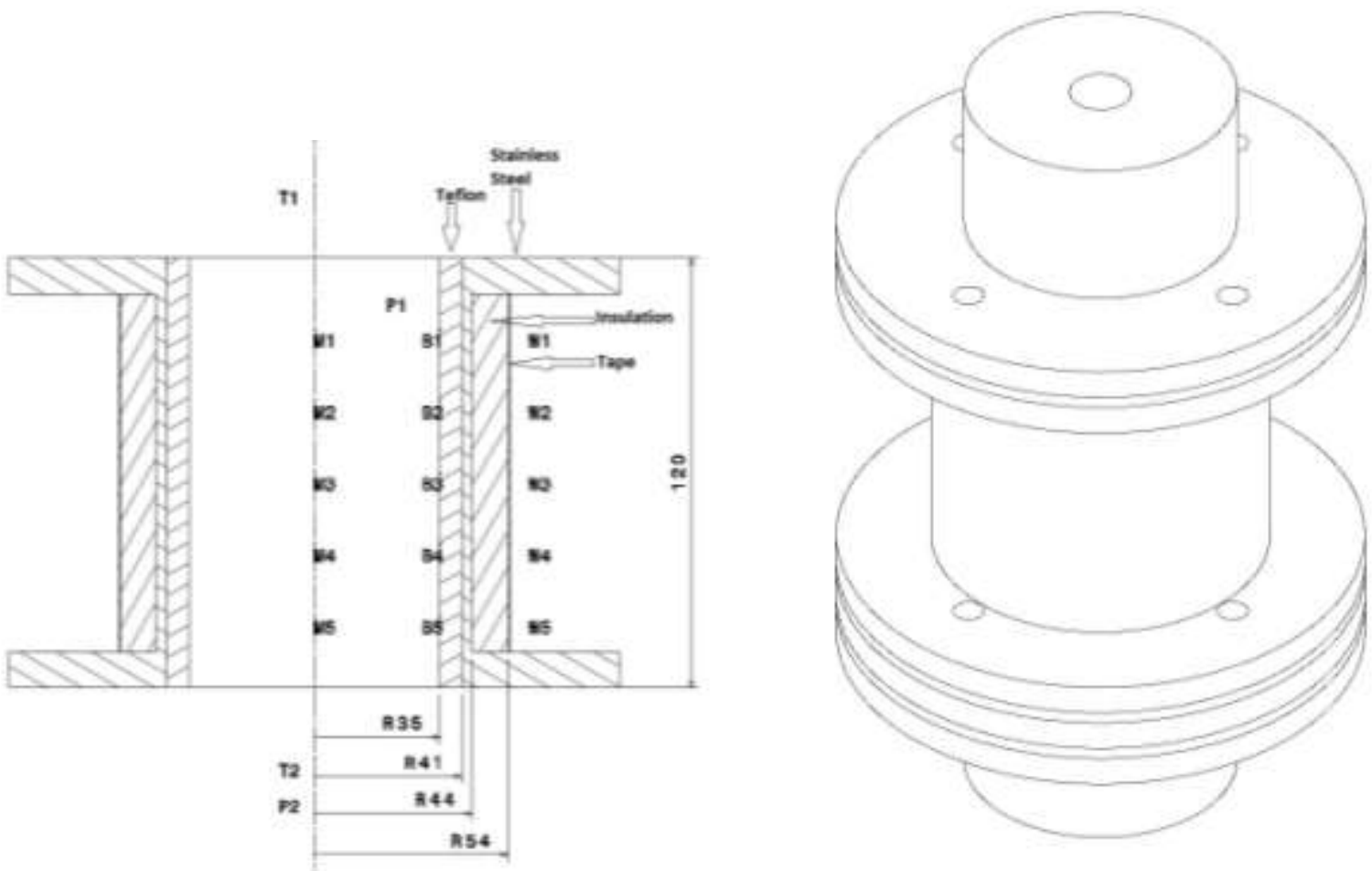

Figure 2: Schematic view of the reactor and the positioning of the thermocouples and pressure gauges (left). All dimensions are in $\mathrm{mm}$. Perspective view of the reactor (right).

Table 1: Material characteristics of the reactor (not measured but taken from specifications or from literature)

\begin{tabular}{|c|c|c|c|}
\hline Material & Density $\left(\mathrm{kg} / \mathrm{m}^{3}\right)$ & $\begin{array}{c}\text { Heat Capacity } \\
(\mathrm{J} / \mathrm{kg} . \mathrm{K})\end{array}$ & $\begin{array}{c}\text { Thermal conductivity } \\
(\mathrm{W} / \mathrm{m} . \mathrm{K})\end{array}$ \\
\hline Teflon & 2200 & 1005 & 0.25 \\
\hline Stainless steel & 8238 & 468 & 13.4 \\
\hline Insulation & 192 & 1000 & 0.04 \\
\hline PEEK (Filter) & 1320 & 320 & 0.25 \\
\hline
\end{tabular}


Material properties

Around 248 grams (weighted at ambient temperature and and humidity) zeolite $13 \mathrm{X}$ predried (dried at a temperature of $200^{\circ} \mathrm{C}$ for two hours) was used for the adsorption and desorption experiments. Table 2 shows the properties of zeolite $13 \mathrm{X}$.

Table 2: Properties of zeolite 13X (not measured but taken from literature)

\begin{tabular}{|c|c|c|c|c|}
\hline Material & $\begin{array}{c}\text { Diameter of pellets } \\
(\mathrm{mm})\end{array}$ & $\begin{array}{c}\text { Density } \\
\left(\mathrm{kg} / \mathrm{m}^{3}\right)\end{array}$ & $\begin{array}{c}\text { Heat Capacity } \\
(\mathrm{J} / \mathrm{kg} . \mathrm{K})\end{array}$ & $\begin{array}{c}\text { Thermal } \\
\text { conductivity } \\
(\mathrm{W} / \mathrm{m} . \mathrm{K})\end{array}$ \\
\hline Zeolite 13X & $1.3-2.5$ & 1876 & 1047 & 0.076 \\
\hline
\end{tabular}

\section{DETAILED DESCRIPTION OF THE MEASURING PROCEDURE}

17 thermocouples are attached to the reactor. T1 and T2 measure the inlet and outlet temperature, respectively. M1 up to M5 measure the temperature over the bed. B1 up to B5 are attached at the inner side of the Teflon wall, measuring the inner wall temperature. The thermocouples labeled $\mathrm{W} 1$ up to $\mathrm{W} 5$ are used to measure the outer wall temperatures. The thermocouples $\mathrm{M}$ and $\mathrm{B}$ are of type $\mathrm{T}$. The thermocouples attached to the wall are of type $\mathrm{K}$. In the reactor, every $2 \mathrm{~cm}$ a thermocouple is positioned. The filter is mounted at the bottom and has a thickness of $0.5 \mathrm{~cm}$. The distance between bottom side of the reactor and M5 is $2.5 \mathrm{~cm}$ (total length of the reactor and filter is $12.5 \mathrm{~cm}$ ). Thermocouples $\mathrm{T} 1$ and $\mathrm{T} 2$ are positioned in the gas stream leading to typical measuring errors in the range of $2 \%$. The humidity/temperature sensor has an accuracy of $1.5 \%$ on the relative humidity and $0.2^{\circ} \mathrm{C}$ on the temperature. It can measure from $0 \%$ to $100 \%$ of relative humidity and its response time is less than $15 \mathrm{~s}$. Since there are only 16 slots available at the data acquisition system, not all temperatures are measured simultaneously. Furthermore, two slots are required for measuring the humidity and temperature at the outlet. So, 14 slots remain available to measure temperatures in the reactor. To this end the 3 thermocouples labeled W1, W3 and W5 are not used in the presented measurements. Two pressure gauges are positioned at the inlet and outlet of the reactor to measure the pressure difference over the reactor. The reactor is filled with more or less spherical particles of zeolite $13 \mathrm{X}$ on top of the filter. The particle bed is not pressed, leading to a 'natural' porosity in the range of around 0.6 (not measured).

At the start of the experiment the reactor was in thermal equilibrium with the surroundings.

\section{RESULTS}

Adsorption

During the adsorption experiment a regulated gas flow of $24 \mathrm{l} / \mathrm{min}$ and a liquid flow of $0.28 \mathrm{~g} / \mathrm{min}$ enter the reactor. These numbers result in a relative humidity of $59 \%$. The 248 grams of zeolite used in the adsorption experiment resulted in a bed height of 8.5 $\mathrm{cm}$, covering M2. The experiment lasted 6 hours until the reaction ceased. Figure 3-top shows the temperature profiles in the reactor bed. The reactor inlet temperature is 17.5 ${ }^{\circ} \mathrm{C}$ which is different from the temperature of the compressed air $\left(25^{\circ} \mathrm{C}\right)$. This difference comes from the required energy for evaporation of water droplets.

The maximum temperature reached was $54^{\circ} \mathrm{C}$ which occurred at the top of the bed. The outlet temperature remains constant for almost 4 hours at $42^{\circ} \mathrm{C}$. the temperature profiles for $\mathrm{T} 1$ and $\mathrm{M} 1$ are identical. The thermocouples M2, M3, M4 and M5 show successive temperature peaks and this indicates a moving reaction front. The smaller this front, the more concentrated the energy released and so the higher the temperatures reached. Deeper in the reactor, the reaction front stretches out and the elevated temperatures last longer. This is caused by the fact that not all water vapor is consumed within the reaction front so material downstream the reaction front will hydrate in steps. So, deeper inside the reactor zeolite $13 \mathrm{X}$ loses some of its stored energy before the reaction front passes 
and, as a consequence, less elevated temperatures are reached which last longer. The reaction ceased after 5 hours $(300 \mathrm{~min}$ ) when the outlet temperature drops close to the inlet temperature.

Figure 3-bottom shows the outlet humidity. The vapor inflow is kept constant by the liquid flow controller and has a value of $0.28 \mathrm{~g} / \mathrm{min}$ during this experiment. The vapor outflow is not constant: at the start of the experiment it decreases to zero. In this period of time, all the supplied water vapor is consumed by the reaction. After 50 minutes it starts to rise and it stabilizes after 300 minutes. According to the measurements 56.3 grams $\mathrm{H}_{2} \mathrm{O}$ was absorbed in 300 minutes which is $22 \%$ wt of the zeolite.
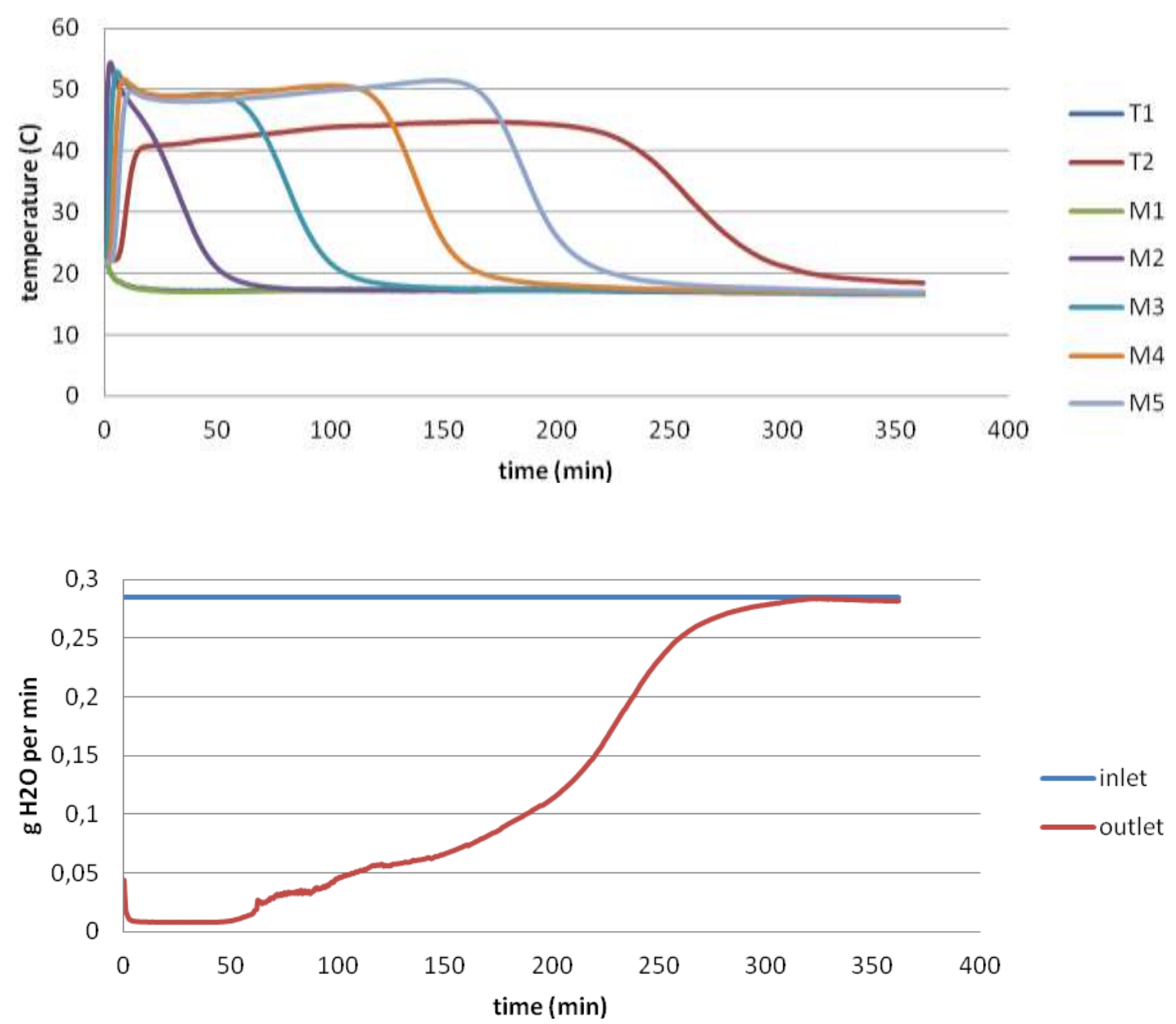

Figure 3: Temperature profile (top) and vapor in- and outflow (bottom) as function of time during the adsorption reaction of zeolite $13 \mathrm{X}$

Desorption

For the desorption experiment the heater was set to a heating rate of $1^{\circ} \mathrm{C}$ per minute. The maximum temperature was set to $200^{\circ} \mathrm{C}$ and the heater kept the maximum temperature for 2 hours. Figure 4-top shows the temperature profiles during the desorption experiment. At the beginning of the experiment the temperature at several positions drops a few degrees below the inlet temperature because water is expelled and process absorbs heat. As the inlet flow gradually heats up, the reactor temperature increases as well.

The outlet humidity graph shows that at the beginning of the desorption, a huge amount of water is expelled. Zeolite $13 \mathrm{X}$ has a maximum water uptake of $30 \mathrm{wt} \%$. Figure 4bottom shows that the vapor content decreases in time. The water vapor content starts at $1 \mathrm{~g} / \mathrm{min}$ and decreases quickly in the first 10 minutes. The incoming dry air causes the 
weakly bonded water molecules to separate from the zeolite. By further heating the air, more vapor is released from the zeolite (second peak at $t=45 \mathrm{~min}$ ). The vapor content that is released from the zeolite gradually reduces, but is more or less constant between $\mathrm{t}=100 \mathrm{~min}$ and $\mathrm{t}=170 \mathrm{~min}$. In this time interval the temperature of the incoming air is ranging between $70^{\circ} \mathrm{C}$ and $130^{\circ} \mathrm{C}$. The total amount of water expelled from the zeolite during the experiment was 70 grams, which is $28 \mathrm{wt} \%$. The zeolite apparently released more water than it took up in the adsrption experiment as described above. Possibly the zeolite was not fully dehydrated before the start of the adsorption experiment. The vapor content of the incoming heated air stream was $0.038 \mathrm{~g} / \mathrm{min}$.
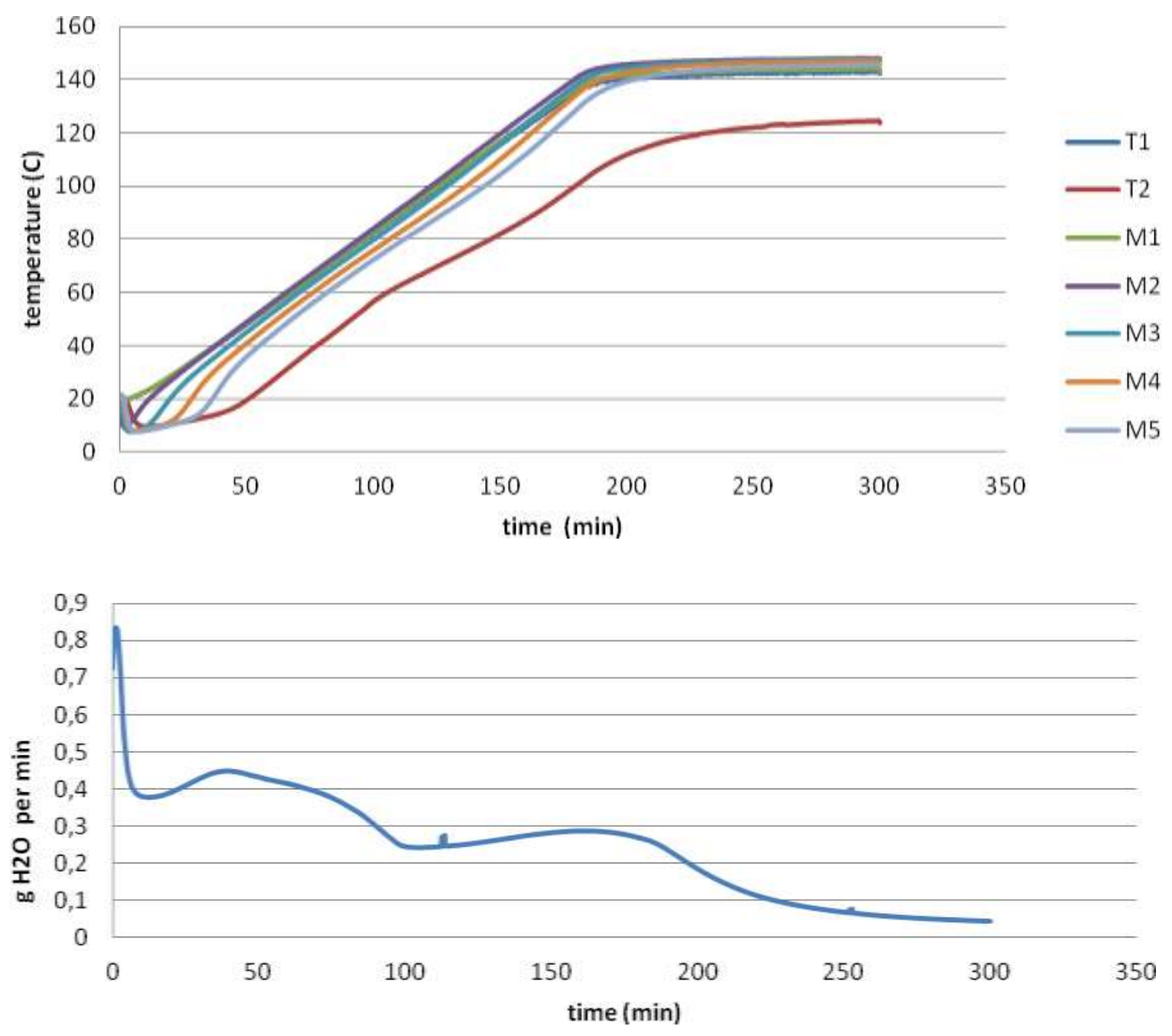

Figure 4: Temperature profiles in the reactor (top) and vapor outflow (bottom) as function of time during the desorption reaction of zeolite $13 X$.

\section{CLOSURE}

An experimental database has been created for adsorption and desorption of zeolite $13 \mathrm{X}$ using a small-scale reactor. Temperature profiles in the reactor are shown as function of time. The data can be used for benchmarking. For further information please contact c.c.m.rindt@tue.nl.

\section{BIBLIOGRAPHY}

[1] A.J. Brouwer, Development of an experimental device for the investigation of seasonal heat storage by thermo-chemical materials, M.Sc. Thesis, WET 2008.07, Eindhoven University of Technology, Eindhoven, the Netherlands, (2008) 
[2] P.J. van Kimmenade, Design of a test reactor for thermo-chemical heat storage materials, M.Sc. Thesis, WET 2010.13, Eindhoven University of Technology, Eindhoven, the Netherlands, (2010)

[3] E.C.J.A Dukers, Fixed bed reactor analysis for thermochemical heat storage, M.Sc. Thesis, WET 2012.01, Eindhoven University of Technology, Eindhoven, the Netherlands, (2012)

[4] H. Rajaei, Fixed bed reactor analysis for seasonal heat storage by thermochemical materials , M.Sc. Internship Report, WET 2012.16, Eindhoven University of Technology, Eindhoven, the Netherlands, (2012) 


\section{ADSORPTION HEAT STORAGE: DYNAMIC PROPERTIES}

Gerrit FUELDNER, Fraunhofer Institute Solar Energy Systems, Freiburg, Germany.

\section{INTRODUCTION}

Adsorption heat storage uses the exothermal process of physical adsorption of a gas (e.g. water vapor) on highly porous materials such as zeolites or silicagel. The storage can be loaded by drying the material with high temperature $\left(100-250^{\circ} \mathrm{C}\right)$ heat. If kept dry, it only cools down sensibly, and when exposed to water vapor will release the heat of adsorption at a medium temperature level $\left(35-70^{\circ} \mathrm{C}\right)$. The storage can be built as an open system where hot air flows through an adsorbent bed for desorption and cool air is heated by adsorption of its water content. It can also be built as a closed (vacuum) system with pure water vapor atmosphere. In this case an additional heat exchanger is needed to bring in and out the heat. As well, a low temperature $\left(0-20^{\circ} \mathrm{C}\right)$ evaporation source is necessary for the adsorption process in a closed system adsorption storage.

Porous adsorbent materials can be characterized in various ways. The typical physical properties which are of importance when considering a material in the context of thermal energy storage are mass/volume specific working fluid uptake (isobars/isotherms), heat capacity, heat conductivity, diffusivity, porosity and density. There are different characterization techniques for all these parameters. All of them have an influence on both the energy storage density and on the possible power of the storage, i.e. how fast can the storage be (un-)loaded. Of course, also the complete storage setup with casing, heat exchangers etc. will influence both, and it is often not easily possible to find the limiting factors.

\section{LAY-OUT OF THE EXPERIMENTAL SET-UP}

To evaluate the dynamic properties of different heat-exchanger/adsorbent setups a volumetric adsorption kinetics measurement facility will be presented. In this the transient adsorption process is measured. Physical parameters like heat transfer resistances or diffusivities can be drawn from such measurements by comparison to a detailed model.

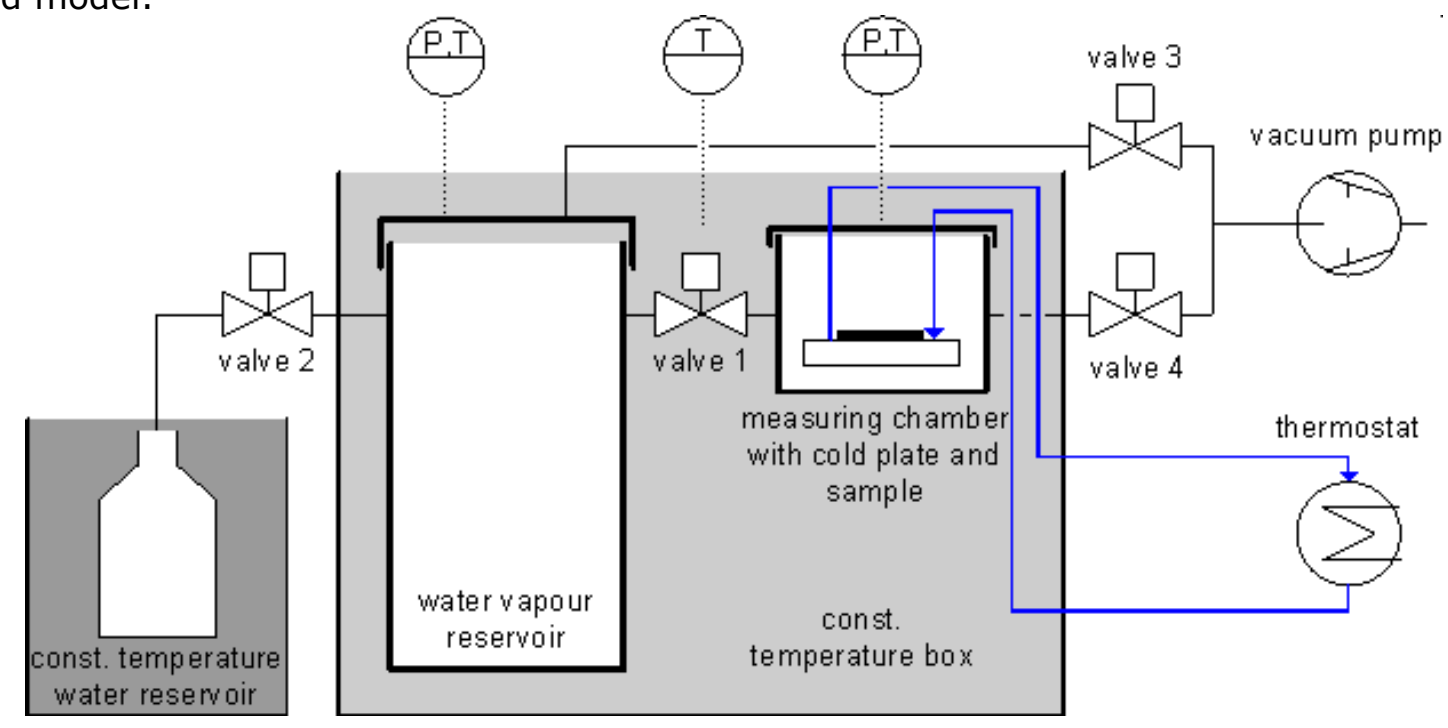

Figure 1: Scheme of the measurement setup for adsorption kinetics (most important parts).

The dosing chamber (water vapour reservoir, Volume 42.888 liters) with a defined quantity of pure water vapor (given by the saturation pressure at water bottle temperature) and the measuring chamber (Volume 0.7.. litres) are put in a thermostated rack $\left(40^{\circ} \mathrm{C}\right)$. The sample is put on a coldplate thermostated by a water flow at constant temperature. 
The exemplary sample presented in this report is a composite adsorbent material in a thin layer (thickness $0.72 \mathrm{~mm}$ ) that is glued to an aluminum plate (thickness $0.4 \mathrm{~mm}$ ) representing the heat exchanger. The material consists of a rare earth exchanged $\mathrm{Y}$ zeolite in a polymer fibre matrix (UOP DDZ-70) [1]. The sample size is $5 \times 5 \mathrm{~cm}^{2}$, the density of the dry material is $650 \mathrm{~kg} / \mathrm{m}^{3}$ (dry adsorbent mass $1.12 \mathrm{~g}$ ) and the porosity is $57 \%$ [2]. The mean intercrystalline poresize between the zeolite crystals (from permeability and mercury intrusion) is approximately 3-5 $\mu \mathrm{m}$, the pore tortuosity factor is about 7 [3].

The heat capacity is $1000 \mathrm{~J} /(\mathrm{kg} \mathrm{K})$, the heat conductivity of the dry material about 0.12 $\mathrm{W} /(\mathrm{m} \mathrm{K})$ [2]. The adsorption equilibrium can be described by a generalized form of Dubinin's characteristic curve giving the adsorbed volume $\mathrm{W}\left[\mathrm{cm}^{3}\right.$ of adsorbate $/ \mathrm{kg}$ of dry adsorbent] as a function of the adsorption potential $A=R T$ In $\mathrm{p}_{\text {sat }}(\mathrm{T}) / \mathrm{p}[\mathrm{J} / \mathrm{g}$ of adsorbate].

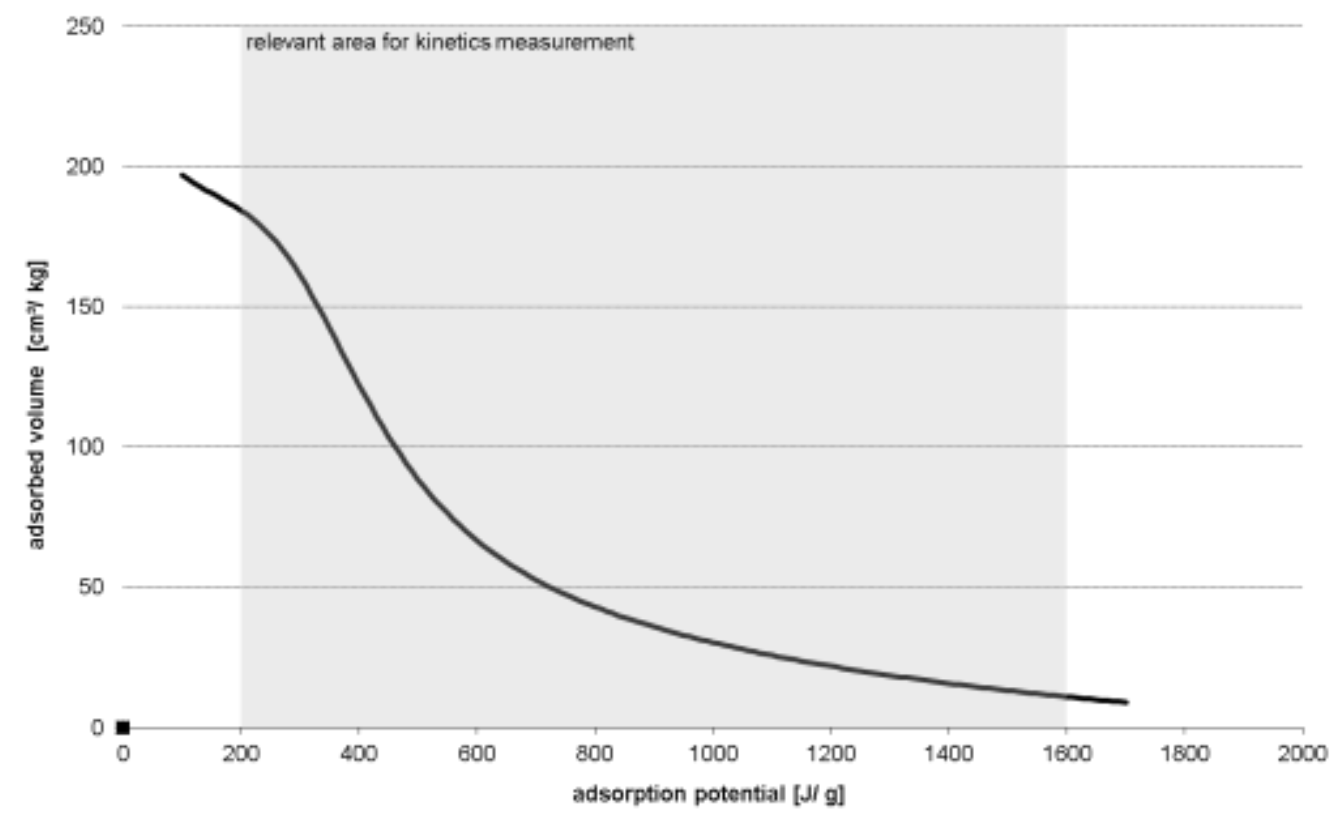

Figure 2: Characteristic curve UOP DDZ-70 with $20 \%$ of polymeric binder.

$W=\left(a+c A+e A^{2}+g A^{3}\right) /\left(1+b A+d A^{2}+f A^{3}\right)[4,2]$

with the parameters

\begin{tabular}{|l|l|}
\hline a & 221,160732 \\
\hline$b$ & $-2,01 \mathrm{E}-03$ \\
\hline$c$ & $-7,91 \mathrm{E}-01$ \\
\hline$d$ & $-2,22 \mathrm{E}-06$ \\
\hline e & $1,48 \mathrm{E}-03$ \\
\hline$f$ & $1,65 \mathrm{E}-08$ \\
\hline $\mathrm{g}$ & $-5,13 \mathrm{E}-07$ \\
\hline
\end{tabular}

\section{DETAILED DESCRIPTION OF THE MEASURING PROCEDURE}

To measure the transient adsorption process, the desorbed (activated) sample is cooled to $40^{\circ} \mathrm{C}$ and then exposed to water vapor atmosphere by opening valve 1 . The sample immediately starts to adsorb. 
The possible measurements vary with respect to the activation (desorption) conditions and with respect to the actual adsorption process.

\section{Desorption Conditions}

For desorption two different conditions are applied:

1. The sample is heated to $95^{\circ} \mathrm{C}$ and the measurement cell is evacuated to ending pressure of a two stage vacuum pump (about $0.1 \mathrm{mbar}$ ).

2. For conditions closer to real working conditions in an adsorption storage, the desorption is against a condenser (the thermostated water reservoir) at e.g. $30^{\circ} \mathrm{C}$.

In both conditions one has to keep in mind that the starting point (equilibrium uptake at $\mathrm{t}=0$ ) is not directly defined by the desorption conditions (e.g. $95^{\circ} \mathrm{C}$ and $42 \mathrm{mbar}$ condenser pressure), since the sample is cooled down after the desorption phase and takes up some water from the small but not negligible volume of the measurement cell.

\section{Canonical Measurement}

"Canonical" in this context means that we have a closed system so the amount of water molecules in the system stays constant during the measurement. After opening valve 1 it is possible to calculate the absolute uptake of the sample by the drop in pressure (knowing the exact volume of measurement cell + dosing chamber). As starting pressure usually either $12.3 \mathrm{mbar}$ (evaporator $10^{\circ} \mathrm{C}$ ) or $17 \mathrm{mbar}$ (evaporator $15^{\circ} \mathrm{C}$ ) are chosen.

\section{Coupling of the Sample to Coldplate/HF-Sensor}

The sample has been characterized in three different coupling variants. First, the sample has only been pressed to the coldplate without Thermigrease and without heat flux (HF) sensor to get the pressure drop without the danger of polluting the sample with the thermigrease. Then, to get the fastest possible adsorption kinetics, the sample is coupled to the coldplate with a thin layer of Thermigrease but without HF sensor. Finally the samples can be characterized with the HF sensor included in the setup.

\section{RESULTS}

The measurement gives data on the surface temperature, the pressure in the measurement chamber and - if included - on the heat flux to the coldplate. Figure 3 shows 4 measurements, two measured with heatflux sensor and two without.

To evaluate the measurements, a detailed model of the non-isothermal adsorption kinetics taking into account heat transfer in the adsorbent and the metal, heat transfer resistances both between the adsorbent and the metal as well as between the metal and the coldplate and of course also mass transfer through macro- and micropores is fitted to the experiment [5]. The blue marks show the fitted model results. 

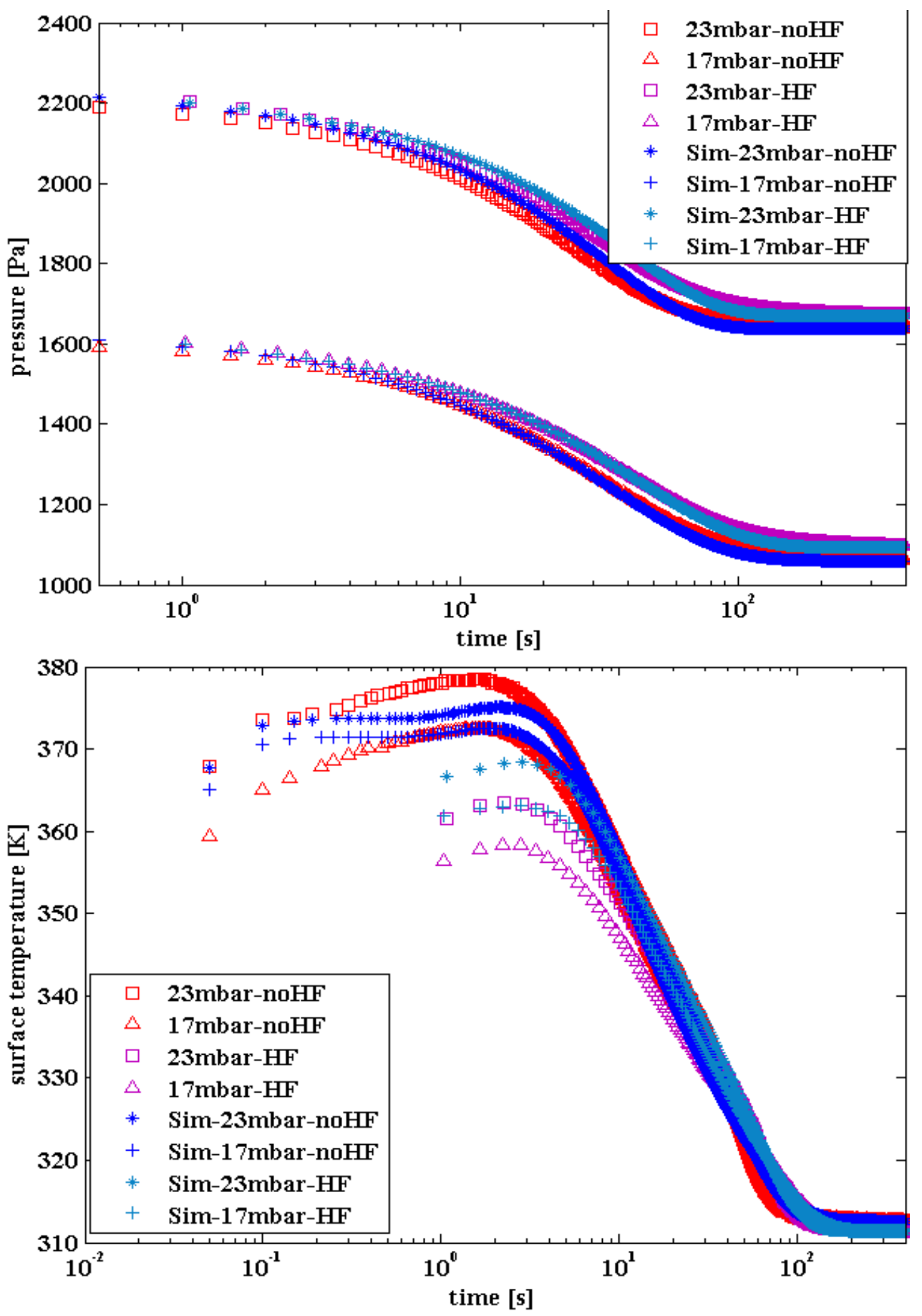

Figure 3: Pressure in measurement chamber (upper) and surface temperature of the sample after step change in pressure to 17 or 23 mbar after desorption and cooling. The measurements have been carried out with and without a heat flux (HF) sensor. For the measurements with $H F$, data on the heat flux is available as well. The HF introduces an additional heat transfer resistance which slows down the kinetics and thus has to be taken into account when modeling the transient uptake.

\section{CLOSURE}

By measuring the uptake kinetics of macroscopic composite samples, heat and mass transfer parameters relevant for designing adsorption heat storages can be extracted. Using these parameters in simulation of the cyclic ad- and desorption process allows to predict the performance of different storage designs and materials $[6,7]$. 
For further information and detailed experimental data, please contact gerrit.fueldner@ise.fraunhofer.de

\section{BIBLIOGRAPHY}

[1] Dawoud, B., Vedder, U., Amer, E. and Dunne, S., Non-isothermal adsorption kinetics of water vapour into a consolidated zeolite layer, International Journal of Heat and Mass Transfer, 50, 2190 - 2199, (2007)

[2] Schnabel, L., Experimentelle und numerische Untersuchung der Adsorptionskinetik an Adsorbens-Metall-Verbundstrukturen,PhD Thesis Faculty III - Process Sciences, Technical University Berlin, Germany, (2009)

[3] Füldner G., Permeability of composite adsorbent layer, Unpublished measurements, (2008-2010)

[4] Núñez, T., Charakterisierung und Bewertung von Adsorbentien für Wärmetransformationsanwendungen, PhD Thesis Faculty of Physics, University of Freiburg, Germany, (2001)

[5] Füldner G. and Schnabel L., Non-isothermal kinetics of water adsorption in compact adsorbent layers on a metal support, Proc. of the Int. COMSOL Conf., Hannover, Germany, (2008)

[6] Schnabel L. and Füldner G., Water Adsorption in Compact Adsorbent Layers Kinetic Measurements and Numerical Layer Optimization, Proc. of Heat Powered Cycles 2009, TU Berlin, Germany: 520, (2009)

[7] Füldner, G.; Schnabel, L.; Wittstadt, U.; Henning, H. \& Schmidt, Numerical layer optimization of aluminium fibre/Sapo-34 composites for the application in adsorptive heat exchangers, F. Lazzarin, R.; Longo, G. \& Noro, M. (ed.), Proceedings of the International Sorption Heat Pump Conference, Padua Italy, 533-542, (2011) 


\section{FIXED BED REACTOR FOR HYDRATION / DEHYDRATION OR ADSORPTION / DESORPTION EXPERIMENTS}

Barbara METTE, Florian BERTSCH, Henner KERSKES, Instiute for Thermodynamic and Thermal Engineering, Stuttgart University, Stuttgart, Germany.

\section{INTRODUCTION}

Experiments on the hydration and dehydration or adsorption and desorption behavior of thermochemical energy storage materials are carried out in a small-scale fixed bed reactor. The experiments are performed under controlled inlet conditions of the airflow (humidity, temperature and mass flow). During the experiments, the temperature profile inside of the material bed is measured at five different axial positions. In addition, the inlet and outlet temperature, the inlet and outlet humidity and the mass flow of the airflow are measured.

\section{LAY-OUT OF THE EXPERIMENTAL SET-UP}

Figure 1 depicts the experimental set up of the fixed bed reactor. Compressed air is filtered, additionally dried and then entering the fixed bed reactor test rig. For the drying process of the compressed air, the air is conducted through a bulk of zeolite $13 \mathrm{X}$ particles which has been dried at a temperature of $\vartheta=180^{\circ} \mathrm{C}$. This drying process further reduces the air humidity to values of $\mathrm{p}_{\mathrm{H} 2 \mathrm{O}}<0.3$ mbar.

The mass flow rate of the air is measured and regulated with a mass flow controller (Bronkhorst, El-Flow, control range: $0 \ldots 0.16 \ldots 8 \mathrm{~m}^{3} / \mathrm{h}$ ). During the hydration / adsorption experiments, the air is humidified by directing part of the air flow through the air humidifier and part of it through the bypass. Afterward, the two air flows are mixed together again and the air humidity is measured with a dew points sensor (EdgeTech Dew Master, dew point range: -20 to $95{ }^{\circ} \mathrm{C}$, accuracy $+/-0.2 \mathrm{~K}$ ). A pneumatic control valve regulates the volume flow through the bypass so that the resulting combined flow has the desired air humidity. During the dehydration / desorption experiments the complete air flow is passing through the bypass.

In an electrically heated pipe the air is heated up to the desired reactor inlet temperature. The electrical power of the heating coils can be regulated so that the variation in the inlet temperature is less than $+/-0.3 \mathrm{~K}$.

The reactor inlet and outlet temperature of the airflow and the temperature of the material bed at five different axial positions $\left(T_{R, 1}=20 \mathrm{~mm}, T_{R, 2}=40 \mathrm{~mm}, T_{R, 3}=60 \mathrm{~mm}\right.$, $T_{R, 4}=80 \mathrm{~mm}, T_{R, 5}=120 \mathrm{~mm}$ ) of the reactor are measured with thermocouples (type $\mathrm{K}$, diameter $1 \mathrm{~mm}$, accuracy $+/-1 \mathrm{~K}$ ). The air humidity at the reactor inlet and outlet are measured with dew point sensors.

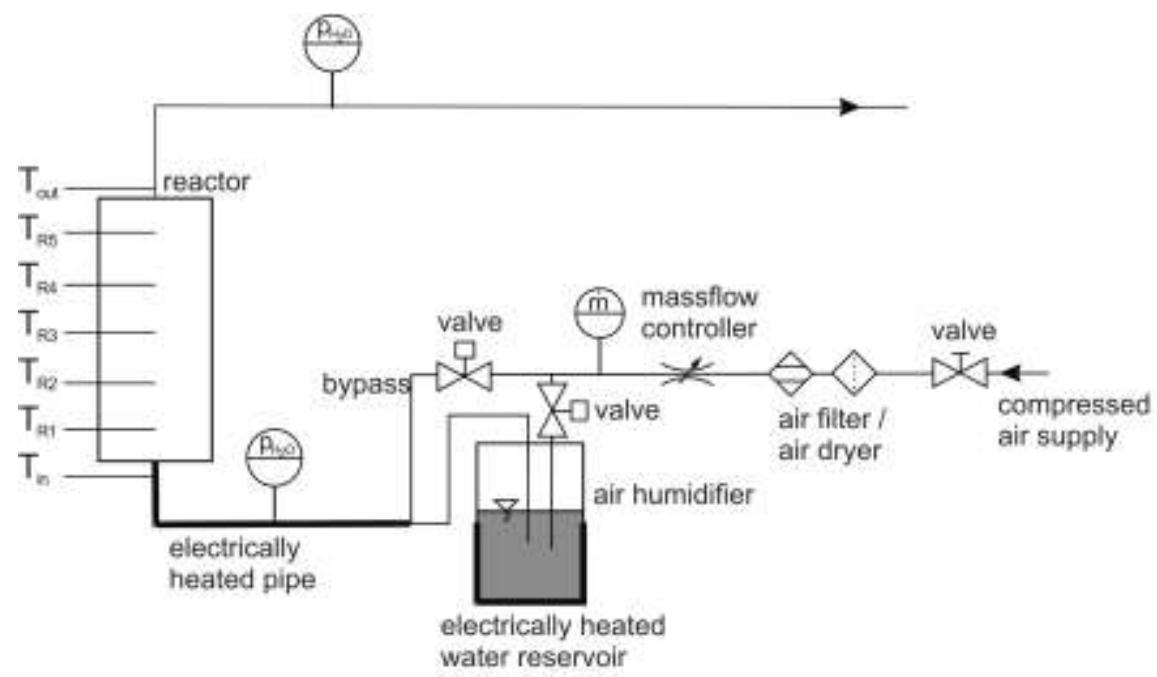

Figure 1: Experimental set up of the fixed-bed reactor test rig 
A more detailed sketch of the fixed bed reactor is given in figure 2. The reactor is made of stainless steel (wall thickness of $3 \mathrm{~mm}$ ) and has a volume of approximately $165 \mathrm{ml}$ (reactor height $=125 \mathrm{~mm}$, reactor diameter = $40.5 \mathrm{~mm}$ ). The reactor is insulated with glass wool of a thickness of approximately $50 \mathrm{~mm}$.

The temperature sensors for measuring the material bed temperatures are not in direct contact with the material bed. The sensors are inserted in brass tubes (inner diameter of $1 \mathrm{~mm}$, outer diameter of $1.4 \mathrm{~mm}$ ) which are horizontally passed through the reactor. This set up allows an easy and reproducible measurement of the bed temperature in many experiments.

A clamp ring connection allows an easy installation and removal of the reactor. A reducer pipe from the reactor diameter to $20 \mathrm{~mm}$ is installed before and behind the fixed bed reactor. Two filters (sintered bronze, pore size of $1 \mathrm{~mm}$ ), which are positioned in the top and bottom flange, are fixing the material inside the reactor.

The following inlet conditions of the air flow can be set:

- Mass flow (dry air): $100 \ldots 3000 \mathrm{~g} / \mathrm{h}$

- Air humidity: 5 ... 100 mbar

- Reactor inlet temperature: $25 \ldots 190^{\circ} \mathrm{C}$

\section{DETAILED DESCRIPTION OF THE MEASURING PROCEDURE}

A measuring cycle in general consists of at least three steps which are all conducted in the fixed bed reactor: Desorption / dehydration of the material, cooling down the material, adsorption / hydration of the material. In all three phases air at a defined mass flow is flowing through the material bed.

The different steps will be described in more details by the example of an adsorption / desorption cycle of binder-free zeolite 13X and a hydration / dehydration cycle of a composite of calcium chloride on a mineral clay matrix.

\section{Binder-free zeolite 13X}

The reactor is filled with binder-free zeolite $13 \mathrm{X}$ (Köstrolith ${ }^{\circledR} 13 \mathrm{XBFK}$ ) of the company Chemiewerke Bad Köstritz up to the fifth temperature sensor (approximately $88 \mathrm{~g}$ ). The particles are spherical and have a grain size of $1.6-2.0 \mathrm{~mm}$.

During the desorption process the material is dried in the reactor with a dry air flow of the following reactor inlet conditions: air mass flow rate $\mathrm{h}=1000 \mathrm{~g} / \mathrm{h}$, reactor inlet temperature $\vartheta=180^{\circ} \mathrm{C}$, reactor inlet air humidity $\mathrm{p}_{\mathrm{H} 2 \mathrm{O}}<0.3 \mathrm{mbar}$. Due to heat losses over the reactor length no uniform temperature distribution over the reactor length is achieved in steady-state conditions. A temperature drop of $\triangle T=T_{\text {in }}-T_{\text {out }}=30 \mathrm{~K}$ is measured over the reactor length.

In the cooling phase the material (and also the periphery to and from the reactor) is cooled down by air flown through the fixed bed reactor. The reactor inlet temperature is set to the desired temperature of the adsorption phase. The mass flow rate and air humidity remain constant.

For the adsorption process the air flow is humidified to the desired inlet air humidity. Due the control algorithm of the pneumatic valve it takes a few minutes (up to 8 minutes) until the air humidity is constant at the desired set point value. A bypassing of the reactor is not possible so that during the first minutes of the measurements the inflow conditions are not stationary.

The adsorption is performed at an inlet temperature of the air flow of $\vartheta=35^{\circ} \mathrm{C}$ and an inlet humidity of $\mathrm{p}_{\mathrm{H} 2 \mathrm{O}}=20$ mbar. 
Composite of calcium chloride on a mineral clay matrix

The composite of calcium chloride and mineral clay was prepared at ITW by impregnating mineral clay (grain size of 2 to $5 \mathrm{~mm}$ ) in a salt solution of calcium chloride. Afterwards the sample was dried in an oven at $150{ }^{\circ} \mathrm{C}$. The uptake of calcium chloride into the mineral clay matrix was approximately 34 weight-\% (related to the mineral clay mass). Afterwards the sample was stored under room conditions.

For investigating the hydration behavior of this composite $71 \mathrm{~g}$ of the material was filled in the fixed bed reactor, just covering the fifth temperature sensor.

For the dehydration of the composite, the temperature of the airflow is stepwise increased: 4 hours at $50^{\circ} \mathrm{C}, 5$ hours at $100^{\circ} \mathrm{C}, 6$ hours at $150{ }^{\circ} \mathrm{C}$. The mass flow is set constant to $\mathrm{rh}=1000 \mathrm{~g} / \mathrm{h}$, the reactor inlet air humidity is $\mathrm{p}_{\mathrm{H} 2 \mathrm{O}}<0.3 \mathrm{mbar}$. Due to heat losses over the reactor length a temperature drop over the reactor of $\triangle T=22 \mathrm{~K}$ is measured at a reactor inlet temperature of $\vartheta=150^{\circ} \mathrm{C}$.

The cooling and the hydration phase were conducted in the same manner as for the binder-free zeolite $13 \mathrm{X}$.

\section{Results}

Binder-free zeolite 13X

Figure 3 depicts the temperature profile in the material bed, the reactor inlet and outlet temperatures and the reactor inlet and outlet water vapor pressures of the airflow during the adsorption process.

Successively the temperatures measured at the five thermocouples $T_{R 1}$ to $T_{R 5}$ are increasing to a maximum temperature of around $\vartheta=80^{\circ} \mathrm{C}$ and are then decreasing again. The sharp temperature peaks indicate a sharp reaction front which is moving through the reactor.

Over almost 1.5 hours the air humidity at the reactor outlet is almost zero. This indicates a high affinity of this zeolite towards water. During the next 40 minutes, the reactor outlet water vapor pressure is comparatively rapidly increasing to $18.5 \mathrm{mbar}$ and then over a long period of roughly 30 to 40 minutes slowly approaching the value of the water vapor pressure of the reactor inlet of 20 mbar. The total amount of water vapor adsorbed is measured to $23 \mathrm{~g}$, equivalent to 26.4 weight-\% (related to the dry material mass).

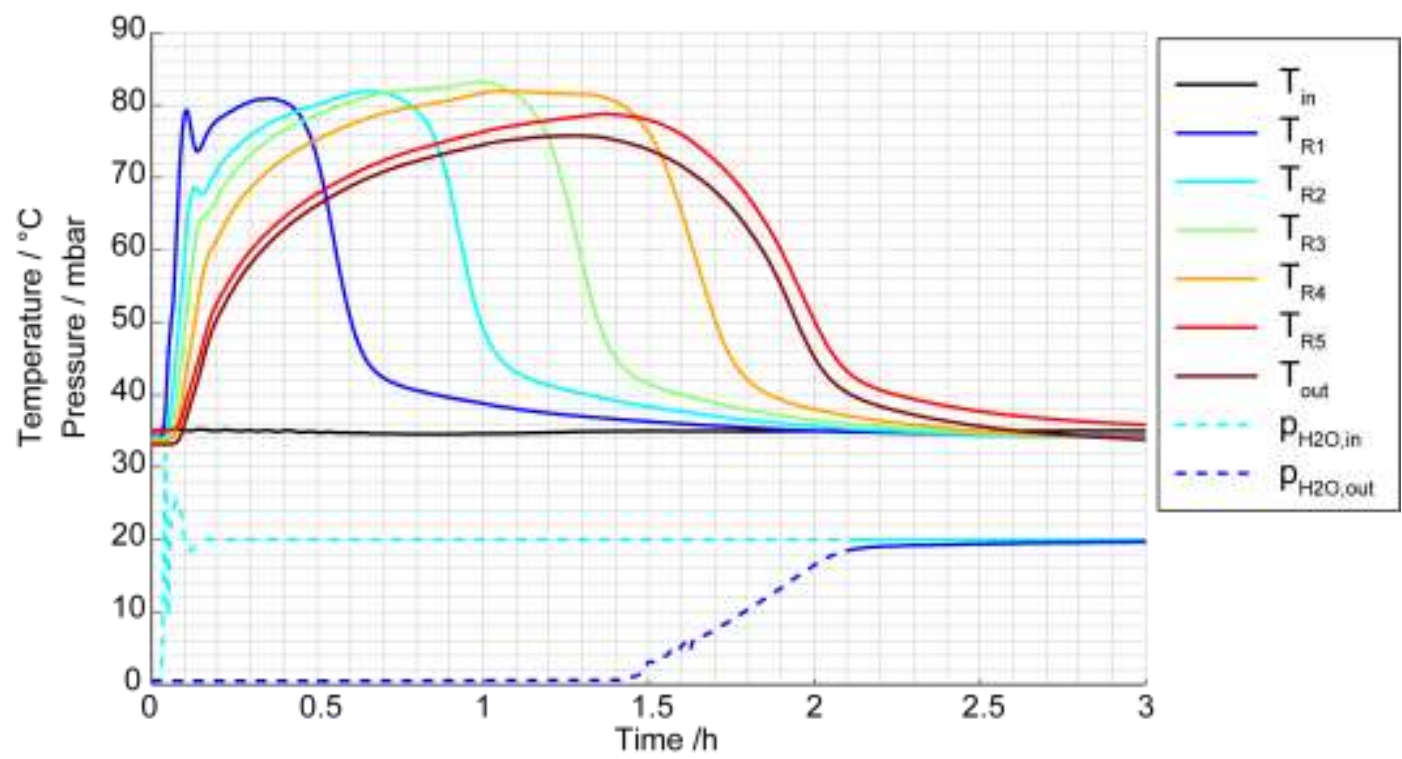

Figure 3: Temperature distribution over the reactor length, reactor inlet and outlet air temperatures and reactor inlet and outlet water vapor pressures depicted over the reaction time during the adsorption of binder-free zeolite $13 X$ 
Composite of calcium chloride on a mineral clay matrix

In figure 4 the temperature profile in the material bed, the reactor inlet and outlet temperatures and the reactor inlet and outlet water vapor pressures of the airflow during the hydration phase are depicted.

As soon as water vapor is given to the airflow a temperature increase at all temperature sensors is measured immediately. After 6 minutes, a maximum temperature of about $\vartheta=60{ }^{\circ} \mathrm{C}$ is reached at temperature sensor $T_{R 3}$ and $T_{R 4}$. Afterwards, the temperature in the whole material bed is first dropping quickly to around $\vartheta=45^{\circ} \mathrm{C}$, then only slightly decreasing for a quite long period and then decreasing faster again to the air flow inlet temperature. For example, the temperature at sensor $T_{R 3}$ is first dropping by $15 \mathrm{~K}$ (from $\vartheta=60^{\circ} \mathrm{C}$ to $\vartheta=45^{\circ} \mathrm{C}$ ) in 1.5 hours, then only dropping by $3 \mathrm{~K}$ (to $\vartheta=42{ }^{\circ} \mathrm{C}$ ) during the next 3.5 hours and then by $5 \mathrm{~K}$ again (to $\vartheta=37^{\circ} \mathrm{C}$ ) in 2.5 hours.

The curve of the partial pressure of the water vapor at the reactor outlet can be classified in four phases: a very quick increase from $\mathrm{p}_{\mathrm{H} 2 \mathrm{O}}=0$ to $\mathrm{p}_{\mathrm{H} 2 \mathrm{O}}=12.5 \mathrm{mbar}$ in the first hour, then a slow increase to $\mathrm{P}_{\mathrm{H} 2 \mathrm{O}}=14 \mathrm{mbar}$ in the next 4 hours, and then a faster increase to $\mathrm{p}_{\mathrm{H} 2 \mathrm{O}}=17.5 \mathrm{mbar}$ in the next 2.5 hours. Afterwards, the water vapor at the reactor outlet only approaches very slowly the water vapor inlet pressure. Even after 10 hours of reaction only a water vapor pressure of $\mathrm{p}_{\mathrm{H} 2 \mathrm{O}}=19 \mathrm{mbar}$ is measured at the reactor outlet. In total, the water uptake of the composite was measured to be 31.7 weight-\% (related to the dry material) during 10 hours of hydration.

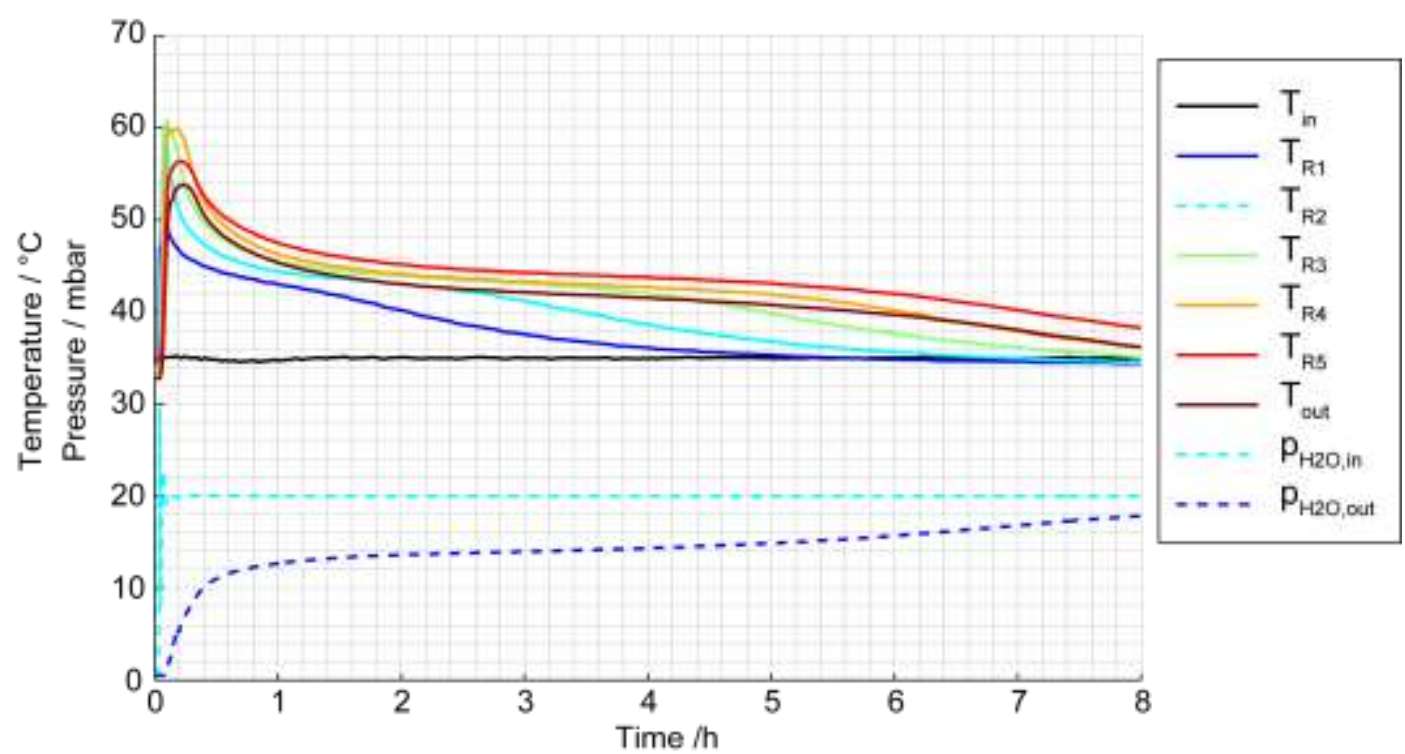

Figure 4: Temperature distribution over the reactor length, reactor inlet and outlet air temperatures and reactor inlet and outlet water vapor pressures depicted over the reaction time during the hydration of the composite of mineral clay and calcium-chloride.

An explanation for the fast increase in temperature in the beginning of the hydration experiment is that the anhydrated salt first reacts comparatively quickly with the water vapor. Due to the superposition of two effects, the maximum temperature is measured at the temperature sensors TR3 and TR4: 1) the air flow transports the heat of reaction from further upstream in this area and preheats the material and 2) the material in this area is reacting with the water vapor which is transported via the air flow, heat is released and further increase the materials temperature.

Further downstream the water vapor in the air flow is consumed and no further reaction takes place. Hence, no further heat is produced and the air flow is slowly cooled down by preheating the material.

As soon as a first hydration of the material has occurred the reaction rate rapidly decreases. This explains the fast temperature decrease over the whole reactor length after the first peak. 
Now, the reaction front is distributed over the whole reactor length and even at the reactor outlet not the whole water vapor is consumed but blown out with the air flow. The almost constant temperature plateau inside the reactor which is measured over a long time period of 3 to 5 hours especially at the temperature sensors TR4 and TR5 can be explained by the fact that over the whole reactor length an almost constant heat of reaction is produced. This explanation is supported by the measurement of the water vapor pressure at the reactor outlet which is also only very slightly increasing during this time period.

With increasing material hydration the reaction rate further decreases. After 4 hours of reaction the temperature measured at the temperature sensor TR1, after 6 and 7 hours the temperature measured at temperature sensor TR2 and TR3 has dropped almost to the air inlet temperature. This indicates that the hydration reaction has almost stopped in this area. Due to a slower hydration reaction of the material also further downstream, less water vapor is consumed in the reactor and the water vapor outlet pressure is increasing more rapidly. This is also associated with less heat production inside the reactor. Less or no preheating of the material further downstream is possible. The temperatures at the temperature sensors TR4 and TR5 are dropping faster again. 


\section{CLOSURE}

The experimental investigations in the fixed bed reactor allow to gain insight in the overall heat and mass transport phenomena during a desorption / dehydration and adsorption / hydration reaction of thermochemical energy storage materials. Information on the energy density of the material and the material loading can be determined.

The measured data can be used to determine the heat and mass transport parameters which are needed for a mathematical description of the reaction and to validate numerical codes. Information on the equilibrium data cannot be obtained from these experiments and have to be determined by other means.

The validated simulation software can be used to investigate the heat and mass transport phenomena of different thermochemical energy storage materials under arbitrary boundary conditions. In addition different reactor designs and different operations of the reactor can be investigated in great detail which forms the basis for the designing process of a thermochemical energy storage.

For further information and detailed experimental data contact Barbara Mette, University of Stuttgart, Institute for Thermodynamic and Thermal Engineering, Pfaffenwaldring 6, 70550 Stuttgart, Germany. 


\section{ADSORPTION HEAT STORAGE: EQUILIBRIUM PROPERTIES DETERMINATION WITH COMPARISON TO MOLECULAR SIMULATIONS}

Stefan HENNINGER, Fraunhofer Institut Solar Energy Systems, Freiburg, Germany.

\section{INTRODUCTION}

As written above, adsorption heat storage uses the exothermal process of physical adsorption of a gas (e.g. water vapor) on highly porous materials such as zeolites or silicagel.

Therefore, the determination of the water adsorption equilibrium on sorption materials is the first step for evaluation of the materials to be used in adsorption heat storage. Unfortunately measurement procedures are up today not standardized and therefore hardly comparable. Several measurements are published, but even for the same materials they may be dissimilar due to different measurement techniques and boundary conditions. Beside different measurement methods like thermogravimetry or volumetric characterization, the pre-treatment and the measuring procedure have a great influence on the results (see fig. 1) [1].

The pre-treatment, more precisely the drying or desorption temperature previous to the measurement leads to different results. Obviously, a higher desorption temperature may lead to less residual water within the sample and therefore higher water uptake capacity. In addition, the atmospheric conditions (drying under continuous evacuation or under inert gas flow) play another important role for the initial state or the net weight of the sample and the measurement. Further important points are the heating or scanning rate for continuous measurements or the equilibration time for non-continuous, true equilibrium measurements. Depending on the material used, a difference between the adsorption and desorption path can be observed. This hysteresis leads to significant errors in comparison with computer simulations like e.g. Monte Carlo simulation.

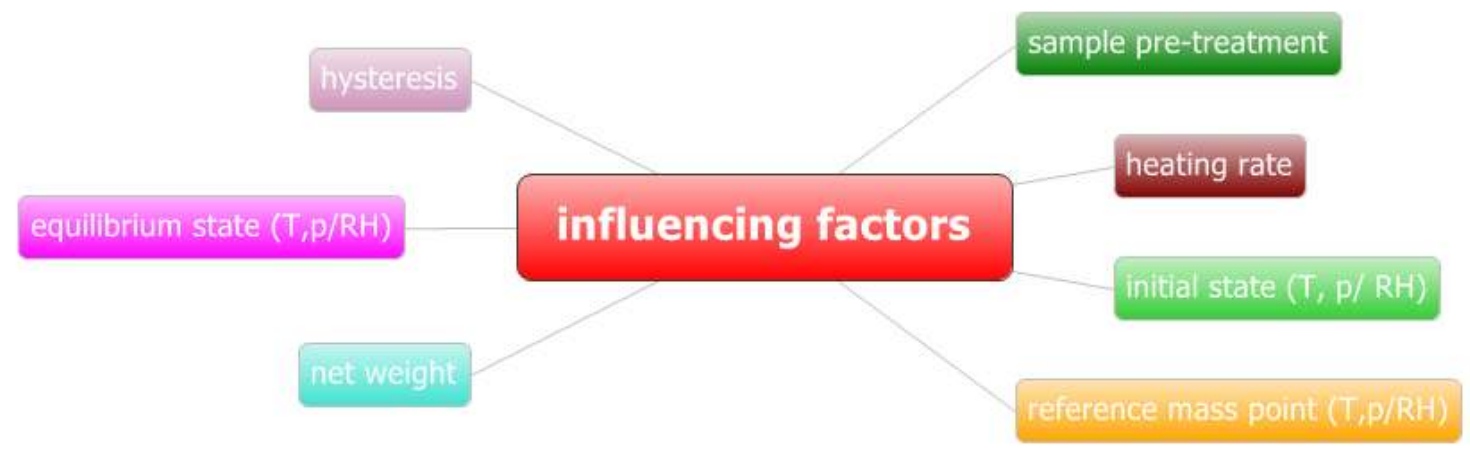

Figure1: Influencing factors for water adsorption measurements [1].

\section{GENERAL OVERVIEW}

The characterization of micro- and mesoporous materials in terms of working fluid uptake for several combinations of adsorbent/adsorbate with regard to the application in heat transformation processes has been and still is a field of intensive investigations [2-5]. Different measurement methods are used, with thermogravimetry and volumetry being the most common methods. In case of thermogravimetric measurements there are in principle three possibilities.

Commonly used in chemistry are open flow systems mainly using nitrogen as carrier gas. There exist several publications with thermogravimetric analysis (TGA), performing a desorption curve under an inert carrier gas flow with a defined temperature-scanning rate. Previous to the measurement the samples are prepared under a more or less defined humid atmosphere.

Unfortunately the shape of the curve and therefore the differential thermogravimetric (DTG) signal to determine the temperature on set point for the released water strongly depends on the used heating rate. Furthermore comparison of materials measured with 
this method leads to large discrepancies as the initial state, which is room temperature, is not well defined and therefore difficult to reproduce. In addition without a possibility to perform adsorption curves, possible hysteresis effects cannot be detected.

Another possibility in case of open systems is to use a well defined humidified carrier gas (e.g. Setaram WetSys) which flows around the sample. To prevent condensation, the transfer line and the measurement cell has to be temperature controlled in an accurate way.

The third possibilities are systems with closed working fluid atmosphere. As shown in Henninger et al. [6] measurements with open and closed systems are comparable if using the same reference conditions. Beside the differences in the apparatuses an additional uncertainty is the difference in isobaric versus isothermal measurements. Isothermal measurement in principle allows the determination of the heat of adsorption, by calculation for at least two isotherms or direct measurement within a simultaneous TG/DSC. In addition, especially with regard to the Dubinin transformation, the temperature independency can be verified.

Isobaric measurement can in principle be performed in a broader temperature range therefore covering a larger range of the adsorption potential $A=R T \ln p / p 0$. Furthermore as the real cycle (ideally) consists of two isobaric phases of desorption and adsorption at condenser and evaporator pressure, the isothermal measured data is not directly adoptable to the operating device. An overview on the adsorption equilibrium characterization is given in fig. 2 .

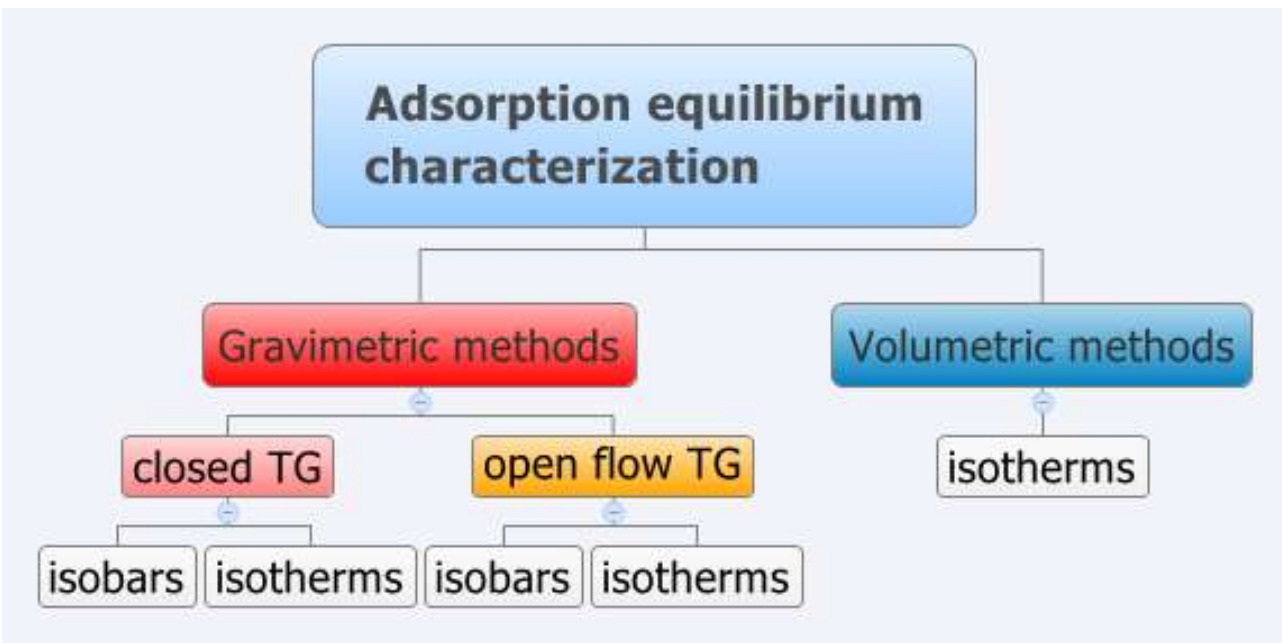

Figure 1: Overview on possible adsorption equilibrium characterization methods. This list is not exhaustive.

\section{MEASUREMENT PROCEDURES}

As a result of the consideration described above a common method for determination of water adsorption characteristics with focus on adsorption heat transformation must be defined.

Within this Task a round robin test (RRT) consisting of two isothermal measurements has been performed. The results of this RRT will be described within another report.

Beside this proposed procedure here another procedure is described, allowing for comparison of measurement with simulation were isotherms are difficult to be performed [1]. As defined below, in case of grand canonical simulations the definition of the temperature is more straight forward than the definition of a pressure via the fugacity.

The procedure consists of a pre-treatment of the sample under continuous evacuation (vacuum level: $1 \mathrm{e}-4 \mathrm{kPa}$ ) or dry carrier gas flow.

The optimal sample pre-treatment temperature should be selected according to the hydrophilicity of the samples.

- Strongly hydrophilic zeolites $(4 \mathrm{~A}, 13 \mathrm{X})$ : pre-treatment $\mathrm{T}=300^{\circ} \mathrm{C}$.

- Hydrophilic aluminosilicates (NaY): pre-treatment $\mathrm{T}=200^{\circ} \mathrm{C}$ 
- Hydrophobic aluminosilicates (silicalites, ZSM5): $\mathrm{T}=150^{\circ} \mathrm{C}$

- Aluminophospates (AIPO, SAPO): $\mathrm{T}=150^{\circ} \mathrm{C}$

- Others (silica gels, activated carbons): $\mathrm{T}=150^{\circ} \mathrm{C}$

The sample is heated starting from ambient conditions with a heating rate of $1 \mathrm{~K} / \mathrm{min}$ followed by an isothermal drying step for another 8 hours. In the following step, isobar measurement at a water vapour pressure of 1.2 and $5.6 \mathrm{kPa}$ takes place.

The selection of the two pressure levels is motivated with respect to the possible applications. The pressure level of $1.2 \mathrm{kPa}$ corresponds to an evaporation temperature of $10^{\circ} \mathrm{C}$, which marks a useful temperature level for low temperature heat source. The second pressure level of $5.6 \mathrm{kPa}$ corresponds to $35^{\circ} \mathrm{C}$ which either marks the temperature where heat can be rejected (in desorption case) or can be used for low temperature heating (heat pumping application).

For each pressure level the sample temperature is varied in 5 or $10 \mathrm{~K}$ steps between $150^{\circ} \mathrm{C}$ and $40^{\circ} \mathrm{C}$ (for $5.6 \mathrm{kPa}$ ) or $20^{\circ} \mathrm{C}$ (for $1.2 \mathrm{kPa}$ ) respectively. In addition at least one adsorption and desorption measurements should be performed in order to detect possible hysteresis effects.

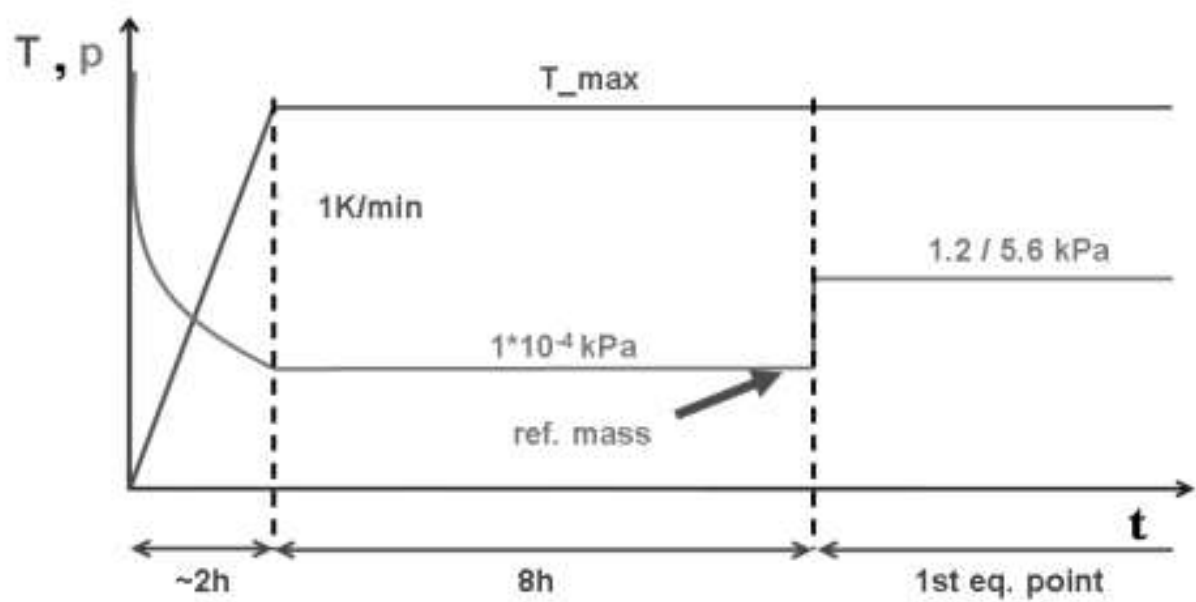

Figure 2: Proposed measurement procedure, including sample pre-treatment and the first isobaric step.

This procedure has successfully been used within the IEA annex 34 "Thermally driven heat pumps". First promising results with a good agreement between measurements performed at Fraunhofer ISE and at CNR-ITAE, using different techniques were performed. As first two candidates of a standard material to be used in a round robin test, a silica gel $127 \mathrm{~B}$ and a SAPO-34 have been chosen.

\section{CALIBRATION AND COMPARISON WITH MODELLING RESULT}

New materials are necessary in order to improve the adsorption characteristics for these applications. Molecular simulations are seen as a promising tool to investigate the influence of molecular structure on the adsorption characteristics and thus to provide means for future improvements of such materials for application in heat transformation. The field of molecular simulation enfolds a broad range, from model systems of generally theoretical interest to real fluids or solids in material science up to applications in life science, e.g. drug design.

Within a recently published work, a simulation program specially tailored to the problem has been developed [7]. The program uses the grand canonical ensemble and the simple point charge model (SPC) and the enhanced version (SPC/E) developed by Berendsen et al. $[7,8]$. Calculation of long-range electrostatic interactions is realised by the use of the Ewald summation technique $[9,10]$ in combination with periodic boundary conditions respecting the minimum image convention [11]. The accurate implementation of the long ranged coulomb interactions has been examined by calculation of the Madelung constant 
for a $\mathrm{NaCl}$ ion lattice. Furthermore the combined interaction energy for water within a zeolite structure has been confirmed for a fixed water configuration with the molecular dynamic program MOSCITO [12].

For comparison with experimental data the chemical potential is converted according to the ideal gas law

$$
\beta \cdot \mu=\beta \cdot \mu_{\text {ideal }}+\ln (\beta \cdot P \phi)
$$

with the fugacity $\mathrm{f}=P \phi$ and $\beta=1 / k_{B} T$.

Calculation of the isosteric adsorption enthalpy is achieved by the ensemble fluctuation method [13-15].

As result of the simulations, the number of water molecules adsorbed in thermodynamic equilibrium under given conditions of temperature and chemical potential (pressure) are compared with the experimental data. To assure thermodynamic equilibrium, all simulations start with an equilibration phase followed by a production phase. The number of required equilibration cycles varies strongly with the different simulated frameworks, depending on size and number of water molecules within the unit cell. As an average two million equilibration cycles have been chosen for the equilibration phase. Within one cycle there is one attempt for a displacement, five attempts for exchange and one attempt for a rotation of a water molecule. Simulation results out of the production cycles are analysed and simulation errors are calculated according to the block transformation method of Flyvbjerg and Petersen [16].

As shown in Fig. 3, the simulated and experimental isobars are in very good agreement.

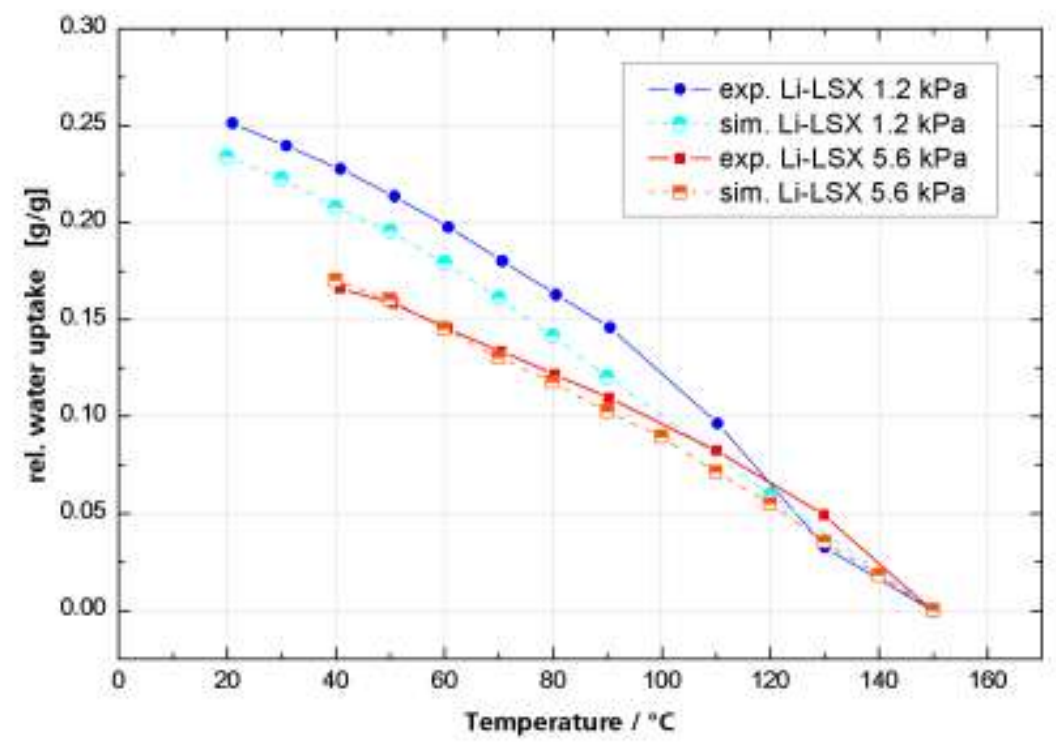

Figure 3: Comparison of simulated (dashed line) and experimental (solid line) adsorption isobars at 1.2 and $5.6 \mathrm{kPa}$.

The relative water uptake (absolute water uptake normalized by the reference mass at $150^{\circ} \mathrm{C}$ ) is shown for the water vapour pressure at $1.2 \mathrm{kPa}$ or $5.6 \mathrm{kPa}$. The reason for choosing this reference mass is due to the fact that the real adsorbent sample in the experimental case is different to the ideal crystalline framework (see Fig.4). Whereas in the simulation there is only the pure crystal, the real sample contains potentially a binding agent, amorphous phases and residual water content. 


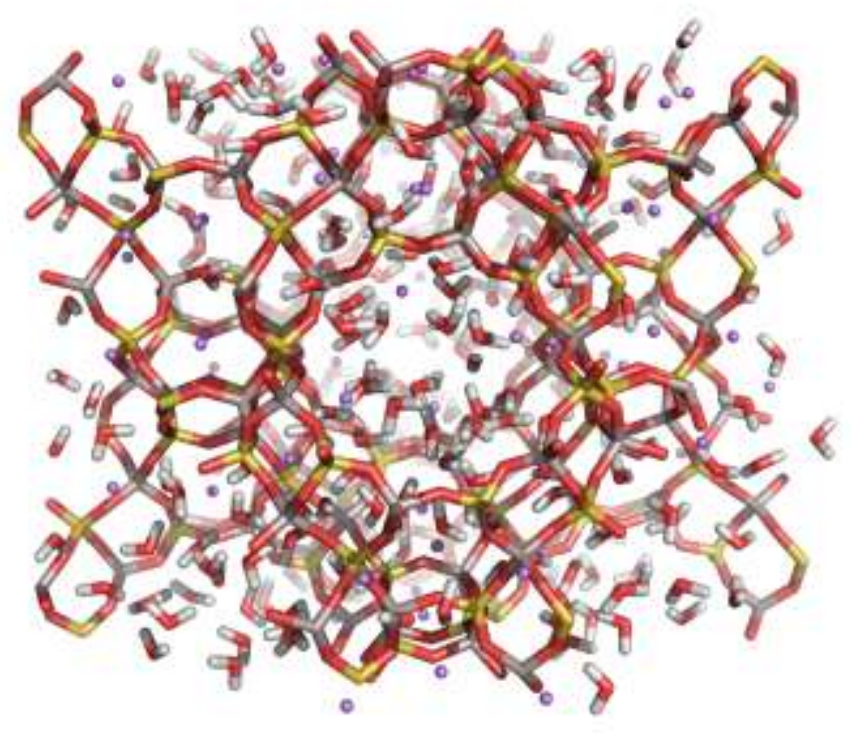

Figure 4: Snapshot of the simulation showing 214 water molecules in a Li-LSX host at $383 \mathrm{~K}, 5.6 \mathrm{kPa}$.

\section{CLOSURE}

To measure equilibrium adsorption characteristic several important influencing factors have to be taken into account. This includes for example the sample preparation. Here the outgassing temperature and surrounding has the greatest impact on the results. With regard to the measurement procedure isobaric vs. isothermal measurements may show different results. By a proper choice of reference mass and illustration this can be overcome.

The apparatus itself also has a great influence on the experimental data. As written above, differences between open flow and closed system can be eliminated by a proper choice of the reference mass.

All these factors have to be taken into account comparing simulated results with experimental data.

However, evaluation of sorption materials on basis of experimental characterisation and molecular simulation methods can give deeper insight into the underlying adsorption mechanism. According to the molecular simulation results, various recommendations on the improvement of sorption materials for heat transformation can be given.

\section{BIBLIOGRAPHY}

[1] Henninger, S. K., Freni, A., Schnabel, L., Schossig, P., \& Restuccia, G. (2011). Unified water adsorption measurement procedure for sorption materials. Proc. of International Sorption Heat Pump Conference (Vol. 4, pp. 513 - 522). Padova, Italy. doi:ISBN: 978-2-913149-84-7

[2] Srivastava, N. C., \& Eames, I. W. (1998). A review of adsorbents and adsorbates in solid-vapour adsorption heat pump systems. Applied Thermal Engineering, 18, 707-714.

[3] Aristov, Y. I., Restuccia, G., Cacciola, G., \& Parmon, V. (2002). A family of new working materials for solid sorption air conditioning systems. Applied Thermal Engineering, 22(2), 191-204. Elsevier 
[4] Jänchen, J., Ackermann, D., \& Stach, H. (2002). Adsorption Properties of Aluminophosphate Molecular Sieves-Potential Applications for Low Temperature Heat Utilization. Proceedings of the International Sorption Heat Pump Conference Shanghai, PR China (pp. 2-5).

[5] Critoph, R. E., \& Zhong, Y. (2005). Review of trends in solid sorption refrigeration and heat pumping technology. Proceedings of the Institution of Mechanical Engineers, Part E: Journal of Process Mechanical Engineering, 219(3), 285-300. doi: $10.1243 / 095440805 \times 6982$.

[6] Henninger, S.K., Schmidt, F. P., \& Henning, H.-M. (2010). Water adsorption characteristics of novel materials for heat transformation applications. Applied Thermal Engineering, 30(13), 1692-1702. Elsevier Ltd. doi:

10.1016/j.applthermaleng.2010.03.028.

[6] Henninger, S., Schmidt, F., \& Henning, H.-M. (2011). Characterisation and improvement of sorption materials with molecular modeling for the use in heat transformation applications. Adsorption, 17(5), 833-843. Springer. doi: $10.1007 / \mathrm{s} 10450-011-9342-6$

[7] Berendsen H. J. C. et al.: Interaction models for water in relation to protein hydration, Pullmann B. (Ed.), Intermolecular Forces, Reidel, Dordrecht. 1981, pp. 331-342

[8] Berendsen H. J. C., Grigera J. R. and Straatsma T. P.:The Missing Term in Effective Pair Potentials, J. Phys. Chem., Vol 91, No. 24, 1987, pp. 6269-6271

[9] Kolafa Jiri and Perram John W., Cutoff errors in the ewald summation formulae for point charge systems, Molecular Simulation, 1992, pp. 351-368

[10] Frenkel Daan and Smit Berend: Understanding Molecular Simulation, Academic Press, San Diego (2002).

[11] Allen M. P. und Tildesley D. J., Computer Simulation of Liquids, Clarendon Press, Oxford, 1986

[12] Paschek Dietmar and Geiger Alfons, User's Guide and Manual MOSCITO 4 Performing Molecular Dynamics Simulations, http://ganter.chemie.unidortmund.de/MOSCITO/index.shtml, Accessed April 7, 2003.

[13] Karavias F. and Myers A.L., Isosteric Heats of Multicomponent Adsorption Thermodynamics and Computer-Simulations, Langmuir , 7, No. 12, 1991, pp. 3118-3126

[14] Pellenq RJM et al., Grand canonical Monte Carlo simulations of adsorption of polar and nonpolar molecules in NaY zeolites, Langmuir ,12, 1996, pp. 4768-4783

[15] Woods G.B. and Rowlinson J.S., Computer-Simulations of Fluids in Zeolite-X and Zeolite-Y, Journal of the Chemical Society - Faraday Transactions II, 85, 1989, pp. 765-781

[16] Flyvbjerg H. und Petersen H. G., Error Estimates on Averages of Correlated Data, J. Chem. Phys., 91, 1989, pp. 461-466 


\title{
CHARACTERIZATION OF THE DEHYDRATION REACTION OF SEVERAL CRYSTALLINE SALT HYDRATES UNDER THE CONDTIONS OF THE SEASONAL HEAT STORAGE
}

\author{
Claire FERCHAUD ${ }^{1}$ and Herbert ZONDAG ${ }^{1,2}$ \\ ${ }^{1}$ Energy Research Center of the Netherland (ECN), \\ ${ }^{2}$ Eindhoven University of Technology, Eindhoven, The Netherlands.
}

\section{INTRODUCTION}

At ECN, research is carried out into seasonal solar heat storage for individual houses, based on the reversible sorption reaction of water vapor. During summer, salt hydrates can be dehydrated by solar heat provided by the solar thermal collectors at a temperature below $150^{\circ} \mathrm{C}$. In the present work, the dehydration reactions of four salt hydrate materials, $\mathrm{Li}_{2} \mathrm{SO}_{4} \cdot \mathrm{H}_{2} \mathrm{O}, \mathrm{CuSO}_{4} .5 \mathrm{H}_{2} \mathrm{O}, \mathrm{MgSO}_{4} .7 \mathrm{H}_{2} \mathrm{O}$ and $\mathrm{MgCl}_{2} \cdot 6 \mathrm{H}_{2} \mathrm{O}$, have been studied by thermal analysis to determine the reaction data for these materials for seasonal heat storage. The dehydration was carried out at a water vapor pressure of 13 mbar, which is a typical value for the Dutch summer.

\section{LAY-OUT OF THE EXPERIMENTAL SET-UP}

\section{Dimensions}

The thermal analysis has been carried out with a Simultaneous Thermal Analysis apparatus (STA 409 PC). This allows measuring the mass loss and the heat flow of the sample, observed for each phase transition of the material by Thermogravimetry (TG) and Differential Scanning Calorimetry (DSC). The inlet air at the entrance of the apparatus has been set at a water vapor pressure of 13 mbar. A moist air flow of 100 $\mathrm{ml} / \mathrm{min}$ was applied from the bottom to the top of the apparatus surrounding the open pan of $25 \mu \mathrm{l}$ ( $5 \mathrm{~mm}$ diameter) containing the salt hydrate sample (fig. 1 ).
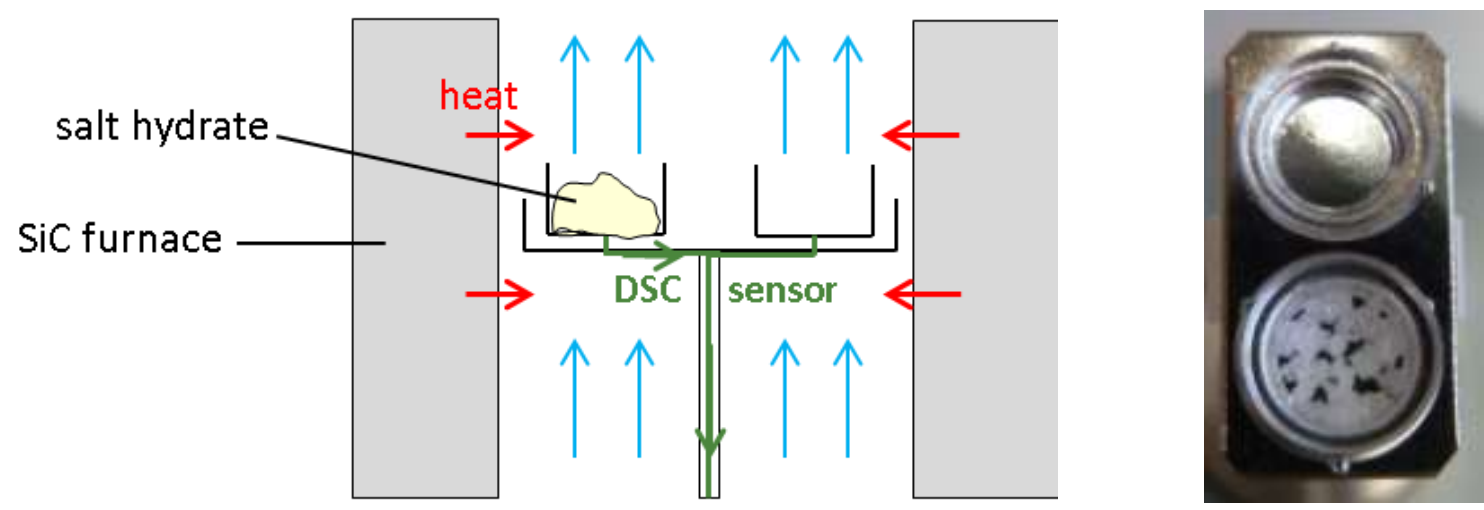

\section{Humidified air flow}

Figure 1: Scheme of the STA system and picture of the $25 \mu$ aluminum cups used during the thermal analyses measurements

\section{Material properties}

Commercial crystalline powders sieved with a particle size distribution of 100-200 $\mu \mathrm{m}$ have been used for these experiments. The weight of the salt hydrate sample used for each measurement was around $10.2 \mathrm{mg}$ with $+/-0.2 \mathrm{mg}$. It corresponds to a homogeneous mono-layer thickness (maximum $200 \mu \mathrm{m}$ ) over the bottom of the aluminium cup. This quantity of material has been taken as reference to be able to compare one material to another, in order to avoid a gradient of gas diffusion through the sample during the measurements. 


\section{DETAILED DESCRIPTION OF THE MEASURING PROCEDURE}

The dehydration of the salt hydrates has been carried out in dynamic mode with a slow heating rate of $0.5 \mathrm{~K} / \mathrm{min}$ to approach the equilibrium conditions of the materials. For the sulfates, the dehydration reaction was carried out between 25 and $150^{\circ} \mathrm{C}$. A different temperature range between 40 and $130^{\circ} \mathrm{C}$ has been chosen for $\mathrm{MgCl}_{2} \cdot 6 \mathrm{H}_{2} \mathrm{O}$ for practical reasons. In-situ X-ray diffraction analyses performed at $13 \mathrm{mbar}$ have shown an overhydration of $\mathrm{MgCl}_{2} \cdot 6 \mathrm{H}_{2} \mathrm{O}$ for temperatures below $40^{\circ} \mathrm{C}$ and a decomposition of the material in $\mathrm{MgOHCl}$ by release of $\mathrm{HCl}$ vapors above the temperature of $130^{\circ} \mathrm{C}$. The TG and DSC curves of the dehydration of the four salt hydrates are presented in this study. Additionally, the temperature of the dehydration reactions (peak temperature), the reaction enthalpy values and energy density values obtained for these materials under the practical conditions of the heat storage have been summarized and compared with the values determined from the NBS data [1]. The energy density values were calculated with the material density values of the reactant phase of each reaction.

\section{RESULTS}

The TG and DSC results in figure 2 shows that the four salt hydrates presented in this study can store heat under the operational conditions of seasonal heat storage by removal of water molecules in their material structure, thereby reaching lower hydrated or anhydrous composition.

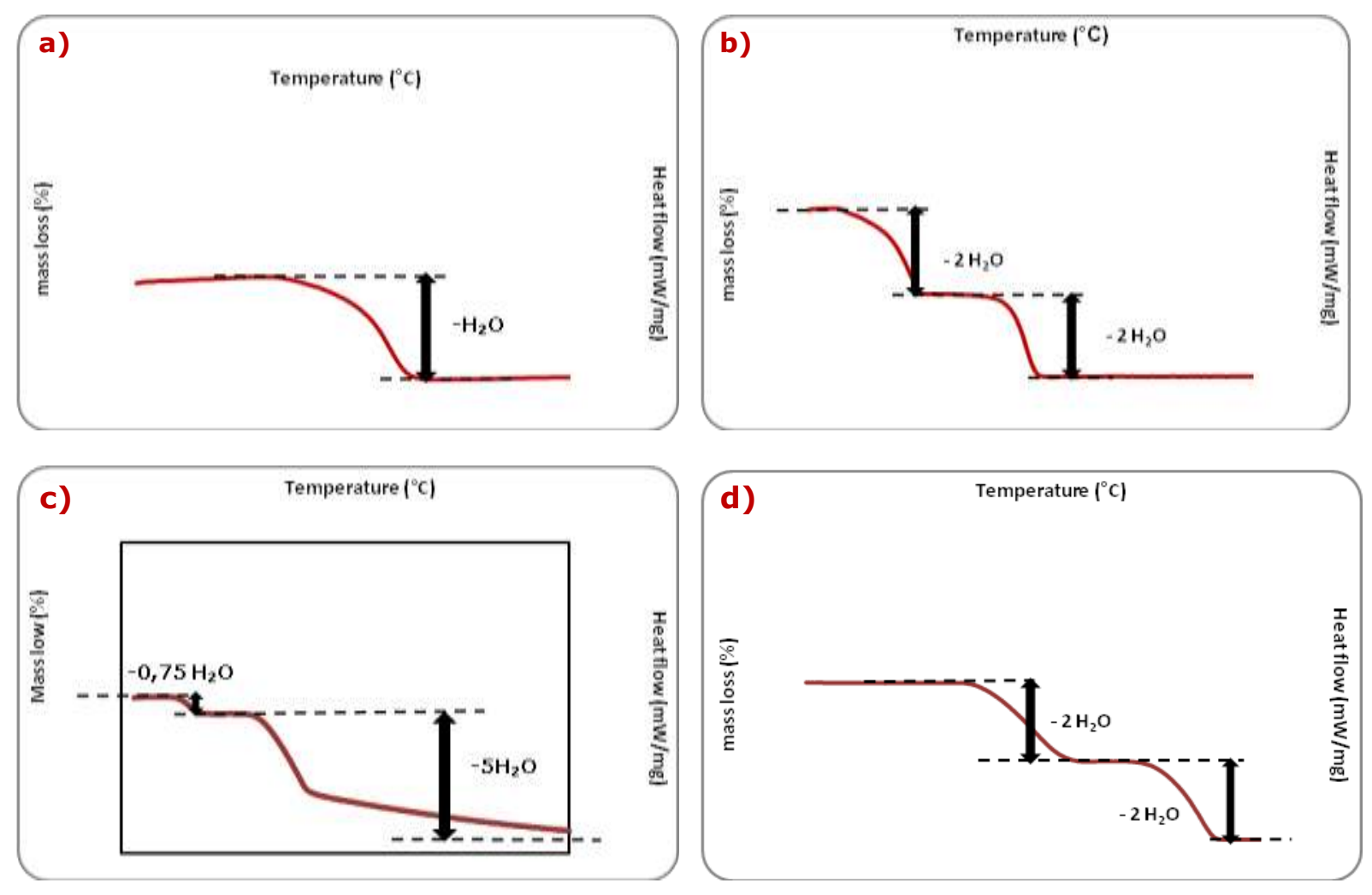

Figure 2 : TG (in red) and DSC (in blue) curves of the dehydration reaction at 13 mbar water vapor pressure and a heating rate of $0.5 \mathrm{~K} / \mathrm{min}$ of (a) $\mathrm{Li}_{2} \mathrm{SO}_{4} \cdot \mathrm{H}_{2} \mathrm{O}$, (b) $\mathrm{CuSO} \mathrm{S}_{4} .5 \mathrm{H}_{2} \mathrm{O}$, (c) $\mathrm{MgSO}_{4} .7 \mathrm{H}_{2} \mathrm{O}$ and (d) $\mathrm{MgCl}_{2} \cdot 6 \mathrm{H}_{2} \mathrm{O}$ powders sieved at 100-200 $\mu \mathrm{m}$

The summary of the temperature of the dehydration reactions (peak temperature), the reaction enthalpy values and energy density values obtained from the thermal analysis measurements are presented in table 1 . The initial composition of magnesium sulfate hydrate powder has been estimated at $\mathrm{MgSO}_{4} \cdot 6.75 \mathrm{H}_{2} \mathrm{O}$ instead of $\mathrm{MgSO}_{4} .7 \mathrm{H}_{2} \mathrm{O}$, because the material was already partially dried as shown on the figure 2c. This phenomenon can be explained by the fact that the transition of $\mathrm{MgSO}_{4} \cdot 7 \mathrm{H}_{2} \mathrm{O}$ to $\mathrm{MgSO}_{4} \cdot 6 \mathrm{H}_{2} \mathrm{O}$ starts at nearly ambient temperature $\left(25-30^{\circ} \mathrm{C}\right)$. Therefore, during the storage and the sieving step performed before the measurement, $25 \%$ of the $\mathrm{MgSO}_{4} \cdot 7 \mathrm{H}_{2} \mathrm{O}$ powder was 
dehydrated and the initial composition of the powder is a mix of $\mathrm{MgSO}_{4} \cdot 7 \mathrm{H}_{2} \mathrm{O}$ and $\mathrm{MgSO}_{4} \cdot 6 \mathrm{H}_{2} \mathrm{O}$ materials. The reaction enthalpy and the energy density values obtained for the loss of 0.75 water molecule have been recalculated for 1 molecule of water in table 1. The energy density of the dehydration reaction of $\mathrm{MgSO}_{4} \cdot 6.75 \mathrm{H}_{2} \mathrm{O}$ in $\mathrm{MgSO}_{4} .6 \mathrm{H}_{2} \mathrm{O}$ has been calculated with the density values of $\mathrm{MgSO}_{4} .7 \mathrm{H}_{2} \mathrm{O}$ because the density of $\mathrm{MgSO}_{4} \cdot 6.75 \mathrm{H}_{2} \mathrm{O}$ does not exist in the literature (indicated by an $*$ in table 1 ).

Table 1 : Temperature of transition and enthalpy values of the phase transition observed during the dehydration reactions of sieved powders of $\mathrm{Li}_{2} \mathrm{SO}_{4} . \mathrm{H}_{2} \mathrm{O}, \mathrm{CuSO}_{4} .5 \mathrm{H}_{2} \mathrm{O}, \mathrm{MgSO}_{4} .7 \mathrm{H}_{2} \mathrm{O}$ and $\mathrm{MgCl}_{2} .6 \mathrm{H}_{2} \mathrm{O}$ at $13 \mathrm{mbar}$ water vapor pressure and $0.5 \mathrm{~K} / \mathrm{min}$ heating rate.

\begin{tabular}{|c|c|c|c|c|c|}
\hline \multirow[b]{2}{*}{ Dehydration reactions } & \multicolumn{3}{|c|}{ Experimental data } & \multicolumn{2}{|c|}{ NBS data [1] } \\
\hline & $\begin{array}{l}T_{\text {peak DSC }} \\
\left({ }^{\circ} \mathrm{C}\right)\end{array}$ & $\begin{array}{c}\Delta \mathbf{r H} \\
{[\mathbf{k J} / \mathbf{m o l}]}\end{array}$ & $\begin{array}{l}\text { Energy } \\
\text { density } \\
\text { GJ } / \mathbf{m}^{3}\end{array}$ & $\begin{array}{c}\Delta \mathbf{r H} \\
{[\mathbf{k J} / \mathbf{m o l}]}\end{array}$ & $\begin{array}{r}\text { Energy } \\
\text { density } \\
\mathbf{G J} / \mathbf{m}^{3}\end{array}$ \\
\hline $\mathrm{Li}_{2} \mathrm{SO}_{4} \cdot \mathrm{H}_{2} \mathrm{O}(\mathrm{s}) \rightarrow \mathrm{Li}_{2} \mathrm{SO}_{4}(\mathrm{~s})+\mathrm{H}_{2} \mathrm{O}(\mathrm{g})$ & 97 & 41.01 & 0.71 & 57.18 & 0.99 \\
\hline $\mathrm{CuSO}_{4} \cdot 5 \mathrm{H}_{2} \mathrm{O}(\mathrm{s}) \rightarrow \mathrm{CuSO}_{4} \cdot 3 \mathrm{H}_{2} \mathrm{O}(\mathrm{s})+2 \mathrm{H}_{2} \mathrm{O}(\mathrm{g})$ & 52 & 89.07 & 0.81 & 111.68 & 1.02 \\
\hline $\mathrm{CuSO}_{4} \cdot 3 \mathrm{H}_{2} \mathrm{O}(\mathrm{s}) \rightarrow \mathrm{CuSO}_{4} \cdot \mathrm{H}_{2} \mathrm{O}(\mathrm{s})+2 \mathrm{H}_{2} \mathrm{O}(\mathrm{g})$ & 86 & 89.44 & 1.12 & 114.82 & 1.44 \\
\hline $\begin{array}{l}\mathrm{MgSO}_{4} \cdot 6.75 \mathrm{H}_{2} \mathrm{O}(\mathrm{s}) \rightarrow \mathrm{MgSO}_{4} \cdot 6 \mathrm{H}_{2} \mathrm{O}(\mathrm{s})+0.75 \mathrm{H}_{2} \mathrm{O}(\mathrm{g}) \\
{\left[\mathrm{MgSO}_{4} \cdot 7 \mathrm{H}_{2} \mathrm{O}(\mathrm{s}) \rightarrow \mathrm{MgSO}_{4} \cdot 6 \mathrm{H}_{2} \mathrm{O}(\mathrm{s})+\mathrm{H}_{2} \mathrm{O}(\mathrm{g})\right]}\end{array}$ & 39 & $\begin{array}{l}42.97(0.75) \\
58.07(1)\end{array}$ & $\begin{array}{l}0.29(0.75) * \\
0.39(1)\end{array}$ & 59.88 & 0.41 \\
\hline $\mathrm{MgSO}_{4} \cdot 6 \mathrm{H}_{2} \mathrm{O}(\mathrm{s}) \rightarrow \mathrm{MgSO}_{4} \cdot \mathrm{H}_{2} \mathrm{O}(\mathrm{s})+5 \mathrm{H}_{2} \mathrm{O}(\mathrm{g})$ & 72 & 249.88 & 1.83 & 275.75 & 2.37 \\
\hline $\mathrm{MgCl}_{2} \cdot 6 \mathrm{H}_{2} \mathrm{O}(\mathrm{s}) \rightarrow \mathrm{MgCl}_{2} \cdot 4 \mathrm{H}_{2} \mathrm{O}(\mathrm{s})+2 \mathrm{H}_{2} \mathrm{O}(\mathrm{g})$ & 85 & 102.61 & 0.79 & 116.37 & 0.89 \\
\hline $\mathrm{MgCl}_{2} \cdot 4 \mathrm{H}_{2} \mathrm{O}(\mathrm{s}) \rightarrow \mathrm{MgCl}_{2} \cdot 2 \mathrm{H}_{2} \mathrm{O}(\mathrm{s})+2 \mathrm{H}_{2} \mathrm{O}(\mathrm{g})$ & 118 & 117.41 & 1.10 & 135.61 & 1.27 \\
\hline
\end{tabular}

The energy density found for each material is directly related to the thermochemical reactions taking place in the material during the dehydration process. According to the present results, the crystal energy density of these materials is between 4 times $\left(\mathrm{Li}_{2} \mathrm{SO}_{4} \cdot \mathrm{H}_{2} \mathrm{O}\right)$ to 11 times $\left(\mathrm{MgSO}_{4} \cdot 7 \mathrm{H}_{2} \mathrm{O}\right)$ higher than the energy density in water $(0.25$ $\mathrm{GJ} / \mathrm{m}^{3}$ ). Note however, that the energy density as presented above will be reduced in practical systems because of the porosity in the packed bed required for the vapor transport.

An additional disclaimer has to be made about the temperatures of reaction presented in this paper to model the water vapor sorption process of these materials. The temperature data presented correspond to the temperatures at which the chemical reactions take place during the dehydration process. Additional experiments showed that these temperatures depend on the heating rate applied to the system during the dehydration process. Then, these temperature results should be only considered to model a system set with a heating rate at $0.5 \mathrm{~K} / \mathrm{min}$. Moreover, the reaction temperatures presented in this paper should not be taken as reaction temperatures for the hydration process of these materials. As represented in fig. 3, the temperature of reaction of the dehydration process is commonly higher than the equilibrium temperature of the chemical reaction, while the temperature of reaction for the reversible hydration process is lower. 


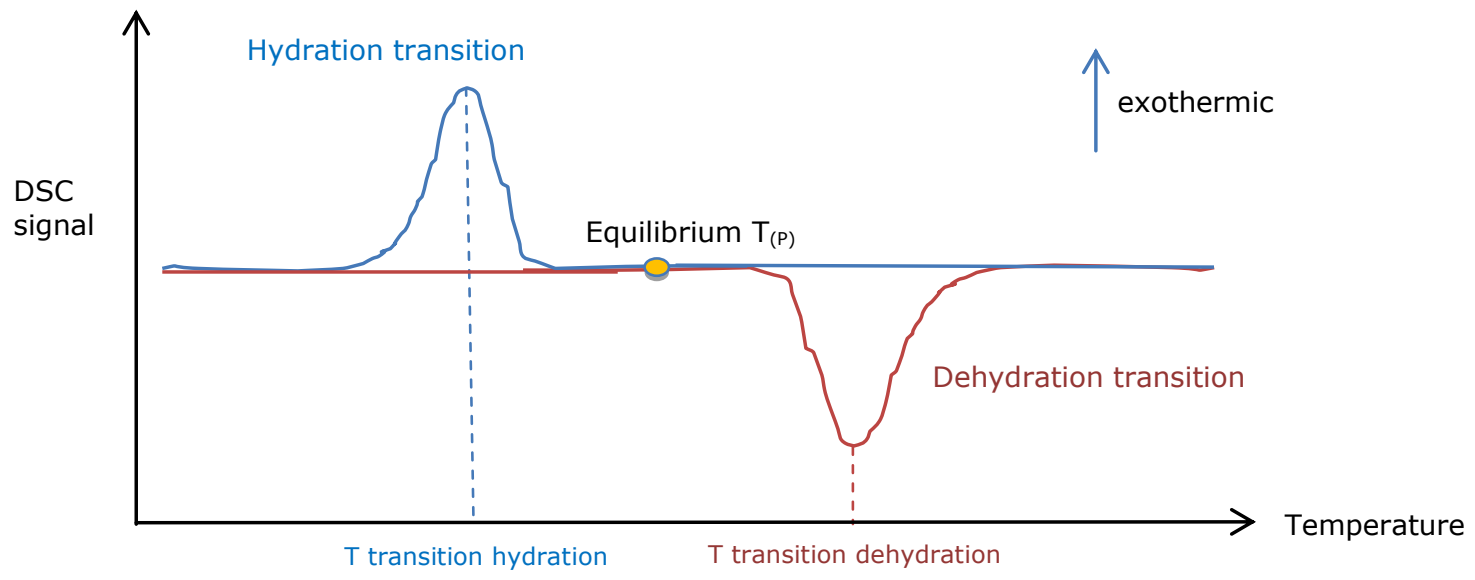

Figure 3: Theoretical representation of the DSC signal obtained for a phase transition during the dehydration and hydration reactions

\section{CLOSURE}

Additional measurements performed with faster heating rates $(1,5,10 \mathrm{~K} / \mathrm{min})$ have also been carried out for these materials, showing a constant energy density but an increase of the temperature of the phase transitions. Information on these measurements can be obtained by contacting Herbert Zondag, ECN - department Thermal Systems, P.O. Box 1, 1755 ZG Petten, The Netherlands, Tel : +31 22456 4941, email : zondag@ecn.nl.

\section{BIBLIOGRAPHY}

[1] D. D. Wagman, W. H. Evans, V. B. Parker, R. H. Schumm, I. Halow, S. M. Balley, K. L. Churney, R. L. Nuttall, The NBS tables of chemical thermodynamic properties : selected values for inorganic and $\mathrm{C}_{1}$ and $\mathrm{C}_{2}$ organic substances in SI units, Journal of physical and chemical reference data, 11 (2), (1982) 


\section{SHORT DESCRIPTION OF TASK 42/ ANNEX 24}

From past IEA SHC and ECES tasks it was concluded that a broad and basic research and development initiative is needed to find and improve compact thermal energy storage materials. The IEA joint Task/Annex 42/24 brings together experts from both the materials development field and the systems integration fields. In four years, the task aims at having finished the first steps towards a new generation of thermal storage technologies.

\section{OBJECTIVE}

The overall objective of this task is to develop advanced materials and systems for the compact storage of thermal energy. This can be subdivided into seven specific objectives:

- to identify, design and develop new materials and composites for compact thermal energy storage,

- to develop measuring and testing procedures to characterise new storage materials reliably and reproducibly,

- to improve the performance, stability, and cost-effectiveness of new storage materials,

- to develop multi-scale numerical models, describing and predicting the performance of new materials in thermal storage systems,

- to develop and demonstrate novel compact thermal energy storage systems employing the advanced materials,

- to assess the impact of new materials on the performance of thermal energy storage in the different applications considered, and

- to disseminate the knowledge and experience acquired in this task.

A secondary objective of this task is to create an active and effective research network in which researchers and industry working in the field of thermal energy storage can collaborate.

\section{SCOPE}

This task deals with advanced materials for latent and chemical thermal energy storage, and excludes materials related to sensible heat storage. The task deals with these materials on three different scales:

- material scale, focused on the behaviour of materials from the molecular to the 'few particles' scale, including e.g. material synthesis, micro-scale mass transport, and sorption reactions;

- bulk scale, focused on bulk behaviour of materials and the performance of the storage in itself, including e.g. heat, mass, and vapour transport, wall-wall and wall-material interactions, and reactor design;

- system scale, focused on the performance of a storage within a heating or cooling system, including e.g. economical feasibility studies, case studies, and system tests.

Because seasonal storage of solar heat for solar assisted heating of buildings is the main focus of the SHC IA, this will be one of the primary topics of this task. However, because there are many more relevant applications for TES, and because materials research is not and can not be limited to one application only, this task will focus on multiple application areas.

In the Task kick-off meeting it was decided to subdivide the Applications Subtask into three Working Groups, corresponding to three different temperature levels of thermal energy storage, as depicted below.

\section{STRUCTURE}

To achieve the maximum amount of cross-fertilisation between the different backgrounds of the two Implementing Agreements and experts in this Joint Task, the Task is organised in a matrix-like structure (see diagram below). 


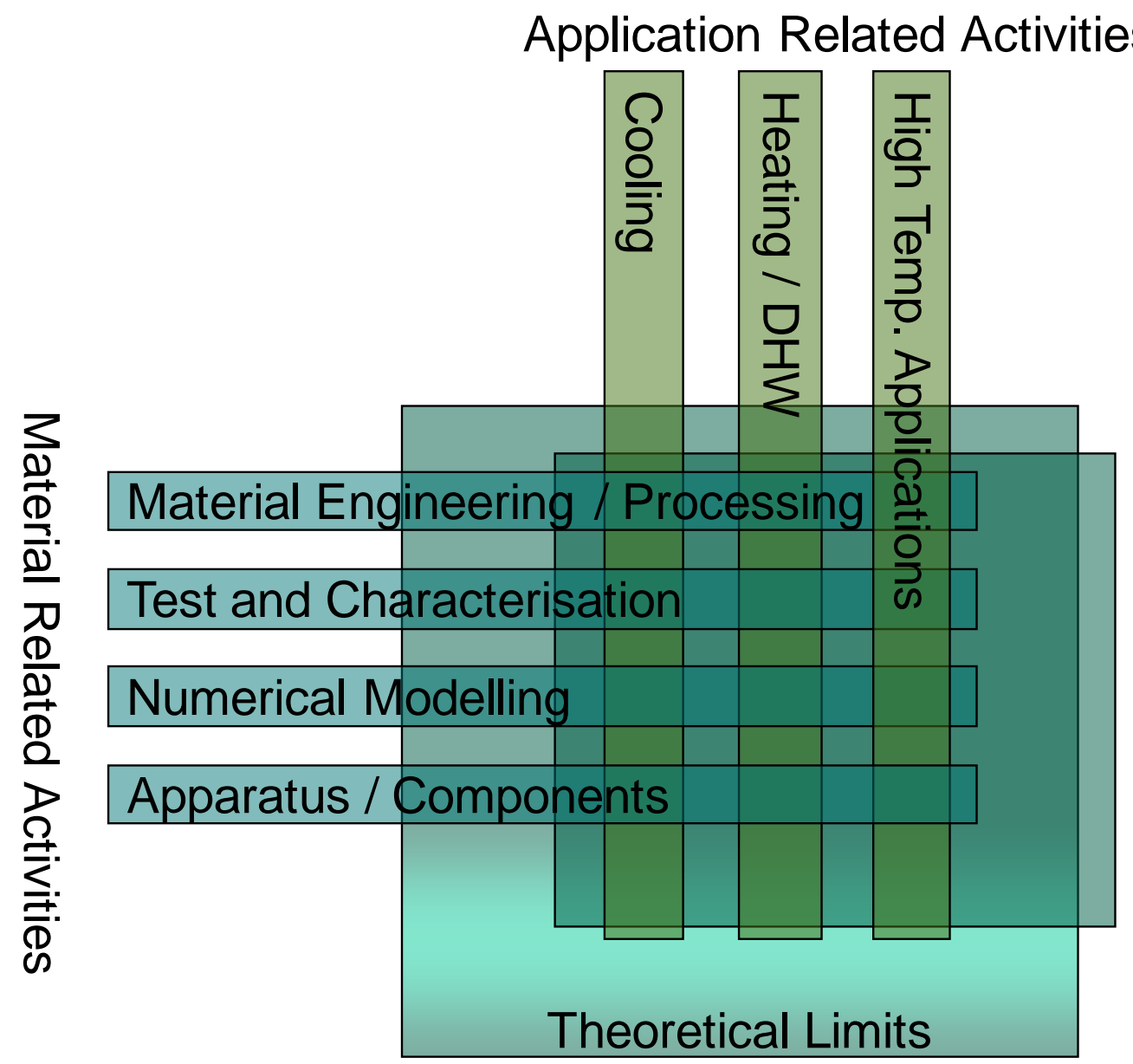




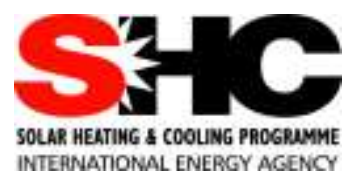

\section{IEA Solar Heating and Cooling Programme}

The International Energy Agency (IEA) is an autonomous body within the framework of the Organization for Economic Co-operation and Development (OECD) based in Paris. Established in 1974 after the first "oil shock," the IEA is committed to carrying out a comprehensive program of energy cooperation among its members and the Commission of the European Communities.

The IEA provides a legal framework, through IEA Implementing Agreements such as the Solar Heating and Cooling Agreement, for international collaboration in energy technology research and development (R\&D) and deployment. This IEA experience has proved that such collaboration contributes significantly to faster technological progress, while reducing costs; to eliminating technological risks and duplication of efforts; and to creating numerous other benefits, such as swifter expansion of the knowledge base and easier harmonization of standards.

The Solar Heating and Cooling Programme was one of the first IEA Implementing Agreements to be established. Since 1977, its members have been collaborating to advance active solar and passive solar and their application in buildings and other areas, such as agriculture and industry. Current members are:

$\begin{array}{lll}\text { Australia } & \text { Finland } & \text { Portugal } \\ \text { Austria } & \text { France } & \text { South Africa } \\ \text { Belgium } & \text { Italy } & \text { Spain } \\ \text { Canada } & \text { Mexico } & \text { Sweden } \\ \text { Denmark } & \text { Netherlands } & \text { Switzerland } \\ \text { European Commission } & \text { New Zealand } & \text { United States } \\ \text { Germany } & \text { Norway } & \end{array}$

A total of 44 Tasks have been initiated, 33 of which have been completed. Each Task is managed by an Operating Agent from one of the participating countries. Overall control of the program rests with an Executive Committee comprised of one representative from each contracting party to the Implementing Agreement. In addition to the Task work, a number of special activitiesMemorandum of Understanding with solar thermal trade organizations, statistics collection and analysis, conferences and workshops - have been undertaken.

To find Solar Heating and Cooling Programme publications and learn more about the Programme visit www.iea-shc.org or contact the SHC Secretariat, Pamela Murphy, e-mail: pmurphy@kmgrp.net. 
Current Tasks \& Working Group:

Task $36 \quad$ Solar Resource Knowledge Management

Task $39 \quad$ Polymeric Materials for Solar Thermal Applications

Task $40 \quad$ Towards Net Zero Energy Solar Buildings

Task $41 \quad$ Solar Energy and Architecture

Task $42 \quad$ Compact Thermal Energy Storage

Task $43 \quad$ Solar Rating and Certification Procedures

Task $44 \quad$ Solar and Heat Pump Systems

Task $45 \quad$ Large Systems: Solar Heating/Cooling Systems, Seasonal Storages, Heat Pumps

Task $46 \quad$ Solar Resource Assessment and Forecasting

Task 47 Renovation of Non-Residential Buildings Towards Sustainable Standards

Task $48 \quad$ Quality Assurance and Support Measures for Solar Cooling

Task $49 \quad$ Solar Process Heat for Production and Advanced Applications

Completed Tasks:

Task 1 Investigation of the Performance of Solar Heating and Cooling Systems

Task 2 Coordination of Solar Heating and Cooling $R \& D$

Task 3 Performance Testing of Solar Collectors

Task $4 \quad$ Development of an Insolation Handbook and Instrument Package

Task 5 Use of Existing Meteorological Information for Solar Energy Application

Task $6 \quad$ Performance of Solar Systems Using Evacuated Collectors

Task $7 \quad$ Central Solar Heating Plants with Seasonal Storage

Task $8 \quad$ Passive and Hybrid Solar Low Energy Buildings

Task $9 \quad$ Solar Radiation and Pyranometry Studies

Task $10 \quad$ Solar Materials $R \& D$

Task $11 \quad$ Passive and Hybrid Solar Commercial Buildings

Task $12 \quad$ Building Energy Analysis and Design Tools for Solar Applications

Task $13 \quad$ Advanced Solar Low Energy Buildings

Task $14 \quad$ Advanced Active Solar Energy Systems

Task $16 \quad$ Photovoltaics in Buildings

Task $17 \quad$ Measuring and Modeling Spectral Radiation

Task $18 \quad$ Advanced Glazing and Associated Materials for Solar and Building Applications

Task 19 Solar Air Systems

Task $20 \quad$ Solar Energy in Building Renovation

Task $21 \quad$ Daylight in Buildings

Task 22 Building Energy Analysis Tools

Task 23

Task 24

Task 25

Task 26

Task 27

Task 28

Task 29

Task 31

Task 32

Task 33

Optimization of Solar Energy Use in Large Buildings

Solar Procurement

Solar Assisted Air Conditioning of Buildings

Solar Combisystems

Performance of Solar Facade Components

Solar Sustainable Housing

Solar Crop Drying

Daylighting Buildings in the $21^{\text {st }}$ Century

Advanced Storage Concepts for Solar and Low Energy Buildings

Solar Heat for Industrial Processes

Task $34 \quad$ Testing and Validation of Building Energy Simulation Tools

Task $35 \quad P V /$ Thermal Solar Systems

Task $37 \quad$ Advanced Housing Renovation with Solar \& Conservation

Task $38 \quad$ Solar Thermal Cooling and Air Conditioning

Completed Working Groups:

CSHPSS; ISOLDE; Materials in Solar Thermal Collectors; Evaluation of Task 13 Houses; Daylight Research 


\section{IEA Energy Conservation Through Energy Storage Programme}

The International Energy Agency (IEA), based in Paris, is an autonomous agency linked with the Organisation for Economic Co-operation and Development (OECD). The IEA is the energy forum for 26 Member countries. IEA Member governments are committed to taking joint measures to meet oil supply emergencies. They have also agreed to share energy information, to co-ordinate their energy policies and to co-operate in the development of rational energy programmes.

The R\&D programme Efficient Energy End-Use Technologies contains 14 different Implementing Agreements (IAs) of which one is the IA on energy storage. The full name of this IA is Energy Conservation though Energy Storage (ECES IA). This IA was founded in 2004 and intends to promote co-operative research, development, demonstrations and exchanges of information regarding energy conservation through energy storage.

The continued development, application and deployment of energy efficient end-use technologies has the potential to significantly reduce energy consumption and greenhouse gases in the buildings, electricity generation, industry, and transport sectors. Energy storage technologies can overcome the temporal mismatch between energy supply and demand, especially regarding renewable energy technologies, the use of waste energy and energy from ambient sources such as cold from the natural environment.

Active participants in ECES IA are at present:

$\begin{array}{lll}\text { Belgium } & \text { Germany } & \text { Sweden } \\ \text { Canada } & \text { Italy } & \text { USA } \\ \text { China } & \text { Japan } & \text { Turkey } \\ \text { Finland } & \text { Korea } & \\ \text { France } & \text { Norway } & \end{array}$

Three sponsors are participating in the ECES at the moment:

IF Technology B.V. (Netherlands)

Institute of Heat Engineering, University of Technology of Warsaw (Poland)

Energesis Ingeniería, S.L. (Spain).

Other countries have signed the agreement but are not presently engaged in the activities. Further countries have recently shown interest in participating in the near future, including countries from Eastern Europe.

The work within the ECES IA is lead by an Executive Committee (XC) and the work undertaken by this $\mathrm{XC}$ is done by mutual agreements defined in Annexes as listed on the next page. The work is led by Chairman Halime Paksoy (Turkey) and Secretary Hunay Evliya (Turkey).

To find ECES publications and learn more about the Programme visit http://www.iea-eces.org or contact the ECES Secretariat, Hunay Evliya, e-mail: hevliya@cu.edu.tr 
Ongoing Annexes:

Annex $20 \quad$ Sustainable Cooling with Thermal Energy Storage

Annex $21 \quad$ Thermal Response Test for Underground Thermal Energy Storages

Annex 22 Thermal Energy Storage Applications in Closed Greenhouses

Annex 23 Applying Energy Storage in Ultra-low Energy Buildings

Annex 24 Material Development for Improved Thermal Energy Storage Systems

Annex $25 \quad$ Surplus Heat Management using Advanced TES for CO2 mitigation

Annex 26 Electric Energy Storage: Future Energy Storage Demand

Completed Annexes:

Annex $1 \quad$ Large Scale Thermal Storage Systems Evaluation

Annex $2 \quad$ Lake Storage Demonstration Plant in Mannheim

Annex 3 Aquifer Storage Demonstration Plant in Lausanne Dorigny

Annex $4 \quad$ Short Term Water Heat Storage Systems

Annex $5 \quad$ Full Scale Latent Heat Storage Installations

Annex $6 \quad$ Environmental and Chemical aspects of Thermal Energy Storage in Aquifers and Research and Development of Water Treatment Methods

Annex $7 \quad$ Innovative and Cost Effective Seasonal Cold Storage Applications

Annex $8 \quad$ Implementing Underground Thermal Energy Storage Systems

Annex $9 \quad$ Electrical Energy Storage Technologies for Utility Network Optimization

Annex $10 \quad$ Phase Change Materials and Chemical Reactions for Thermal Energy Storage

Annex $12 \quad$ High-Temperature Underground Thermal Energy Storage (HT UTES)

Annex 13 Design, Construction and Maintenance of UTES Wells and Boreholes

Annex $14 \quad$ Cooling with TES in all Climates

Annex $17 \quad$ Advanced Thermal Energy Storage Techniques - Feasibility Studies and

Demonstration Projects

Annex $18 \quad$ Transportation of Thermal Energy Utilizing Thermal Energy Storage Technology

Annex 19 Optimised Industrial Process Heat and Power Generation with Thermal Energy

Storage 
APPENDIX "DETAILED EXPERIMENTAL RESULTS FOR SUBMERGED FINNED HEAT EXCHANGER IN PCM BASED THERMAL ENERGY STORAGE" BY NM. J. CHIU AND V. MARTIN

\section{Congealing Process}

\begin{tabular}{|c|c|c|c|c|c|c|c|c|}
\hline \multicolumn{2}{|c|}{ Inlet $\mathrm{T} 11^{\circ} \mathrm{C}$} & & \multirow[b]{2}{*}{ Freezing } & \multirow[b]{2}{*}{ Run B } & & \multirow[b]{2}{*}{ Freezing } & \multirow[b]{2}{*}{ Run C } & \multirow[b]{3}{*}{$\begin{array}{l}\text { Tpcm } \\
\left({ }^{\circ} \mathrm{C}\right)\end{array}$} \\
\hline Freezing & Run A & & & & & & & \\
\hline Time (s) & Tfin $\left({ }^{\circ} \mathrm{C}\right)$ & $\begin{array}{l}\text { Tpcm } \\
\left({ }^{\circ} \mathrm{C}\right)\end{array}$ & Time (s) & $\operatorname{Tfin}\left({ }^{\circ} \mathrm{C}\right)$ & $\begin{array}{l}\mathrm{Tpcm} \\
\left({ }^{\circ} \mathrm{C}\right)\end{array}$ & Time (s) & Tfin $\left({ }^{\circ} \mathrm{C}\right)$ & \\
\hline 0 & 20.31 & 29.08 & 0 & 20.42 & 29.03 & 0 & 23.74 & 29.01 \\
\hline 10 & 20.22 & 28.91 & 10 & 20.33 & 28.85 & 10 & 23.32 & 28.99 \\
\hline 20 & 20.12 & 28.73 & 20 & 20.24 & 28.68 & 20 & 22.94 & 28.95 \\
\hline 30 & 20.05 & 28.56 & 30 & 20.15 & 28.49 & 30 & 22.61 & 28.91 \\
\hline 40 & 19.96 & 28.37 & 40 & 20.08 & 28.32 & 40 & 22.31 & 28.86 \\
\hline 50 & 19.88 & 28.21 & 50 & 20.02 & 28.16 & 50 & 22.06 & 28.79 \\
\hline 60 & 19.81 & 28.05 & 60 & 19.94 & 27.98 & 60 & 21.81 & 28.71 \\
\hline 70 & 19.73 & 27.87 & 70 & 19.86 & 27.80 & 70 & 21.59 & 28.63 \\
\hline 80 & 19.68 & 27.71 & 80 & 19.80 & 27.64 & 80 & 21.38 & 28.52 \\
\hline 90 & 19.62 & 27.54 & 90 & 19.72 & 27.47 & 90 & 21.21 & 28.42 \\
\hline 100 & 19.55 & 27.37 & 100 & 19.66 & 27.32 & 100 & 21.04 & 28.31 \\
\hline 110 & 19.49 & 27.22 & 110 & 19.60 & 27.15 & 110 & 20.89 & 28.19 \\
\hline 120 & 19.43 & 27.05 & 120 & 19.54 & 27.00 & 120 & 20.76 & 28.06 \\
\hline 130 & 19.37 & 26.91 & 130 & 19.47 & 26.86 & 130 & 20.65 & 27.93 \\
\hline 140 & 19.30 & 26.75 & 140 & 19.41 & 26.70 & 140 & 20.53 & 27.81 \\
\hline 150 & 19.25 & 26.60 & 150 & 19.35 & 26.55 & 150 & 20.44 & 27.65 \\
\hline 160 & 19.19 & 26.44 & 160 & 19.28 & 26.39 & 160 & 20.36 & 27.52 \\
\hline 170 & 19.12 & 26.29 & 170 & 19.21 & 26.26 & 170 & 20.27 & 27.38 \\
\hline 180 & 19.07 & 26.16 & 180 & 19.16 & 26.12 & 180 & 20.19 & 27.23 \\
\hline 190 & 19.00 & 26.01 & 190 & 19.08 & 25.97 & 190 & 20.09 & 27.10 \\
\hline 200 & 18.95 & 25.87 & 200 & 19.03 & 25.84 & 200 & 20.03 & 26.95 \\
\hline 210 & 18.90 & 25.74 & 210 & 18.97 & 25.68 & 210 & 19.97 & 26.82 \\
\hline 220 & 18.84 & 25.61 & 220 & 18.92 & 25.55 & 220 & 19.90 & 26.67 \\
\hline 230 & 18.78 & 25.48 & 230 & 18.86 & 25.42 & 230 & 19.82 & 26.51 \\
\hline 240 & 18.73 & 25.35 & 240 & 18.81 & 25.29 & 240 & 19.75 & 26.38 \\
\hline 250 & 18.69 & 25.22 & 250 & 18.78 & 25.17 & 250 & 19.70 & 26.25 \\
\hline 260 & 18.64 & 25.10 & 260 & 18.76 & 25.05 & 260 & 19.62 & 26.11 \\
\hline 270 & 18.59 & 24.97 & 270 & 18.71 & 24.93 & 270 & 19.58 & 25.99 \\
\hline 280 & 18.55 & 24.85 & 280 & 18.67 & 24.81 & 280 & 19.50 & 25.85 \\
\hline 290 & 18.51 & 24.75 & 290 & 18.64 & 24.69 & 290 & 19.45 & 25.72 \\
\hline 300 & 18.48 & 24.62 & 300 & 18.59 & 24.58 & 300 & 19.41 & 25.60 \\
\hline 310 & 18.44 & 24.52 & 310 & 18.52 & 24.45 & 310 & 19.35 & 25.46 \\
\hline 320 & 18.40 & 24.39 & 320 & 18.51 & 24.36 & 320 & 19.30 & 25.35 \\
\hline 330 & 18.37 & 24.29 & 330 & 18.46 & 24.24 & 330 & 19.25 & 25.22 \\
\hline 340 & 18.33 & 24.17 & 340 & 18.43 & 24.15 & 340 & 19.21 & 25.11 \\
\hline 350 & 18.30 & 24.08 & 350 & 18.40 & 24.05 & 350 & 19.18 & 24.99 \\
\hline
\end{tabular}




\begin{tabular}{|c|c|c|c|c|c|c|c|c|}
\hline 360 & 18.26 & 23.98 & 360 & 18.35 & 23.95 & 360 & 19.13 & 24.88 \\
\hline 370 & 18.23 & 23.88 & 370 & 18.31 & 23.84 & 370 & 19.09 & 24.77 \\
\hline 380 & 18.20 & 23.79 & 380 & 18.29 & 23.75 & 380 & 19.04 & 24.65 \\
\hline 390 & 18.16 & 23.68 & 390 & 18.25 & 23.66 & 390 & 19.00 & 24.55 \\
\hline 400 & 18.14 & 23.58 & 400 & 18.19 & 23.57 & 400 & 18.95 & 24.46 \\
\hline 410 & 18.11 & 23.51 & 410 & 18.17 & 23.48 & 410 & 18.89 & 24.35 \\
\hline 420 & 18.06 & 23.41 & 420 & 18.12 & 23.38 & 420 & 18.84 & 24.25 \\
\hline 430 & 18.02 & 23.33 & 430 & 18.08 & 23.30 & 430 & 18.80 & 24.14 \\
\hline 440 & 17.98 & 23.23 & 440 & 18.04 & 23.22 & 440 & 18.75 & 24.05 \\
\hline 450 & 17.94 & 23.15 & 450 & 18.01 & 23.12 & 450 & 18.68 & 23.95 \\
\hline 460 & 17.91 & 23.08 & 460 & 17.97 & 23.04 & 460 & 18.65 & 23.86 \\
\hline 470 & 17.87 & 22.99 & 470 & 17.94 & 22.97 & 470 & 18.59 & 23.77 \\
\hline 480 & 17.82 & 22.92 & 480 & 17.90 & 22.90 & 480 & 18.53 & 23.68 \\
\hline 490 & 17.78 & 22.83 & 490 & 17.87 & 22.82 & 490 & 18.49 & 23.58 \\
\hline 500 & 17.74 & 22.76 & 500 & 17.84 & 22.74 & 500 & 18.44 & 23.51 \\
\hline 510 & 17.70 & 22.67 & 510 & 17.78 & 22.65 & 510 & 18.38 & 23.42 \\
\hline 520 & 17.67 & 22.61 & 520 & 17.75 & 22.58 & 520 & 18.34 & 23.35 \\
\hline 530 & 17.64 & 22.54 & 530 & 17.71 & 22.53 & 530 & 18.30 & 23.28 \\
\hline 540 & 17.61 & 22.48 & 540 & 17.67 & 22.46 & 540 & 18.24 & 23.20 \\
\hline 550 & 17.57 & 22.42 & 550 & 17.63 & 22.39 & 550 & 18.20 & 23.13 \\
\hline 560 & 17.53 & 22.33 & 560 & 17.59 & 22.32 & 560 & 18.16 & 23.06 \\
\hline 570 & 17.48 & 22.27 & 570 & 17.55 & 22.25 & 570 & 18.12 & 22.98 \\
\hline 580 & 17.44 & 22.21 & 580 & 17.51 & 22.20 & 580 & 18.08 & 22.93 \\
\hline 590 & 17.40 & 22.15 & 590 & 17.46 & 22.13 & 590 & 18.03 & 22.85 \\
\hline 600 & 17.35 & 22.08 & 600 & 17.43 & 22.07 & 600 & 17.99 & 22.77 \\
\hline 610 & 17.32 & 22.02 & 610 & 17.38 & 22.02 & 610 & 17.95 & 22.71 \\
\hline 620 & 17.28 & 21.97 & 620 & 17.36 & 21.96 & 620 & 17.92 & 22.65 \\
\hline 630 & 17.24 & 21.91 & 630 & 17.32 & 21.91 & 630 & 17.88 & 22.58 \\
\hline 640 & 17.22 & 21.86 & 640 & 17.28 & 21.86 & 640 & 17.84 & 22.51 \\
\hline 650 & 17.18 & 21.83 & 650 & 17.25 & 21.81 & 650 & 17.82 & 22.47 \\
\hline 660 & 17.14 & 21.76 & 660 & 17.22 & 21.76 & 660 & 17.78 & 22.42 \\
\hline 670 & 17.09 & 21.72 & 670 & 17.18 & 21.72 & 670 & 17.75 & 22.34 \\
\hline 680 & 17.06 & 21.67 & 680 & 17.17 & 21.69 & 680 & 17.70 & 22.30 \\
\hline 690 & 17.03 & 21.62 & 690 & 17.12 & 21.62 & 690 & 17.68 & 22.26 \\
\hline 700 & 17.01 & 21.58 & 700 & 17.10 & 21.61 & 700 & 17.64 & 22.20 \\
\hline 710 & 16.98 & 21.53 & 710 & 17.06 & 21.55 & 710 & 17.62 & 22.14 \\
\hline 720 & 16.93 & 21.49 & 720 & 17.02 & 21.52 & 720 & 17.58 & 22.11 \\
\hline 730 & 16.90 & 21.46 & 730 & 17.00 & 21.49 & 730 & 17.54 & 22.06 \\
\hline 740 & 16.87 & 21.42 & 740 & 16.98 & 21.46 & 740 & 17.52 & 22.02 \\
\hline 750 & 16.84 & 21.38 & 750 & 16.93 & 21.42 & 750 & 17.49 & 21.97 \\
\hline 760 & 16.81 & 21.35 & 760 & 16.91 & 21.40 & 760 & 17.46 & 21.94 \\
\hline 770 & 16.78 & 21.31 & 770 & 16.86 & 21.36 & 770 & 17.43 & 21.89 \\
\hline 780 & 16.75 & 21.28 & 780 & 16.83 & 21.33 & 780 & 17.40 & 21.86 \\
\hline 790 & 16.72 & 21.24 & 790 & 16.80 & 21.30 & 790 & 17.37 & 21.83 \\
\hline
\end{tabular}




\begin{tabular}{|c|c|c|c|c|c|c|c|c|}
\hline 800 & 16.68 & 21.23 & 800 & 16.78 & 21.28 & 800 & 17.34 & 21.78 \\
\hline 810 & 16.65 & 21.19 & 810 & 16.74 & 21.25 & 810 & 17.31 & 21.77 \\
\hline 820 & 16.62 & 21.17 & 820 & 16.72 & 21.23 & 820 & 17.29 & 21.73 \\
\hline 830 & 16.60 & 21.13 & 830 & 16.69 & 21.20 & 830 & 17.27 & 21.69 \\
\hline 840 & 16.58 & 21.12 & 840 & 16.66 & 21.17 & 840 & 17.23 & 21.67 \\
\hline 850 & 16.56 & 21.09 & 850 & 16.65 & 21.15 & 850 & 17.20 & 21.64 \\
\hline 860 & 16.53 & 21.06 & 860 & 16.63 & 21.14 & 860 & 17.17 & 21.60 \\
\hline 870 & 16.51 & 21.04 & 870 & 16.60 & 21.12 & 870 & 17.14 & 21.57 \\
\hline 880 & 16.48 & 21.02 & 880 & 16.58 & 21.09 & 880 & 17.12 & 21.54 \\
\hline 890 & 16.44 & 20.99 & 890 & 16.54 & 21.08 & 890 & 17.09 & 21.52 \\
\hline 900 & 16.42 & 20.97 & 900 & 16.53 & 21.04 & 900 & 17.07 & 21.50 \\
\hline 910 & 16.40 & 20.97 & 910 & 16.50 & 21.04 & 910 & 17.04 & 21.48 \\
\hline 920 & 16.38 & 20.94 & 920 & 16.45 & 21.00 & 920 & 17.01 & 21.44 \\
\hline 930 & 16.35 & 20.92 & 930 & 16.44 & 20.98 & 930 & 17.00 & 21.42 \\
\hline 940 & 16.34 & 20.90 & 940 & 16.41 & 20.98 & 940 & 16.96 & 21.40 \\
\hline 950 & 16.32 & 20.88 & 950 & 16.39 & 20.96 & 950 & 16.95 & 21.37 \\
\hline 960 & 16.30 & 20.88 & 960 & 16.38 & 20.95 & 960 & 16.91 & 21.35 \\
\hline 970 & 16.26 & 20.87 & 970 & 16.35 & 20.94 & 970 & 16.89 & 21.33 \\
\hline 980 & 16.24 & 20.87 & 980 & 16.33 & 20.94 & 980 & 16.86 & 21.29 \\
\hline 990 & 16.22 & 20.84 & 990 & 16.31 & 20.93 & 990 & 16.84 & 21.28 \\
\hline 1000 & 16.19 & 20.82 & 1000 & 16.29 & 20.90 & 1000 & 16.82 & 21.25 \\
\hline 1010 & 16.18 & 20.81 & 1010 & 16.26 & 20.90 & 1010 & 16.80 & 21.24 \\
\hline 1020 & 16.17 & 20.82 & 1020 & 16.24 & 20.88 & 1020 & 16.77 & 21.22 \\
\hline 1030 & 16.15 & 20.80 & 1030 & 16.22 & 20.88 & 1030 & 16.74 & 21.21 \\
\hline 1040 & 16.11 & 20.79 & 1040 & 16.21 & 20.87 & 1040 & 16.72 & 21.20 \\
\hline 1050 & 16.11 & 20.80 & 1050 & 16.18 & 20.86 & 1050 & 16.70 & 21.19 \\
\hline 1060 & 16.08 & 20.78 & 1060 & 16.18 & 20.85 & 1060 & 16.68 & 21.17 \\
\hline 1070 & 16.05 & 20.77 & 1070 & 16.15 & 20.85 & 1070 & 16.64 & 21.17 \\
\hline 1080 & 16.04 & 20.76 & 1080 & 16.14 & 20.84 & 1080 & 16.62 & 21.17 \\
\hline 1090 & 16.03 & 20.75 & 1090 & 16.11 & 20.82 & 1090 & 16.61 & 21.16 \\
\hline 1100 & 15.99 & 20.74 & 1100 & 16.08 & 20.82 & 1100 & 16.58 & 21.15 \\
\hline 1110 & 15.99 & 20.76 & 1110 & 16.07 & 20.82 & 1110 & 16.56 & 21.15 \\
\hline 1120 & 15.96 & 20.74 & 1120 & 16.06 & 20.81 & 1120 & 16.53 & 21.15 \\
\hline 1130 & 15.95 & 20.73 & 1130 & 16.05 & 20.79 & 1130 & 16.52 & 21.13 \\
\hline 1140 & 15.93 & 20.75 & 1140 & 16.01 & 20.79 & 1140 & 16.48 & 21.14 \\
\hline 1150 & 15.91 & 20.72 & 1150 & 16.00 & 20.78 & 1150 & 16.47 & 21.13 \\
\hline 1160 & 15.88 & 20.72 & 1160 & 15.98 & 20.77 & 1160 & 16.43 & 21.13 \\
\hline 1170 & 15.86 & 20.71 & 1170 & 15.97 & 20.77 & 1170 & 16.44 & 21.12 \\
\hline 1180 & 15.85 & 20.71 & 1180 & 15.95 & 20.76 & 1180 & 16.41 & 21.12 \\
\hline 1190 & 15.82 & 20.71 & 1190 & 15.94 & 20.75 & 1190 & 16.40 & 21.12 \\
\hline 1200 & 15.82 & 20.70 & 1200 & 15.92 & 20.74 & 1200 & 16.37 & 21.10 \\
\hline 1210 & 15.79 & 20.69 & 1210 & 15.89 & 20.74 & 1210 & 16.34 & 21.10 \\
\hline 1220 & 15.78 & 20.69 & 1220 & 15.88 & 20.73 & 1220 & 16.34 & 21.09 \\
\hline 1230 & 15.74 & 20.69 & 1230 & 15.86 & 20.72 & 1230 & 16.30 & 21.07 \\
\hline
\end{tabular}




\begin{tabular}{|c|c|c|c|c|c|c|c|c|}
\hline 1240 & 15.74 & 20.69 & 1240 & 15.86 & 20.73 & 1240 & 16.29 & 21.07 \\
\hline 1250 & 15.73 & 20.67 & 1250 & 15.84 & 20.72 & 1250 & 16.28 & 21.07 \\
\hline 1260 & 15.70 & 20.67 & 1260 & 15.80 & 20.70 & 1260 & 16.25 & 21.03 \\
\hline 1270 & 15.69 & 20.66 & 1270 & 15.79 & 20.70 & 1270 & 16.24 & 21.02 \\
\hline 1280 & 15.69 & 20.65 & 1280 & 15.77 & 20.69 & 1280 & 16.21 & 21.01 \\
\hline 1290 & 15.66 & 20.64 & 1290 & 15.75 & 20.68 & 1290 & 16.19 & 21.02 \\
\hline 1300 & 15.65 & 20.65 & 1300 & 15.73 & 20.67 & 1300 & 16.17 & 21.00 \\
\hline 1310 & 15.64 & 20.62 & 1310 & 15.73 & 20.67 & 1310 & 16.15 & 20.99 \\
\hline 1320 & 15.62 & 20.61 & 1320 & 15.70 & 20.65 & 1320 & 16.14 & 20.97 \\
\hline 1330 & 15.58 & 20.60 & 1330 & 15.67 & 20.65 & 1330 & 16.11 & 20.97 \\
\hline 1340 & 15.57 & 20.59 & 1340 & 15.67 & 20.65 & 1340 & 16.09 & 20.96 \\
\hline 1350 & 15.56 & 20.59 & 1350 & 15.65 & 20.63 & 1350 & 16.09 & 20.95 \\
\hline 1360 & 15.54 & 20.58 & 1360 & 15.64 & 20.63 & 1360 & 16.06 & 20.94 \\
\hline 1370 & 15.53 & 20.58 & 1370 & 15.62 & 20.62 & 1370 & 16.05 & 20.94 \\
\hline 1380 & 15.52 & 20.56 & 1380 & 15.61 & 20.63 & 1380 & 16.04 & 20.95 \\
\hline 1390 & 15.51 & 20.56 & 1390 & 15.59 & 20.62 & 1390 & 16.01 & 20.93 \\
\hline 1400 & 15.50 & 20.54 & 1400 & 15.58 & 20.61 & 1400 & 16.00 & 20.91 \\
\hline 1410 & 15.47 & 20.54 & 1410 & 15.55 & 20.61 & 1410 & 15.98 & 20.93 \\
\hline 1420 & 15.45 & 20.55 & 1420 & 15.53 & 20.61 & 1420 & 15.96 & 20.91 \\
\hline 1430 & 15.44 & 20.54 & 1430 & 15.51 & 20.60 & 1430 & 15.94 & 20.91 \\
\hline 1440 & 15.41 & 20.53 & 1440 & 15.50 & 20.62 & 1440 & 15.93 & 20.91 \\
\hline 1450 & 15.41 & 20.51 & 1450 & 15.49 & 20.60 & 1450 & 15.92 & 20.91 \\
\hline 1460 & 15.40 & 20.50 & 1460 & 15.47 & 20.58 & 1460 & 15.89 & 20.88 \\
\hline 1470 & 15.39 & 20.49 & 1470 & 15.46 & 20.57 & 1470 & 15.87 & 20.89 \\
\hline 1480 & 15.37 & 20.49 & 1480 & 15.45 & 20.57 & 1480 & 15.86 & 20.88 \\
\hline 1490 & 15.36 & 20.48 & 1490 & 15.42 & 20.57 & 1490 & 15.85 & 20.88 \\
\hline 1500 & 15.33 & 20.46 & 1500 & 15.42 & 20.54 & 1500 & 15.83 & 20.89 \\
\hline 1510 & 15.32 & 20.47 & 1510 & 15.40 & 20.54 & 1510 & 15.82 & 20.91 \\
\hline 1520 & 15.31 & 20.46 & 1520 & 15.39 & 20.52 & 1520 & 15.80 & 20.90 \\
\hline 1530 & 15.28 & 20.44 & 1530 & 15.37 & 20.50 & 1530 & 15.78 & 20.88 \\
\hline 1540 & 15.27 & 20.45 & 1540 & 15.37 & 20.49 & 1540 & 15.76 & 20.88 \\
\hline 1550 & 15.26 & 20.44 & 1550 & 15.35 & 20.49 & 1550 & 15.76 & 20.87 \\
\hline 1560 & 15.24 & 20.44 & 1560 & 15.33 & 20.47 & 1560 & 15.74 & 20.85 \\
\hline 1570 & 15.23 & 20.43 & 1570 & 15.32 & 20.45 & 1570 & 15.71 & 20.85 \\
\hline 1580 & 15.22 & 20.42 & 1580 & 15.31 & 20.44 & 1580 & 15.70 & 20.85 \\
\hline 1590 & 15.19 & 20.42 & 1590 & 15.29 & 20.43 & 1590 & 15.69 & 20.84 \\
\hline 1600 & 15.20 & 20.43 & 1600 & 15.29 & 20.42 & 1600 & 15.67 & 20.84 \\
\hline 1610 & 15.17 & 20.42 & 1610 & 15.27 & 20.40 & 1610 & 15.65 & 20.84 \\
\hline 1620 & 15.16 & 20.41 & 1620 & 15.26 & 20.38 & 1620 & 15.65 & 20.84 \\
\hline 1630 & 15.15 & 20.39 & 1630 & 15.24 & 20.37 & 1630 & 15.62 & 20.83 \\
\hline 1640 & 15.13 & 20.37 & 1640 & 15.23 & 20.36 & 1640 & 15.62 & 20.83 \\
\hline 1650 & 15.12 & 20.36 & 1650 & 15.22 & 20.33 & 1650 & 15.60 & 20.81 \\
\hline 1660 & 15.11 & 20.36 & 1660 & 15.21 & 20.33 & 1660 & 15.58 & 20.80 \\
\hline 1670 & 15.09 & 20.34 & 1670 & 15.18 & 20.33 & 1670 & 15.56 & 20.80 \\
\hline
\end{tabular}




\begin{tabular}{|c|c|c|c|c|c|c|c|c|}
\hline 1680 & 15.08 & 20.33 & 1680 & 15.18 & 20.32 & 1680 & 15.55 & 20.78 \\
\hline 1690 & 15.06 & 20.32 & 1690 & 15.16 & 20.31 & 1690 & 15.55 & 20.77 \\
\hline 1700 & 15.06 & 20.29 & 1700 & 15.15 & 20.31 & 1700 & 15.53 & 20.75 \\
\hline 1710 & 15.05 & 20.29 & 1710 & 15.13 & 20.28 & 1710 & 15.51 & 20.73 \\
\hline 1720 & 15.04 & 20.27 & 1720 & 15.13 & 20.28 & 1720 & 15.49 & 20.73 \\
\hline 1730 & 15.02 & 20.26 & 1730 & 15.12 & 20.26 & 1730 & 15.49 & 20.69 \\
\hline 1740 & 15.01 & 20.24 & 1740 & 15.11 & 20.25 & 1740 & 15.48 & 20.69 \\
\hline 1750 & 15.00 & 20.21 & 1750 & 15.11 & 20.25 & 1750 & 15.46 & 20.67 \\
\hline 1760 & 14.99 & 20.21 & 1760 & 15.09 & 20.23 & 1760 & 15.46 & 20.64 \\
\hline 1770 & 14.97 & 20.21 & 1770 & 15.06 & 20.21 & 1770 & 15.42 & 20.64 \\
\hline 1780 & 14.96 & 20.18 & 1780 & 15.06 & 20.18 & 1780 & 15.42 & 20.63 \\
\hline 1790 & 14.94 & 20.15 & 1790 & 15.06 & 20.17 & 1790 & 15.40 & 20.62 \\
\hline 1800 & 14.94 & 20.14 & 1800 & 15.05 & 20.16 & 1800 & 15.40 & 20.61 \\
\hline 1810 & 14.94 & 20.14 & 1810 & 15.03 & 20.16 & 1810 & 15.37 & 20.61 \\
\hline 1820 & 14.91 & 20.11 & 1820 & 15.02 & 20.11 & 1820 & 15.36 & 20.59 \\
\hline 1830 & 14.90 & 20.10 & 1830 & 15.00 & 20.09 & 1830 & 15.35 & 20.59 \\
\hline 1840 & 14.89 & 20.09 & 1840 & 14.99 & 20.07 & 1840 & 15.34 & 20.59 \\
\hline 1850 & 14.89 & 20.05 & 1850 & 14.99 & 20.06 & 1850 & 15.32 & 20.58 \\
\hline 1860 & 14.88 & 20.05 & 1860 & 14.97 & 20.04 & 1860 & 15.31 & 20.56 \\
\hline 1870 & 14.86 & 20.03 & 1870 & 14.95 & 20.03 & 1870 & 15.30 & 20.55 \\
\hline 1880 & 14.84 & 20.01 & 1880 & 14.95 & 20.01 & 1880 & 15.29 & 20.52 \\
\hline 1890 & 14.85 & 19.99 & 1890 & 14.93 & 19.99 & 1890 & 15.28 & 20.50 \\
\hline 1900 & 14.84 & 19.97 & 1900 & 14.93 & 19.97 & 1900 & 15.26 & 20.50 \\
\hline 1910 & 14.81 & 19.95 & 1910 & 14.91 & 19.97 & 1910 & 15.26 & 20.49 \\
\hline 1920 & 14.81 & 19.93 & 1920 & 14.90 & 19.96 & 1920 & 15.25 & 20.47 \\
\hline 1930 & 14.79 & 19.92 & 1930 & 14.89 & 19.93 & 1930 & 15.23 & 20.47 \\
\hline 1940 & 14.79 & 19.90 & 1940 & 14.88 & 19.92 & 1940 & 15.22 & 20.46 \\
\hline 1950 & 14.77 & 19.90 & 1950 & 14.86 & 19.89 & 1950 & 15.20 & 20.45 \\
\hline 1960 & 14.75 & 19.87 & 1960 & 14.86 & 19.87 & 1960 & 15.19 & 20.43 \\
\hline 1970 & 14.75 & 19.86 & 1970 & 14.85 & 19.86 & 1970 & 15.18 & 20.41 \\
\hline 1980 & 14.73 & 19.84 & 1980 & 14.84 & 19.83 & 1980 & 15.16 & 20.41 \\
\hline 1990 & 14.72 & 19.84 & 1990 & 14.81 & 19.80 & 1990 & 15.15 & 20.38 \\
\hline 2000 & 14.72 & 19.83 & 2000 & 14.82 & 19.78 & 2000 & 15.14 & 20.38 \\
\hline 2010 & 14.71 & 19.81 & 2010 & 14.79 & 19.77 & 2010 & 15.13 & 20.36 \\
\hline 2020 & 14.69 & 19.79 & 2020 & 14.78 & 19.73 & 2020 & 15.12 & 20.34 \\
\hline 2030 & 14.68 & 19.76 & 2030 & 14.78 & 19.70 & 2030 & 15.11 & 20.32 \\
\hline 2040 & 14.68 & 19.75 & 2040 & 14.76 & 19.68 & 2040 & 15.11 & 20.29 \\
\hline 2050 & 14.67 & 19.73 & 2050 & 14.76 & 19.66 & 2050 & 15.08 & 20.27 \\
\hline 2060 & 14.66 & 19.71 & 2060 & 14.74 & 19.64 & 2060 & 15.07 & 20.24 \\
\hline 2070 & 14.64 & 19.67 & 2070 & 14.74 & 19.60 & 2070 & 15.06 & 20.22 \\
\hline 2080 & 14.64 & 19.66 & 2080 & 14.73 & 19.58 & 2080 & 15.05 & 20.18 \\
\hline 2090 & 14.62 & 19.63 & 2090 & 14.71 & 19.55 & 2090 & 15.05 & 20.16 \\
\hline 2100 & 14.62 & 19.61 & 2100 & 14.70 & 19.52 & 2100 & 15.03 & 20.14 \\
\hline 2110 & 14.60 & 19.59 & 2110 & 14.69 & 19.50 & 2110 & 15.02 & 20.10 \\
\hline
\end{tabular}




\begin{tabular}{|c|c|c|c|c|c|c|c|c|}
\hline 2120 & 14.59 & 19.58 & 2120 & 14.68 & 19.49 & 2120 & 15.02 & 20.08 \\
\hline 2130 & 14.58 & 19.56 & 2130 & 14.66 & 19.45 & 2130 & 15.00 & 20.06 \\
\hline 2140 & 14.57 & 19.55 & 2140 & 14.66 & 19.43 & 2140 & 14.99 & 20.02 \\
\hline 2150 & 14.56 & 19.52 & 2150 & 14.64 & 19.41 & 2150 & 14.98 & 19.99 \\
\hline 2160 & 14.55 & 19.50 & 2160 & 14.63 & 19.38 & 2160 & 14.98 & 19.96 \\
\hline 2170 & 14.54 & 19.48 & 2170 & 14.62 & 19.35 & 2170 & 14.96 & 19.94 \\
\hline 2180 & 14.54 & 19.45 & 2180 & 14.61 & 19.34 & 2180 & 14.95 & 19.90 \\
\hline 2190 & 14.52 & 19.42 & 2190 & 14.61 & 19.32 & 2190 & 14.94 & 19.88 \\
\hline 2200 & 14.51 & 19.40 & 2200 & 14.60 & 19.29 & 2200 & 14.92 & 19.84 \\
\hline 2210 & 14.50 & 19.37 & 2210 & 14.58 & 19.25 & 2210 & 14.91 & 19.80 \\
\hline 2220 & 14.50 & 19.36 & 2220 & 14.58 & 19.22 & 2220 & 14.90 & 19.78 \\
\hline 2230 & 14.48 & 19.34 & 2230 & 14.56 & 19.20 & 2230 & 14.89 & 19.74 \\
\hline 2240 & 14.47 & 19.34 & 2240 & 14.55 & 19.17 & 2240 & 14.89 & 19.70 \\
\hline 2250 & 14.46 & 19.31 & 2250 & 14.55 & 19.16 & 2250 & 14.87 & 19.67 \\
\hline 2260 & 14.45 & 19.29 & 2260 & 14.54 & 19.13 & 2260 & 14.86 & 19.66 \\
\hline 2270 & 14.44 & 19.26 & 2270 & 14.53 & 19.11 & 2270 & 14.85 & 19.63 \\
\hline 2280 & 14.43 & 19.25 & 2280 & 14.51 & 19.06 & 2280 & 14.84 & 19.60 \\
\hline 2290 & 14.42 & 19.21 & 2290 & 14.50 & 19.02 & 2290 & 14.83 & 19.56 \\
\hline 2300 & 14.40 & 19.19 & 2300 & 14.50 & 19.03 & 2300 & 14.82 & 19.52 \\
\hline 2310 & 14.41 & 19.16 & 2310 & 14.49 & 18.99 & 2310 & 14.82 & 19.50 \\
\hline 2320 & 14.39 & 19.13 & 2320 & 14.49 & 18.97 & 2320 & 14.80 & 19.48 \\
\hline 2330 & 14.39 & 19.11 & 2330 & 14.47 & 18.93 & 2330 & 14.80 & 19.45 \\
\hline 2340 & 14.37 & 19.07 & 2340 & 14.46 & 18.92 & 2340 & 14.78 & 19.40 \\
\hline 2350 & 14.37 & 19.05 & 2350 & 14.45 & 18.90 & 2350 & 14.78 & 19.38 \\
\hline 2360 & 14.35 & 19.02 & 2360 & 14.43 & 18.86 & 2360 & 14.76 & 19.35 \\
\hline 2370 & 14.34 & 19.00 & 2370 & 14.43 & 18.83 & 2370 & 14.76 & 19.31 \\
\hline 2380 & 14.32 & 18.97 & 2380 & 14.41 & 18.80 & 2380 & 14.74 & 19.30 \\
\hline 2390 & 14.31 & 18.95 & 2390 & 14.39 & 18.78 & 2390 & 14.73 & 19.26 \\
\hline 2400 & 14.31 & 18.91 & 2400 & 14.39 & 18.74 & 2400 & 14.71 & 19.22 \\
\hline 2410 & 14.31 & 18.90 & 2410 & 14.38 & 18.73 & 2410 & 14.70 & 19.20 \\
\hline 2420 & 14.28 & 18.85 & 2420 & 14.37 & 18.70 & 2420 & 14.70 & 19.17 \\
\hline 2430 & 14.28 & 18.83 & 2430 & 14.37 & 18.68 & 2430 & 14.70 & 19.16 \\
\hline 2440 & 14.27 & 18.81 & 2440 & 14.36 & 18.65 & 2440 & 14.68 & 19.12 \\
\hline 2450 & 14.26 & 18.77 & 2450 & 14.36 & 18.62 & 2450 & 14.67 & 19.09 \\
\hline 2460 & 14.25 & 18.74 & 2460 & 14.35 & 18.60 & 2460 & 14.66 & 19.06 \\
\hline 2470 & 14.25 & 18.73 & 2470 & 14.32 & 18.57 & 2470 & 14.66 & 19.04 \\
\hline 2480 & 14.23 & 18.69 & 2480 & 14.31 & 18.54 & 2480 & 14.64 & 19.00 \\
\hline 2490 & 14.22 & 18.66 & 2490 & 14.30 & 18.53 & 2490 & 14.64 & 18.98 \\
\hline 2500 & 14.21 & 18.65 & 2500 & 14.31 & 18.49 & 2500 & 14.61 & 18.95 \\
\hline 2510 & 14.21 & 18.61 & 2510 & 14.29 & 18.47 & 2510 & 14.61 & 18.92 \\
\hline 2520 & 14.20 & 18.59 & 2520 & 14.28 & 18.43 & 2520 & 14.60 & 18.88 \\
\hline 2530 & 14.20 & 18.57 & 2530 & 14.27 & 18.41 & 2530 & 14.60 & 18.85 \\
\hline 2540 & 14.19 & 18.53 & 2540 & 14.26 & 18.39 & 2540 & 14.59 & 18.81 \\
\hline 2550 & 14.18 & 18.51 & 2550 & 14.25 & 18.36 & 2550 & 14.58 & 18.78 \\
\hline
\end{tabular}




\begin{tabular}{|c|c|c|c|c|c|c|c|c|}
\hline 2560 & 14.17 & 18.49 & 2560 & 14.24 & 18.33 & 2560 & 14.56 & 18.75 \\
\hline 2570 & 14.16 & 18.45 & 2570 & 14.23 & 18.31 & 2570 & 14.55 & 18.72 \\
\hline 2580 & 14.16 & 18.43 & 2580 & 14.22 & 18.29 & 2580 & 14.54 & 18.69 \\
\hline 2590 & 14.14 & 18.39 & 2590 & 14.21 & 18.25 & 2590 & 14.53 & 18.66 \\
\hline 2600 & 14.15 & 18.37 & 2600 & 14.21 & 18.22 & 2600 & 14.52 & 18.63 \\
\hline 2610 & 14.12 & 18.35 & 2610 & 14.18 & 18.18 & 2610 & 14.52 & 18.58 \\
\hline 2620 & 14.13 & 18.31 & 2620 & 14.16 & 18.15 & 2620 & 14.50 & 18.56 \\
\hline 2630 & 14.10 & 18.28 & 2630 & 14.18 & 18.14 & 2630 & 14.49 & 18.53 \\
\hline 2640 & 14.09 & 18.26 & 2640 & 14.16 & 18.10 & 2640 & 14.48 & 18.50 \\
\hline 2650 & 14.08 & 18.23 & 2650 & 14.15 & 18.08 & 2650 & 14.48 & 18.46 \\
\hline 2660 & 14.08 & 18.21 & 2660 & 14.14 & 18.04 & 2660 & 14.46 & 18.44 \\
\hline 2670 & 14.07 & 18.19 & 2670 & 14.14 & 18.02 & 2670 & 14.45 & 18.40 \\
\hline 2680 & 14.06 & 18.16 & 2680 & 14.12 & 18.00 & 2680 & 14.43 & 18.38 \\
\hline 2690 & 14.05 & 18.11 & 2690 & 14.11 & 17.97 & 2690 & 14.44 & 18.35 \\
\hline 2700 & 14.05 & 18.10 & 2700 & 14.11 & 17.94 & 2700 & 14.42 & 18.32 \\
\hline 2710 & 14.04 & 18.07 & 2710 & 14.10 & 17.92 & 2710 & 14.41 & 18.28 \\
\hline 2720 & 14.04 & 18.06 & 2720 & 14.10 & 17.88 & 2720 & 14.40 & 18.26 \\
\hline 2730 & 14.01 & 18.02 & 2730 & 14.07 & 17.85 & 2730 & 14.39 & 18.23 \\
\hline 2740 & 14.01 & 17.99 & 2740 & 14.07 & 17.82 & 2740 & 14.38 & 18.20 \\
\hline 2750 & 13.99 & 17.97 & 2750 & 14.05 & 17.79 & 2750 & 14.37 & 18.17 \\
\hline 2760 & 13.99 & 17.93 & 2760 & 14.05 & 17.75 & 2760 & 14.37 & 18.14 \\
\hline 2770 & 13.97 & 17.91 & 2770 & 14.04 & 17.73 & 2770 & 14.36 & 18.11 \\
\hline 2780 & 13.98 & 17.89 & 2780 & 14.03 & 17.71 & 2780 & 14.34 & 18.07 \\
\hline 2790 & 13.98 & 17.87 & 2790 & 14.03 & 17.68 & 2790 & 14.32 & 18.05 \\
\hline 2800 & 13.96 & 17.83 & 2800 & 14.01 & 17.65 & 2800 & 14.32 & 18.01 \\
\hline 2810 & 13.95 & 17.81 & 2810 & 14.00 & 17.63 & 2810 & 14.30 & 17.98 \\
\hline 2820 & 13.94 & 17.78 & 2820 & 14.00 & 17.62 & 2820 & 14.30 & 17.95 \\
\hline 2830 & 13.95 & 17.75 & 2830 & 13.99 & 17.57 & 2830 & 14.29 & 17.93 \\
\hline 2840 & 13.93 & 17.72 & 2840 & 13.98 & 17.53 & 2840 & 14.28 & 17.90 \\
\hline 2850 & 13.92 & 17.69 & 2850 & 13.96 & 17.51 & 2850 & 14.27 & 17.86 \\
\hline 2860 & 13.92 & 17.67 & 2860 & 13.96 & 17.48 & 2860 & 14.26 & 17.83 \\
\hline 2870 & 13.91 & 17.64 & 2870 & 13.95 & 17.47 & 2870 & 14.25 & 17.80 \\
\hline 2880 & 13.89 & 17.63 & 2880 & 13.94 & 17.43 & 2880 & 14.24 & 17.78 \\
\hline 2890 & 13.87 & 17.58 & 2890 & 13.94 & 17.40 & 2890 & 14.24 & 17.75 \\
\hline 2900 & 13.88 & 17.56 & 2900 & 13.93 & 17.37 & 2900 & 14.22 & 17.72 \\
\hline 2910 & 13.86 & 17.53 & 2910 & 13.92 & 17.35 & 2910 & 14.21 & 17.70 \\
\hline 2920 & 13.85 & 17.50 & 2920 & 13.91 & 17.32 & 2920 & 14.20 & 17.64 \\
\hline 2930 & 13.85 & 17.48 & 2930 & 13.90 & 17.29 & 2930 & 14.19 & 17.63 \\
\hline 2940 & 13.84 & 17.45 & 2940 & 13.89 & 17.28 & 2940 & 14.18 & 17.60 \\
\hline 2950 & 13.83 & 17.40 & 2950 & 13.88 & 17.24 & 2950 & 14.18 & 17.58 \\
\hline 2960 & 13.84 & 17.39 & 2960 & 13.87 & 17.21 & 2960 & 14.16 & 17.54 \\
\hline 2970 & 13.81 & 17.37 & 2970 & 13.85 & 17.19 & 2970 & 14.16 & 17.52 \\
\hline 2980 & 13.81 & 17.34 & 2980 & 13.84 & 17.14 & 2980 & 14.14 & 17.49 \\
\hline 2990 & 13.78 & 17.30 & 2990 & 13.85 & 17.11 & 2990 & 14.13 & 17.45 \\
\hline
\end{tabular}




\begin{tabular}{|c|c|c|c|c|c|c|c|c|}
\hline 3000 & 13.78 & 17.29 & 3000 & 13.83 & 17.10 & 3000 & 14.13 & 17.44 \\
\hline 3010 & 13.78 & 17.25 & 3010 & 13.81 & 17.07 & 3010 & 14.13 & 17.40 \\
\hline 3020 & 13.77 & 17.24 & 3020 & 13.80 & 17.04 & 3020 & 14.11 & 17.37 \\
\hline 3030 & 13.76 & 17.19 & 3030 & 13.80 & 17.02 & 3030 & 14.09 & 17.33 \\
\hline 3040 & 13.74 & 17.17 & 3040 & 13.80 & 16.99 & 3040 & 14.08 & 17.32 \\
\hline 3050 & 13.73 & 17.15 & 3050 & 13.78 & 16.96 & 3050 & 14.08 & 17.28 \\
\hline 3060 & 13.73 & 17.12 & 3060 & 13.79 & 16.94 & 3060 & 14.07 & 17.27 \\
\hline 3070 & 13.71 & 17.10 & 3070 & 13.77 & 16.90 & 3070 & 14.06 & 17.23 \\
\hline 3080 & 13.71 & 17.07 & 3080 & 13.76 & 16.88 & 3080 & 14.05 & 17.21 \\
\hline 3090 & 13.69 & 17.05 & 3090 & 13.76 & 16.86 & 3090 & 14.04 & 17.18 \\
\hline 3100 & 13.69 & 17.01 & 3100 & 13.74 & 16.83 & 3100 & 14.03 & 17.15 \\
\hline 3110 & 13.68 & 16.99 & 3110 & 13.74 & 16.80 & 3110 & 14.02 & 17.12 \\
\hline 3120 & 13.67 & 16.96 & 3120 & 13.73 & 16.77 & 3120 & 14.01 & 17.09 \\
\hline 3130 & 13.66 & 16.94 & 3130 & 13.71 & 16.74 & 3130 & 14.00 & 17.06 \\
\hline 3140 & 13.65 & 16.91 & 3140 & 13.70 & 16.72 & 3140 & 13.99 & 17.05 \\
\hline 3150 & 13.64 & 16.88 & 3150 & 13.70 & 16.69 & 3150 & 13.98 & 17.01 \\
\hline 3160 & 13.63 & 16.85 & 3160 & 13.68 & 16.67 & 3160 & 13.96 & 17.00 \\
\hline 3170 & 13.62 & 16.82 & 3170 & 13.68 & 16.63 & 3170 & 13.96 & 16.96 \\
\hline 3180 & 13.62 & 16.81 & 3180 & 13.68 & 16.63 & 3180 & 13.95 & 16.94 \\
\hline 3190 & 13.60 & 16.77 & 3190 & 13.67 & 16.58 & 3190 & 13.95 & 16.91 \\
\hline 3200 & 13.59 & 16.77 & 3200 & 13.65 & 16.56 & 3200 & 13.92 & 16.89 \\
\hline 3210 & 13.58 & 16.72 & 3210 & 13.64 & 16.54 & 3210 & 13.91 & 16.85 \\
\hline 3220 & 13.59 & 16.71 & 3220 & 13.64 & 16.52 & 3220 & 13.92 & 16.83 \\
\hline 3230 & 13.57 & 16.67 & 3230 & 13.62 & 16.49 & 3230 & 13.90 & 16.80 \\
\hline 3240 & 13.55 & 16.66 & 3240 & 13.61 & 16.44 & 3240 & 13.90 & 16.78 \\
\hline 3250 & 13.55 & 16.64 & 3250 & 13.61 & 16.43 & 3250 & 13.88 & 16.76 \\
\hline 3260 & 13.54 & 16.60 & 3260 & 13.59 & 16.40 & 3260 & 13.88 & 16.73 \\
\hline 3270 & 13.54 & 16.58 & 3270 & 13.58 & 16.38 & 3270 & 13.86 & 16.69 \\
\hline 3280 & 13.51 & 16.54 & 3280 & 13.57 & 16.36 & 3280 & 13.86 & 16.67 \\
\hline 3290 & 13.51 & 16.51 & 3290 & 13.56 & 16.34 & 3290 & 13.83 & 16.65 \\
\hline 3300 & 13.51 & 16.50 & 3300 & 13.56 & 16.31 & 3300 & 13.84 & 16.62 \\
\hline 3310 & 13.50 & 16.47 & 3310 & 13.54 & 16.29 & 3310 & 13.83 & 16.59 \\
\hline 3320 & 13.48 & 16.44 & 3320 & 13.54 & 16.25 & 3320 & 13.80 & 16.57 \\
\hline 3330 & 13.49 & 16.42 & 3330 & 13.53 & 16.24 & 3330 & 13.82 & 16.55 \\
\hline 3340 & 13.48 & 16.40 & 3340 & 13.50 & 16.21 & 3340 & 13.78 & 16.52 \\
\hline 3350 & 13.45 & 16.37 & 3350 & 13.49 & 16.17 & 3350 & 13.79 & 16.50 \\
\hline 3360 & 13.47 & 16.35 & 3360 & 13.48 & 16.16 & 3360 & 13.78 & 16.46 \\
\hline 3370 & 13.45 & 16.33 & 3370 & 13.47 & 16.11 & 3370 & 13.77 & 16.45 \\
\hline 3380 & 13.45 & 16.30 & 3380 & 13.47 & 16.10 & 3380 & 13.76 & 16.42 \\
\hline 3390 & 13.43 & 16.27 & 3390 & 13.48 & 16.10 & 3390 & 13.74 & 16.40 \\
\hline 3400 & 13.42 & 16.24 & 3400 & 13.46 & 16.06 & 3400 & 13.75 & 16.38 \\
\hline 3410 & 13.41 & 16.22 & 3410 & 13.45 & 16.04 & 3410 & 13.73 & 16.35 \\
\hline 3420 & 13.40 & 16.20 & 3420 & 13.43 & 16.01 & 3420 & 13.71 & 16.32 \\
\hline 3430 & 13.40 & 16.17 & 3430 & 13.42 & 15.99 & 3430 & 13.71 & 16.30 \\
\hline
\end{tabular}




\begin{tabular}{|c|c|c|c|c|c|c|c|c|}
\hline 3440 & 13.38 & 16.14 & 3440 & 13.41 & 15.96 & 3440 & 13.69 & 16.27 \\
\hline 3450 & 13.36 & 16.12 & 3450 & 13.41 & 15.94 & 3450 & 13.69 & 16.25 \\
\hline 3460 & 13.35 & 16.10 & 3460 & 13.41 & 15.92 & 3460 & 13.68 & 16.22 \\
\hline 3470 & 13.36 & 16.09 & 3470 & 13.39 & 15.89 & 3470 & 13.68 & 16.20 \\
\hline 3480 & 13.35 & 16.04 & 3480 & 13.39 & 15.87 & 3480 & 13.65 & 16.17 \\
\hline 3490 & 13.34 & 16.03 & 3490 & 13.38 & 15.85 & 3490 & 13.64 & 16.14 \\
\hline 3500 & 13.33 & 15.99 & 3500 & 13.37 & 15.81 & 3500 & 13.64 & 16.13 \\
\hline 3510 & 13.32 & 15.97 & 3510 & 13.36 & 15.79 & 3510 & 13.63 & 16.10 \\
\hline 3520 & 13.31 & 15.93 & 3520 & 13.34 & 15.77 & 3520 & 13.62 & 16.08 \\
\hline 3530 & 13.30 & 15.92 & 3530 & 13.35 & 15.74 & 3530 & 13.61 & 16.06 \\
\hline 3540 & 13.29 & 15.90 & 3540 & 13.33 & 15.72 & 3540 & 13.61 & 16.03 \\
\hline 3550 & 13.27 & 15.87 & 3550 & 13.31 & 15.68 & 3550 & 13.60 & 16.00 \\
\hline 3560 & 13.27 & 15.85 & 3560 & 13.32 & 15.68 & 3560 & 13.60 & 15.99 \\
\hline 3570 & 13.26 & 15.83 & 3570 & 13.30 & 15.64 & 3570 & 13.59 & 15.96 \\
\hline 3580 & 13.24 & 15.81 & 3580 & 13.31 & 15.63 & 3580 & 13.55 & 15.93 \\
\hline 3590 & 13.23 & 15.77 & 3590 & 13.29 & 15.59 & 3590 & 13.56 & 15.91 \\
\hline 3600 & 13.23 & 15.75 & 3600 & 13.28 & 15.58 & 3600 & 13.54 & 15.89 \\
\hline 3610 & 13.22 & 15.73 & 3610 & 13.27 & 15.55 & 3610 & 13.54 & 15.87 \\
\hline 3620 & 13.21 & 15.71 & 3620 & 13.26 & 15.55 & 3620 & 13.53 & 15.84 \\
\hline 3630 & 13.21 & 15.68 & 3630 & 13.25 & 15.50 & 3630 & 13.52 & 15.82 \\
\hline 3640 & 13.19 & 15.67 & 3640 & 13.24 & 15.48 & 3640 & 13.51 & 15.80 \\
\hline 3650 & 13.18 & 15.63 & 3650 & 13.22 & 15.46 & 3650 & 13.50 & 15.77 \\
\hline 3660 & 13.17 & 15.60 & 3660 & 13.21 & 15.44 & 3660 & 13.50 & 15.75 \\
\hline 3670 & 13.16 & 15.58 & 3670 & 13.22 & 15.41 & 3670 & 13.49 & 15.73 \\
\hline 3680 & 13.17 & 15.55 & 3680 & 13.20 & 15.38 & 3680 & 13.47 & 15.71 \\
\hline 3690 & 13.15 & 15.54 & 3690 & 13.20 & 15.36 & 3690 & 13.45 & 15.69 \\
\hline 3700 & 13.14 & 15.51 & 3700 & 13.18 & 15.35 & 3700 & 13.45 & 15.66 \\
\hline 3710 & 13.14 & 15.50 & 3710 & 13.17 & 15.34 & 3710 & 13.44 & 15.63 \\
\hline 3720 & 13.13 & 15.48 & 3720 & 13.17 & 15.31 & 3720 & 13.44 & 15.61 \\
\hline 3730 & 13.12 & 15.44 & 3730 & 13.15 & 15.28 & 3730 & 13.44 & 15.60 \\
\hline 3740 & 13.11 & 15.43 & 3740 & 13.15 & 15.25 & 3740 & 13.42 & 15.57 \\
\hline 3750 & 13.11 & 15.41 & 3750 & 13.15 & 15.25 & 3750 & 13.41 & 15.55 \\
\hline 3760 & 13.09 & 15.38 & 3760 & 13.13 & 15.21 & 3760 & 13.40 & 15.52 \\
\hline 3770 & 13.07 & 15.35 & 3770 & 13.13 & 15.19 & 3770 & 13.39 & 15.51 \\
\hline 3780 & 13.08 & 15.35 & 3780 & 13.13 & 15.17 & 3780 & 13.39 & 15.48 \\
\hline 3790 & 13.08 & 15.32 & 3790 & 13.11 & 15.15 & 3790 & 13.38 & 15.47 \\
\hline 3800 & 13.05 & 15.31 & 3800 & 13.11 & 15.14 & 3800 & 13.37 & 15.44 \\
\hline 3810 & 13.05 & 15.27 & 3810 & 13.09 & 15.12 & 3810 & 13.35 & 15.41 \\
\hline 3820 & 13.03 & 15.25 & 3820 & 13.08 & 15.09 & 3820 & 13.35 & 15.40 \\
\hline 3830 & 13.03 & 15.22 & 3830 & 13.07 & 15.07 & 3830 & 13.34 & 15.39 \\
\hline 3840 & 13.02 & 15.20 & 3840 & 13.07 & 15.06 & 3840 & 13.33 & 15.36 \\
\hline 3850 & 13.02 & 15.19 & 3850 & 13.06 & 15.04 & 3850 & 13.32 & 15.33 \\
\hline 3860 & 13.02 & 15.16 & 3860 & 13.06 & 15.02 & 3860 & 13.31 & 15.32 \\
\hline 3870 & 13.00 & 15.15 & & & & 3870 & 13.30 & 15.30 \\
\hline
\end{tabular}




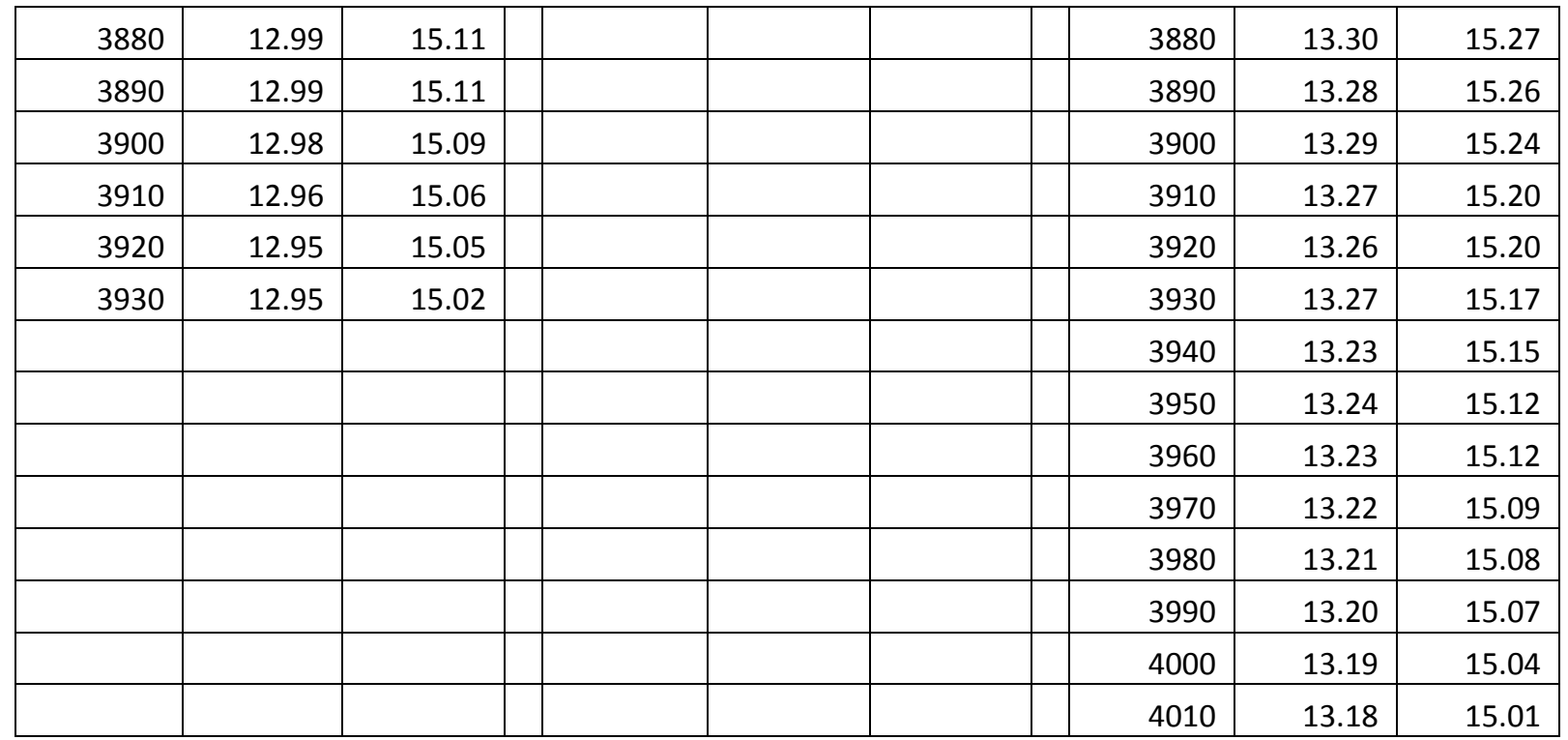


Melting Process

\begin{tabular}{|c|c|c|c|c|c|c|c|c|}
\hline \multicolumn{2}{|c|}{ Inlet $\mathrm{T} 32^{\circ} \mathrm{C}$} & & & & & & & \\
\hline Melting & Run A & & Melting & Run B & & Melting & Run C & \\
\hline Time (s) & $\operatorname{Tfin}\left({ }^{\circ} \mathrm{C}\right)$ & $\begin{array}{l}\mathrm{Tpcm} \\
\left({ }^{\circ} \mathrm{C}\right)\end{array}$ & Time (s) & $\operatorname{Tfin}\left({ }^{\circ} \mathrm{C}\right)$ & $\begin{array}{l}\text { Tpcm } \\
\left({ }^{\circ} \mathrm{C}\right)\end{array}$ & Time (s) & $\operatorname{Tfin}\left({ }^{\circ} \mathrm{C}\right)$ & $\begin{array}{l}\mathrm{Tpcm} \\
\left({ }^{\circ} \mathrm{C}\right)\end{array}$ \\
\hline 0 & 22.87 & 15.08 & 0 & 23.01 & 14.99 & 0 & 22.50 & 15.05 \\
\hline 10 & 22.94 & 15.18 & 10 & 23.12 & 15.12 & 10 & 22.62 & 15.17 \\
\hline 20 & 23.02 & 15.30 & 20 & 23.20 & 15.22 & 20 & 22.72 & 15.26 \\
\hline 30 & 23.09 & 15.42 & 30 & 23.28 & 15.34 & 30 & 22.84 & 15.35 \\
\hline 40 & 23.17 & 15.54 & 40 & 23.35 & 15.45 & 40 & 22.95 & 15.46 \\
\hline 50 & 23.24 & 15.65 & 50 & 23.44 & 15.56 & 50 & 23.05 & 15.57 \\
\hline 60 & 23.32 & 15.77 & 60 & 23.51 & 15.68 & 60 & 23.15 & 15.68 \\
\hline 70 & 23.38 & 15.89 & 70 & 23.56 & 15.78 & 70 & 23.25 & 15.78 \\
\hline 80 & 23.46 & 15.98 & 80 & 23.64 & 15.90 & 80 & 23.36 & 15.87 \\
\hline 90 & 23.51 & 16.10 & 90 & 23.71 & 16.00 & 90 & 23.43 & 15.99 \\
\hline 100 & 23.58 & 16.22 & 100 & 23.78 & 16.13 & 100 & 23.51 & 16.08 \\
\hline 110 & 23.63 & 16.31 & 110 & 23.84 & 16.22 & 110 & 23.58 & 16.19 \\
\hline 120 & 23.69 & 16.42 & 120 & 23.91 & 16.32 & 120 & 23.68 & 16.30 \\
\hline 130 & 23.74 & 16.53 & 130 & 23.97 & 16.42 & 130 & 23.74 & 16.39 \\
\hline 140 & 23.80 & 16.63 & 140 & 24.02 & 16.52 & 140 & 23.81 & 16.48 \\
\hline 150 & 23.86 & 16.73 & 150 & 24.08 & 16.62 & 150 & 23.88 & 16.57 \\
\hline 160 & 23.91 & 16.83 & 160 & 24.13 & 16.71 & 160 & 23.94 & 16.69 \\
\hline 170 & 23.96 & 16.93 & 170 & 24.19 & 16.83 & 170 & 24.01 & 16.79 \\
\hline 180 & 24.01 & 17.03 & 180 & 24.23 & 16.91 & 180 & 24.08 & 16.87 \\
\hline 190 & 24.06 & 17.11 & 190 & 24.27 & 16.99 & 190 & 24.13 & 16.98 \\
\hline 200 & 24.11 & 17.21 & 200 & 24.33 & 17.09 & 200 & 24.20 & 17.05 \\
\hline 210 & 24.15 & 17.30 & 210 & 24.39 & 17.19 & 210 & 24.26 & 17.15 \\
\hline 220 & 24.20 & 17.40 & 220 & 24.44 & 17.28 & 220 & 24.33 & 17.25 \\
\hline 230 & 24.23 & 17.49 & 230 & 24.49 & 17.36 & 230 & 24.37 & 17.34 \\
\hline 240 & 24.29 & 17.58 & 240 & 24.52 & 17.44 & 240 & 24.43 & 17.43 \\
\hline 250 & 24.33 & 17.66 & 250 & 24.56 & 17.52 & 250 & 24.48 & 17.52 \\
\hline 260 & 24.39 & 17.75 & 260 & 24.61 & 17.62 & 260 & 24.54 & 17.61 \\
\hline 270 & 24.42 & 17.83 & 270 & 24.66 & 17.71 & 270 & 24.58 & 17.69 \\
\hline 280 & 24.46 & 17.92 & 280 & 24.70 & 17.78 & 280 & 24.62 & 17.77 \\
\hline 290 & 24.49 & 18.01 & 290 & 24.75 & 17.88 & 290 & 24.67 & 17.86 \\
\hline 300 & 24.54 & 18.08 & 300 & 24.78 & 17.95 & 300 & 24.71 & 17.94 \\
\hline 310 & 24.58 & 18.16 & 310 & 24.83 & 18.02 & 310 & 24.77 & 18.02 \\
\hline 320 & 24.61 & 18.22 & 320 & 24.86 & 18.10 & 320 & 24.82 & 18.11 \\
\hline 330 & 24.65 & 18.32 & 330 & 24.90 & 18.18 & 330 & 24.86 & 18.18 \\
\hline 340 & 24.68 & 18.39 & 340 & 24.95 & 18.25 & 340 & 24.91 & 18.26 \\
\hline 350 & 24.71 & 18.46 & 350 & 24.98 & 18.34 & 350 & 24.95 & 18.35 \\
\hline 360 & 24.76 & 18.54 & 360 & 25.03 & 18.41 & 360 & 24.99 & 18.42 \\
\hline 370 & 24.80 & 18.61 & 370 & 25.06 & 18.48 & 370 & 25.04 & 18.50 \\
\hline
\end{tabular}




\begin{tabular}{|c|c|c|c|c|c|c|c|c|}
\hline 380 & 24.84 & 18.68 & 380 & 25.08 & 18.55 & 380 & 25.08 & 18.58 \\
\hline 390 & 24.86 & 18.74 & 390 & 25.14 & 18.62 & 390 & 25.11 & 18.65 \\
\hline 400 & 24.90 & 18.81 & 400 & 25.17 & 18.68 & 400 & 25.14 & 18.73 \\
\hline 410 & 24.91 & 18.88 & 410 & 25.20 & 18.76 & 410 & 25.20 & 18.79 \\
\hline 420 & 24.95 & 18.96 & 420 & 25.23 & 18.83 & 420 & 25.22 & 18.87 \\
\hline 430 & 24.98 & 19.02 & 430 & 25.26 & 18.90 & 430 & 25.27 & 18.93 \\
\hline 440 & 25.02 & 19.10 & 440 & 25.29 & 18.96 & 440 & 25.30 & 19.00 \\
\hline 450 & 25.05 & 19.15 & 450 & 25.31 & 19.03 & 450 & 25.34 & 19.08 \\
\hline 460 & 25.08 & 19.23 & 460 & 25.36 & 19.09 & 460 & 25.36 & 19.16 \\
\hline 470 & 25.11 & 19.28 & 470 & 25.39 & 19.15 & 470 & 25.40 & 19.22 \\
\hline 480 & 25.14 & 19.33 & 480 & 25.42 & 19.21 & 480 & 25.44 & 19.28 \\
\hline 490 & 25.18 & 19.40 & 490 & 25.45 & 19.28 & 490 & 25.47 & 19.35 \\
\hline 500 & 25.21 & 19.46 & 500 & 25.49 & 19.34 & 500 & 25.50 & 19.41 \\
\hline 510 & 25.23 & 19.52 & 510 & 25.51 & 19.39 & 510 & 25.54 & 19.48 \\
\hline 520 & 25.25 & 19.57 & 520 & 25.55 & 19.45 & 520 & 25.56 & 19.53 \\
\hline 530 & 25.28 & 19.65 & 530 & 25.56 & 19.51 & 530 & 25.60 & 19.61 \\
\hline 540 & 25.31 & 19.69 & 540 & 25.59 & 19.56 & 540 & 25.63 & 19.66 \\
\hline 550 & 25.35 & 19.74 & 550 & 25.63 & 19.62 & 550 & 25.66 & 19.72 \\
\hline 560 & 25.37 & 19.80 & 560 & 25.66 & 19.67 & 560 & 25.70 & 19.79 \\
\hline 570 & 25.40 & 19.87 & 570 & 25.69 & 19.72 & 570 & 25.72 & 19.85 \\
\hline 580 & 25.41 & 19.90 & 580 & 25.72 & 19.78 & 580 & 25.77 & 19.90 \\
\hline 590 & 25.45 & 19.97 & 590 & 25.75 & 19.83 & 590 & 25.79 & 19.96 \\
\hline 600 & 25.46 & 20.01 & 600 & 25.77 & 19.89 & 600 & 25.81 & 20.02 \\
\hline 610 & 25.51 & 20.06 & 610 & 25.79 & 19.95 & 610 & 25.86 & 20.08 \\
\hline 620 & 25.53 & 20.12 & 620 & 25.83 & 20.00 & 620 & 25.89 & 20.13 \\
\hline 630 & 25.55 & 20.16 & 630 & 25.85 & 20.05 & 630 & 25.90 & 20.18 \\
\hline 640 & 25.58 & 20.22 & 640 & 25.88 & 20.10 & 640 & 25.93 & 20.24 \\
\hline 650 & 25.60 & 20.26 & 650 & 25.90 & 20.14 & 650 & 25.96 & 20.28 \\
\hline 660 & 25.64 & 20.31 & 660 & 25.94 & 20.20 & 660 & 25.98 & 20.34 \\
\hline 670 & 25.64 & 20.33 & 670 & 25.96 & 20.24 & 670 & 26.00 & 20.41 \\
\hline 680 & 25.66 & 20.38 & 680 & 26.00 & 20.28 & 680 & 26.04 & 20.44 \\
\hline 690 & 25.70 & 20.44 & 690 & 26.01 & 20.31 & 690 & 26.06 & 20.50 \\
\hline 700 & 25.72 & 20.47 & 700 & 26.03 & 20.36 & 700 & 26.09 & 20.55 \\
\hline 710 & 25.76 & 20.53 & 710 & 26.07 & 20.42 & 710 & 26.11 & 20.58 \\
\hline 720 & 25.77 & 20.56 & 720 & 26.08 & 20.45 & 720 & 26.13 & 20.65 \\
\hline 730 & 25.79 & 20.60 & 730 & 26.10 & 20.51 & 730 & 26.18 & 20.70 \\
\hline 740 & 25.80 & 20.64 & 740 & 26.12 & 20.55 & 740 & 26.19 & 20.74 \\
\hline 750 & 25.85 & 20.68 & 750 & 26.15 & 20.59 & 750 & 26.22 & 20.79 \\
\hline 760 & 25.86 & 20.73 & 760 & 26.17 & 20.63 & 760 & 26.23 & 20.84 \\
\hline 770 & 25.88 & 20.78 & 770 & 26.21 & 20.68 & 770 & 26.28 & 20.90 \\
\hline 780 & 25.91 & 20.80 & 780 & 26.22 & 20.72 & 780 & 26.30 & 20.93 \\
\hline 790 & 25.92 & 20.84 & 790 & 26.24 & 20.76 & 790 & 26.32 & 20.98 \\
\hline 800 & 25.94 & 20.89 & 800 & 26.26 & 20.81 & 800 & 26.33 & 21.02 \\
\hline 810 & 25.97 & 20.92 & 810 & 26.29 & 20.83 & 810 & 26.36 & 21.05 \\
\hline
\end{tabular}




\begin{tabular}{|c|c|c|c|c|c|c|c|c|}
\hline 820 & 25.99 & 20.96 & 820 & 26.31 & 20.87 & 820 & 26.38 & 21.10 \\
\hline 830 & 26.02 & 21.00 & 830 & 26.33 & 20.91 & 830 & 26.41 & 21.16 \\
\hline 840 & 26.02 & 21.03 & 840 & 26.36 & 20.94 & 840 & 26.43 & 21.18 \\
\hline 850 & 26.05 & 21.06 & 850 & 26.38 & 20.98 & 850 & 26.46 & 21.23 \\
\hline 860 & 26.07 & 21.09 & 860 & 26.40 & 21.02 & 860 & 26.48 & 21.26 \\
\hline 870 & 26.08 & 21.12 & 870 & 26.42 & 21.06 & 870 & 26.50 & 21.32 \\
\hline 880 & 26.10 & 21.15 & 880 & 26.44 & 21.08 & 880 & 26.52 & 21.34 \\
\hline 890 & 26.14 & 21.19 & 890 & 26.46 & 21.13 & 890 & 26.55 & 21.38 \\
\hline 900 & 26.15 & 21.23 & 900 & 26.48 & 21.16 & 900 & 26.56 & 21.43 \\
\hline 910 & 26.18 & 21.24 & 910 & 26.50 & 21.20 & 910 & 26.58 & 21.46 \\
\hline 920 & 26.19 & 21.28 & 920 & 26.52 & 21.23 & 920 & 26.61 & 21.48 \\
\hline 930 & 26.21 & 21.31 & 930 & 26.54 & 21.27 & 930 & 26.64 & 21.53 \\
\hline 940 & 26.22 & 21.33 & 940 & 26.56 & 21.28 & 940 & 26.65 & 21.57 \\
\hline 950 & 26.25 & 21.36 & 950 & 26.57 & 21.32 & 950 & 26.68 & 21.61 \\
\hline 960 & 26.25 & 21.40 & 960 & 26.60 & 21.36 & 960 & 26.69 & 21.64 \\
\hline 970 & 26.29 & 21.42 & 970 & 26.62 & 21.40 & 970 & 26.71 & 21.68 \\
\hline 980 & 26.31 & 21.45 & 980 & 26.63 & 21.42 & 980 & 26.73 & 21.71 \\
\hline 990 & 26.34 & 21.48 & 990 & 26.65 & 21.46 & 990 & 26.75 & 21.73 \\
\hline 1000 & 26.35 & 21.50 & 1000 & 26.67 & 21.48 & 1000 & 26.77 & 21.77 \\
\hline 1010 & 26.37 & 21.52 & 1010 & 26.70 & 21.50 & 1010 & 26.78 & 21.80 \\
\hline 1020 & 26.38 & 21.54 & 1020 & 26.71 & 21.54 & 1020 & 26.81 & 21.84 \\
\hline 1030 & 26.40 & 21.57 & 1030 & 26.73 & 21.57 & 1030 & 26.83 & 21.86 \\
\hline 1040 & 26.42 & 21.60 & 1040 & 26.75 & 21.60 & 1040 & 26.84 & 21.90 \\
\hline 1050 & 26.44 & 21.61 & 1050 & 26.76 & 21.62 & 1050 & 26.86 & 21.93 \\
\hline 1060 & 26.45 & 21.64 & 1060 & 26.79 & 21.66 & 1060 & 26.89 & 21.98 \\
\hline 1070 & 26.47 & 21.65 & 1070 & 26.80 & 21.67 & 1070 & 26.91 & 22.00 \\
\hline 1080 & 26.49 & 21.67 & 1080 & 26.82 & 21.71 & 1080 & 26.93 & 22.02 \\
\hline 1090 & 26.50 & 21.69 & 1090 & 26.83 & 21.73 & 1090 & 26.94 & 22.06 \\
\hline 1100 & 26.53 & 21.72 & 1100 & 26.85 & 21.75 & 1100 & 26.97 & 22.09 \\
\hline 1110 & 26.54 & 21.74 & 1110 & 26.89 & 21.80 & 1110 & 26.99 & 22.11 \\
\hline 1120 & 26.55 & 21.75 & 1120 & 26.89 & 21.81 & 1120 & 26.99 & 22.14 \\
\hline 1130 & 26.57 & 21.78 & 1130 & 26.92 & 21.84 & 1130 & 27.01 & 22.17 \\
\hline 1140 & 26.58 & 21.80 & 1140 & 26.92 & 21.87 & 1140 & 27.02 & 22.19 \\
\hline 1150 & 26.61 & 21.82 & 1150 & 26.95 & 21.88 & 1150 & 27.04 & 22.21 \\
\hline 1160 & 26.63 & 21.83 & 1160 & 26.97 & 21.90 & 1160 & 27.07 & 22.24 \\
\hline 1170 & 26.65 & 21.86 & 1170 & 26.98 & 21.92 & 1170 & 27.08 & 22.28 \\
\hline 1180 & 26.66 & 21.87 & 1180 & 26.99 & 21.95 & 1180 & 27.10 & 22.30 \\
\hline 1190 & 26.67 & 21.90 & 1190 & 27.01 & 21.99 & 1190 & 27.11 & 22.33 \\
\hline 1200 & 26.69 & 21.90 & 1200 & 27.02 & 22.00 & 1200 & 27.13 & 22.34 \\
\hline 1210 & 26.71 & 21.91 & 1210 & 27.05 & 22.03 & 1210 & 27.14 & 22.37 \\
\hline 1220 & 26.74 & 21.95 & 1220 & 27.07 & 22.03 & 1220 & 27.16 & 22.41 \\
\hline 1230 & 26.75 & 21.94 & 1230 & 27.08 & 22.06 & 1230 & 27.18 & 22.43 \\
\hline 1240 & 26.75 & 21.96 & 1240 & 27.09 & 22.09 & 1240 & 27.19 & 22.44 \\
\hline 1250 & 26.79 & 21.98 & 1250 & 27.11 & 22.10 & 1250 & 27.21 & 22.46 \\
\hline
\end{tabular}




\begin{tabular}{|c|c|c|c|c|c|c|c|c|}
\hline 1260 & 26.80 & 22.01 & 1260 & 27.13 & 22.14 & 1260 & 27.22 & 22.49 \\
\hline 1270 & 26.80 & 22.00 & 1270 & 27.14 & 22.16 & 1270 & 27.24 & 22.52 \\
\hline 1280 & 26.83 & 22.03 & 1280 & 27.15 & 22.16 & 1280 & 27.26 & 22.54 \\
\hline 1290 & 26.84 & 22.04 & 1290 & 27.17 & 22.19 & 1290 & 27.26 & 22.56 \\
\hline 1300 & 26.86 & 22.06 & 1300 & 27.19 & 22.21 & 1300 & 27.30 & 22.59 \\
\hline 1310 & 26.86 & 22.07 & 1310 & 27.20 & 22.23 & 1310 & 27.31 & 22.61 \\
\hline 1320 & 26.89 & 22.09 & 1320 & 27.22 & 22.25 & 1320 & 27.33 & 22.64 \\
\hline 1330 & 26.90 & 22.11 & 1330 & 27.24 & 22.27 & 1330 & 27.34 & 22.66 \\
\hline 1340 & 26.92 & 22.12 & 1340 & 27.25 & 22.29 & 1340 & 27.35 & 22.68 \\
\hline 1350 & 26.93 & 22.13 & 1350 & 27.27 & 22.31 & 1350 & 27.36 & 22.71 \\
\hline 1360 & 26.94 & 22.16 & 1360 & 27.26 & 22.33 & 1360 & 27.37 & 22.74 \\
\hline 1370 & 26.97 & 22.17 & 1370 & 27.30 & 22.35 & 1370 & 27.40 & 22.76 \\
\hline 1380 & 26.98 & 22.18 & 1380 & 27.31 & 22.38 & 1380 & 27.41 & 22.78 \\
\hline 1390 & 26.99 & 22.19 & 1390 & 27.32 & 22.39 & 1390 & 27.43 & 22.80 \\
\hline 1400 & 27.00 & 22.20 & 1400 & 27.33 & 22.40 & 1400 & 27.45 & 22.83 \\
\hline 1410 & 27.02 & 22.24 & 1410 & 27.36 & 22.43 & 1410 & 27.45 & 22.84 \\
\hline 1420 & 27.03 & 22.24 & 1420 & 27.37 & 22.44 & 1420 & 27.46 & 22.86 \\
\hline 1430 & 27.05 & 22.25 & 1430 & 27.38 & 22.46 & 1430 & 27.47 & 22.89 \\
\hline 1440 & 27.06 & 22.27 & 1440 & 27.40 & 22.48 & 1440 & 27.50 & 22.91 \\
\hline 1450 & 27.08 & 22.28 & 1450 & 27.41 & 22.51 & 1450 & 27.50 & 22.94 \\
\hline 1460 & 27.09 & 22.30 & 1460 & 27.43 & 22.53 & 1460 & 27.53 & 22.96 \\
\hline 1470 & 27.10 & 22.31 & 1470 & 27.44 & 22.54 & 1470 & 27.53 & 22.97 \\
\hline 1480 & 27.12 & 22.32 & 1480 & 27.47 & 22.56 & 1480 & 27.56 & 22.99 \\
\hline 1490 & 27.14 & 22.33 & 1490 & 27.47 & 22.57 & 1490 & 27.56 & 23.02 \\
\hline 1500 & 27.14 & 22.36 & 1500 & 27.49 & 22.60 & 1500 & 27.57 & 23.04 \\
\hline 1510 & 27.15 & 22.37 & 1510 & 27.49 & 22.61 & 1510 & 27.59 & 23.07 \\
\hline 1520 & 27.17 & 22.38 & 1520 & 27.51 & 22.64 & 1520 & 27.60 & 23.08 \\
\hline 1530 & 27.19 & 22.40 & 1530 & 27.52 & 22.66 & 1530 & 27.62 & 23.11 \\
\hline 1540 & 27.20 & 22.41 & 1540 & 27.54 & 22.69 & 1540 & 27.63 & 23.14 \\
\hline 1550 & 27.21 & 22.41 & 1550 & 27.55 & 22.70 & 1550 & 27.64 & 23.13 \\
\hline 1560 & 27.23 & 22.45 & 1560 & 27.56 & 22.72 & 1560 & 27.66 & 23.17 \\
\hline 1570 & 27.23 & 22.45 & 1570 & 27.58 & 22.72 & 1570 & 27.66 & 23.17 \\
\hline 1580 & 27.27 & 22.46 & 1580 & 27.60 & 22.74 & 1580 & 27.68 & 23.19 \\
\hline 1590 & 27.26 & 22.48 & 1590 & 27.61 & 22.77 & 1590 & 27.70 & 23.22 \\
\hline 1600 & 27.28 & 22.50 & 1600 & 27.62 & 22.78 & 1600 & 27.71 & 23.24 \\
\hline 1610 & 27.31 & 22.51 & 1610 & 27.63 & 22.80 & 1610 & 27.71 & 23.27 \\
\hline 1620 & 27.34 & 22.53 & 1620 & 27.65 & 22.83 & 1620 & 27.73 & 23.27 \\
\hline 1630 & 27.34 & 22.54 & 1630 & 27.66 & 22.85 & 1630 & 27.75 & 23.30 \\
\hline 1640 & 27.35 & 22.56 & 1640 & 27.67 & 22.86 & 1640 & 27.77 & 23.33 \\
\hline 1650 & 27.36 & 22.57 & 1650 & 27.68 & 22.88 & 1650 & 27.77 & 23.34 \\
\hline 1660 & 27.38 & 22.59 & 1660 & 27.70 & 22.90 & 1660 & 27.79 & 23.36 \\
\hline 1670 & 27.39 & 22.61 & 1670 & 27.72 & 22.93 & 1670 & 27.80 & 23.38 \\
\hline 1680 & 27.39 & 22.60 & 1680 & 27.72 & 22.93 & 1680 & 27.80 & 23.40 \\
\hline 1690 & 27.41 & 22.63 & 1690 & 27.75 & 22.97 & 1690 & 27.82 & 23.42 \\
\hline
\end{tabular}




\begin{tabular}{|c|c|c|c|c|c|c|c|c|}
\hline 1700 & 27.44 & 22.66 & 1700 & 27.74 & 22.97 & 1700 & 27.84 & 23.45 \\
\hline 1710 & 27.45 & 22.67 & 1710 & 27.76 & 22.99 & 1710 & 27.85 & 23.45 \\
\hline 1720 & 27.46 & 22.68 & 1720 & 27.77 & 23.01 & 1720 & 27.86 & 23.47 \\
\hline 1730 & 27.46 & 22.69 & 1730 & 27.78 & 23.03 & 1730 & 27.88 & 23.49 \\
\hline 1740 & 27.47 & 22.71 & 1740 & 27.80 & 23.06 & 1740 & 27.88 & 23.51 \\
\hline 1750 & 27.48 & 22.72 & 1750 & 27.81 & 23.07 & 1750 & 27.89 & 23.54 \\
\hline 1760 & 27.50 & 22.74 & 1760 & 27.82 & 23.09 & 1760 & 27.90 & 23.55 \\
\hline 1770 & 27.51 & 22.75 & 1770 & 27.83 & 23.11 & 1770 & 27.92 & 23.57 \\
\hline 1780 & 27.52 & 22.79 & 1780 & 27.85 & 23.13 & 1780 & 27.94 & 23.59 \\
\hline 1790 & 27.53 & 22.79 & 1790 & 27.85 & 23.14 & 1790 & 27.95 & 23.61 \\
\hline 1800 & 27.55 & 22.80 & 1800 & 27.86 & 23.17 & 1800 & 27.95 & 23.63 \\
\hline 1810 & 27.57 & 22.82 & 1810 & 27.89 & 23.20 & 1810 & 27.97 & 23.64 \\
\hline 1820 & 27.57 & 22.83 & 1820 & 27.91 & 23.21 & 1820 & 27.98 & 23.66 \\
\hline 1830 & 27.59 & 22.85 & 1830 & 27.91 & 23.22 & 1830 & 27.99 & 23.67 \\
\hline 1840 & 27.59 & 22.86 & 1840 & 27.92 & 23.24 & 1840 & 28.01 & 23.68 \\
\hline 1850 & 27.61 & 22.88 & 1850 & 27.93 & 23.26 & 1850 & 28.01 & 23.72 \\
\hline 1860 & 27.61 & 22.89 & 1860 & 27.95 & 23.29 & 1860 & 28.03 & 23.74 \\
\hline 1870 & 27.63 & 22.91 & 1870 & 27.95 & 23.30 & 1870 & 28.03 & 23.75 \\
\hline 1880 & 27.65 & 22.93 & 1880 & 27.96 & 23.32 & 1880 & 28.04 & 23.77 \\
\hline 1890 & 27.67 & 22.95 & 1890 & 27.98 & 23.34 & 1890 & 28.06 & 23.79 \\
\hline 1900 & 27.66 & 22.96 & 1900 & 28.00 & 23.36 & 1900 & 28.07 & 23.79 \\
\hline 1910 & 27.68 & 22.98 & 1910 & 28.00 & 23.38 & 1910 & 28.08 & 23.81 \\
\hline 1920 & 27.70 & 23.00 & 1920 & 28.02 & 23.40 & 1920 & 28.11 & 23.84 \\
\hline 1930 & 27.70 & 23.00 & 1930 & 28.03 & 23.40 & 1930 & 28.11 & 23.86 \\
\hline 1940 & 27.72 & 23.03 & 1940 & 28.04 & 23.44 & 1940 & 28.13 & 23.88 \\
\hline 1950 & 27.72 & 23.03 & 1950 & 28.05 & 23.44 & 1950 & 28.12 & 23.88 \\
\hline 1960 & 27.73 & 23.05 & 1960 & 28.05 & 23.46 & 1960 & 28.14 & 23.91 \\
\hline 1970 & 27.75 & 23.08 & 1970 & 28.07 & 23.48 & 1970 & 28.14 & 23.92 \\
\hline 1980 & 27.75 & 23.09 & 1980 & 28.08 & 23.50 & 1980 & 28.16 & 23.94 \\
\hline 1990 & 27.76 & 23.11 & 1990 & 28.09 & 23.52 & 1990 & 28.16 & 23.95 \\
\hline 2000 & 27.78 & 23.13 & 2000 & 28.11 & 23.54 & 2000 & 28.18 & 23.99 \\
\hline 2010 & 27.79 & 23.13 & 2010 & 28.11 & 23.55 & 2010 & 28.19 & 23.99 \\
\hline 2020 & 27.80 & 23.16 & 2020 & 28.12 & 23.56 & 2020 & 28.21 & 24.01 \\
\hline 2030 & 27.81 & 23.19 & 2030 & 28.13 & 23.60 & 2030 & 28.22 & 24.03 \\
\hline 2040 & 27.82 & 23.19 & 2040 & 28.14 & 23.61 & 2040 & 28.22 & 24.05 \\
\hline 2050 & 27.83 & 23.21 & 2050 & 28.16 & 23.62 & 2050 & 28.23 & 24.07 \\
\hline 2060 & 27.84 & 23.22 & 2060 & 28.18 & 23.66 & 2060 & 28.24 & 24.08 \\
\hline 2070 & 27.86 & 23.25 & 2070 & 28.18 & 23.66 & 2070 & 28.26 & 24.09 \\
\hline 2080 & 27.86 & 23.25 & 2080 & 28.19 & 23.68 & 2080 & 28.26 & 24.10 \\
\hline 2090 & 27.87 & 23.27 & 2090 & 28.21 & 23.70 & 2090 & 28.26 & 24.12 \\
\hline 2100 & 27.88 & 23.30 & 2100 & 28.20 & 23.73 & 2100 & 28.29 & 24.15 \\
\hline 2110 & 27.89 & 23.29 & 2110 & 28.22 & 23.74 & 2110 & 28.29 & 24.15 \\
\hline 2120 & 27.90 & 23.33 & 2120 & 28.23 & 23.76 & 2120 & 28.31 & 24.18 \\
\hline 2130 & 27.91 & 23.33 & 2130 & 28.24 & 23.77 & 2130 & 28.31 & 24.18 \\
\hline
\end{tabular}




\begin{tabular}{|c|c|c|c|c|c|c|c|c|}
\hline 2140 & 27.93 & 23.34 & 2140 & 28.26 & 23.78 & 2140 & 28.32 & 24.21 \\
\hline 2150 & 27.95 & 23.38 & 2150 & 28.26 & 23.79 & 2150 & 28.33 & 24.22 \\
\hline 2160 & 27.95 & 23.38 & 2160 & 28.27 & 23.82 & 2160 & 28.34 & 24.23 \\
\hline 2170 & 27.97 & 23.42 & 2170 & 28.28 & 23.83 & 2170 & 28.35 & 24.25 \\
\hline 2180 & 27.96 & 23.41 & 2180 & 28.30 & 23.85 & 2180 & 28.36 & 24.26 \\
\hline 2190 & 27.97 & 23.43 & 2190 & 28.31 & 23.87 & 2190 & 28.38 & 24.28 \\
\hline 2200 & 27.98 & 23.45 & 2200 & 28.32 & 23.89 & 2200 & 28.38 & 24.31 \\
\hline 2210 & 27.99 & 23.46 & 2210 & 28.34 & 23.91 & 2210 & 28.39 & 24.32 \\
\hline 2220 & 28.00 & 23.48 & 2220 & 28.35 & 23.93 & 2220 & 28.40 & 24.34 \\
\hline 2230 & 28.01 & 23.50 & 2230 & 28.35 & 23.94 & 2230 & 28.41 & 24.35 \\
\hline 2240 & 28.03 & 23.53 & 2240 & 28.36 & 23.95 & 2240 & 28.42 & 24.37 \\
\hline 2250 & 28.03 & 23.54 & 2250 & 28.38 & 23.98 & 2250 & 28.44 & 24.37 \\
\hline 2260 & 28.05 & 23.54 & 2260 & 28.37 & 23.99 & 2260 & 28.45 & 24.40 \\
\hline 2270 & 28.05 & 23.56 & 2270 & 28.40 & 24.01 & 2270 & 28.47 & 24.42 \\
\hline 2280 & 28.07 & 23.59 & 2280 & 28.41 & 24.03 & 2280 & 28.47 & 24.43 \\
\hline 2290 & 28.06 & 23.61 & 2290 & 28.41 & 24.03 & 2290 & 28.47 & 24.45 \\
\hline 2300 & 28.09 & 23.62 & 2300 & 28.43 & 24.06 & 2300 & 28.49 & 24.47 \\
\hline 2310 & 28.09 & 23.62 & 2310 & 28.44 & 24.08 & 2310 & 28.50 & 24.48 \\
\hline 2320 & 28.11 & 23.66 & 2320 & 28.45 & 24.09 & 2320 & 28.50 & 24.48 \\
\hline 2330 & 28.11 & 23.67 & 2330 & 28.47 & 24.11 & 2330 & 28.53 & 24.53 \\
\hline 2340 & 28.11 & 23.67 & 2340 & 28.46 & 24.12 & 2340 & 28.52 & 24.52 \\
\hline 2350 & 28.13 & 23.69 & 2350 & 28.47 & 24.14 & 2350 & 28.54 & 24.55 \\
\hline 2360 & 28.13 & 23.71 & 2360 & 28.49 & 24.15 & 2360 & 28.54 & 24.55 \\
\hline 2370 & 28.15 & 23.72 & 2370 & 28.49 & 24.17 & 2370 & 28.55 & 24.58 \\
\hline 2380 & 28.17 & 23.75 & 2380 & 28.50 & 24.19 & 2380 & 28.56 & 24.59 \\
\hline 2390 & 28.17 & 23.76 & 2390 & 28.52 & 24.20 & 2390 & 28.57 & 24.60 \\
\hline 2400 & 28.17 & 23.78 & 2400 & 28.54 & 24.21 & 2400 & 28.58 & 24.63 \\
\hline 2410 & 28.19 & 23.79 & 2410 & 28.55 & 24.24 & 2410 & 28.59 & 24.64 \\
\hline 2420 & 28.20 & 23.81 & 2420 & 28.54 & 24.25 & 2420 & 28.60 & 24.65 \\
\hline 2430 & 28.21 & 23.82 & 2430 & 28.55 & 24.26 & 2430 & 28.61 & 24.66 \\
\hline 2440 & 28.22 & 23.84 & 2440 & 28.56 & 24.28 & 2440 & 28.63 & 24.69 \\
\hline 2450 & 28.24 & 23.85 & 2450 & 28.58 & 24.30 & 2450 & 28.63 & 24.70 \\
\hline 2460 & 28.23 & 23.87 & 2460 & 28.57 & 24.31 & 2460 & 28.64 & 24.72 \\
\hline 2470 & 28.26 & 23.88 & 2470 & 28.60 & 24.33 & 2470 & 28.65 & 24.72 \\
\hline 2480 & 28.26 & 23.89 & 2480 & 28.60 & 24.34 & 2480 & 28.67 & 24.75 \\
\hline 2490 & 28.27 & 23.91 & 2490 & 28.60 & 24.36 & 2490 & 28.66 & 24.76 \\
\hline 2500 & 28.28 & 23.94 & 2500 & 28.62 & 24.38 & 2500 & 28.66 & 24.78 \\
\hline 2510 & 28.29 & 23.94 & 2510 & 28.63 & 24.38 & 2510 & 28.69 & 24.79 \\
\hline 2520 & 28.30 & 23.97 & 2520 & 28.64 & 24.40 & 2520 & 28.71 & 24.81 \\
\hline 2530 & 28.32 & 23.99 & 2530 & 28.65 & 24.42 & 2530 & 28.70 & 24.83 \\
\hline 2540 & 28.33 & 24.01 & 2540 & 28.65 & 24.43 & 2540 & 28.71 & 24.85 \\
\hline 2550 & 28.34 & 24.02 & 2550 & 28.67 & 24.46 & 2550 & 28.71 & 24.84 \\
\hline 2560 & 28.34 & 24.04 & 2560 & 28.68 & 24.47 & 2560 & 28.72 & 24.88 \\
\hline 2570 & 28.35 & 24.06 & 2570 & 28.68 & 24.48 & 2570 & 28.74 & 24.90 \\
\hline
\end{tabular}




\begin{tabular}{|c|c|c|c|c|c|c|c|c|}
\hline 2580 & 28.34 & 24.07 & 2580 & 28.70 & 24.51 & 2580 & 28.76 & 24.91 \\
\hline 2590 & 28.37 & 24.09 & 2590 & 28.70 & 24.52 & 2590 & 28.77 & 24.92 \\
\hline 2600 & 28.36 & 24.09 & 2600 & 28.71 & 24.53 & 2600 & 28.78 & 24.94 \\
\hline 2610 & 28.39 & 24.12 & 2610 & 28.73 & 24.56 & 2610 & 28.79 & 24.97 \\
\hline 2620 & 28.41 & 24.13 & 2620 & 28.73 & 24.56 & 2620 & 28.79 & 24.98 \\
\hline 2630 & 28.40 & 24.15 & 2630 & 28.75 & 24.59 & 2630 & 28.80 & 24.99 \\
\hline 2640 & 28.41 & 24.17 & 2640 & 28.77 & 24.61 & 2640 & 28.81 & 25.01 \\
\hline 2650 & 28.42 & 24.18 & 2650 & 28.76 & 24.61 & 2650 & 28.82 & 25.03 \\
\hline 2660 & 28.44 & 24.21 & 2660 & 28.76 & 24.64 & 2660 & 28.83 & 25.03 \\
\hline 2670 & 28.43 & 24.21 & 2670 & 28.79 & 24.65 & 2670 & 28.83 & 25.06 \\
\hline 2680 & 28.45 & 24.23 & 2680 & 28.79 & 24.68 & 2680 & 28.85 & 25.07 \\
\hline 2690 & 28.46 & 24.24 & 2690 & 28.81 & 24.67 & 2690 & 28.86 & 25.09 \\
\hline 2700 & 28.46 & 24.26 & 2700 & 28.81 & 24.71 & 2700 & 28.87 & 25.11 \\
\hline 2710 & 28.48 & 24.28 & 2710 & 28.82 & 24.72 & 2710 & 28.88 & 25.12 \\
\hline 2720 & 28.49 & 24.29 & 2720 & 28.84 & 24.73 & 2720 & 28.89 & 25.14 \\
\hline 2730 & 28.49 & 24.31 & 2730 & 28.84 & 24.76 & 2730 & 28.90 & 25.15 \\
\hline 2740 & 28.50 & 24.32 & 2740 & 28.85 & 24.77 & 2740 & 28.91 & 25.17 \\
\hline 2750 & 28.51 & 24.34 & 2750 & 28.86 & 24.78 & 2750 & 28.92 & 25.21 \\
\hline 2760 & 28.52 & 24.35 & 2760 & 28.86 & 24.80 & 2760 & 28.94 & 25.22 \\
\hline 2770 & 28.53 & 24.37 & 2770 & 28.87 & 24.81 & 2770 & 28.94 & 25.23 \\
\hline 2780 & 28.54 & 24.38 & 2780 & 28.88 & 24.83 & 2780 & 28.94 & 25.24 \\
\hline 2790 & 28.55 & 24.42 & 2790 & 28.89 & 24.85 & 2790 & 28.95 & 25.26 \\
\hline 2800 & 28.55 & 24.41 & 2800 & 28.91 & 24.86 & 2800 & 28.97 & 25.29 \\
\hline 2810 & 28.56 & 24.43 & 2810 & 28.91 & 24.88 & 2810 & 28.98 & 25.29 \\
\hline 2820 & 28.57 & 24.45 & 2820 & 28.92 & 24.92 & 2820 & 28.98 & 25.33 \\
\hline 2830 & 28.58 & 24.47 & 2830 & 28.94 & 24.92 & 2830 & 28.98 & 25.34 \\
\hline 2840 & 28.58 & 24.47 & 2840 & 28.94 & 24.94 & 2840 & 29.00 & 25.36 \\
\hline 2850 & 28.60 & 24.50 & 2850 & 28.94 & 24.95 & 2850 & 29.00 & 25.37 \\
\hline 2860 & 28.61 & 24.52 & 2860 & 28.96 & 24.97 & 2860 & 29.01 & 25.39 \\
\hline 2870 & 28.62 & 24.53 & 2870 & 28.96 & 24.98 & 2870 & 29.01 & 25.40 \\
\hline 2880 & 28.64 & 24.56 & 2880 & 28.98 & 25.01 & 2880 & 29.03 & 25.43 \\
\hline 2890 & 28.64 & 24.55 & 2890 & 28.97 & 25.04 & 2890 & 29.04 & 25.45 \\
\hline 2900 & 28.64 & 24.58 & 2900 & 29.00 & 25.04 & 2900 & 29.05 & 25.46 \\
\hline 2910 & 28.66 & 24.60 & 2910 & 29.00 & 25.07 & 2910 & 29.05 & 25.48 \\
\hline 2920 & 28.66 & 24.62 & 2920 & 29.02 & 25.09 & 2920 & 29.07 & 25.50 \\
\hline 2930 & 28.67 & 24.63 & 2930 & 29.02 & 25.11 & 2930 & 29.08 & 25.52 \\
\hline 2940 & 28.68 & 24.65 & 2940 & 29.03 & 25.11 & 2940 & 29.09 & 25.54 \\
\hline 2950 & 28.69 & 24.68 & 2950 & 29.04 & 25.12 & 2950 & 29.10 & 25.56 \\
\hline 2960 & 28.70 & 24.67 & 2960 & 29.04 & 25.14 & 2960 & 29.10 & 25.58 \\
\hline 2970 & 28.71 & 24.69 & 2970 & 29.07 & 25.17 & 2970 & 29.11 & 25.61 \\
\hline 2980 & 28.71 & 24.71 & 2980 & 29.05 & 25.18 & 2980 & 29.12 & 25.60 \\
\hline 2990 & 28.71 & 24.73 & 2990 & 29.06 & 25.20 & 2990 & 29.12 & 25.63 \\
\hline 3000 & 28.74 & 24.75 & 3000 & 29.07 & 25.22 & 3000 & 29.12 & 25.66 \\
\hline 3010 & 28.74 & 24.75 & 3010 & 29.08 & 25.23 & 3010 & 29.14 & 25.68 \\
\hline
\end{tabular}




\begin{tabular}{|c|c|c|c|c|c|c|c|c|}
\hline 3020 & 28.75 & 24.78 & 3020 & 29.09 & 25.26 & 3020 & 29.15 & 25.70 \\
\hline 3030 & 28.75 & 24.79 & 3030 & 29.10 & 25.26 & 3030 & 29.15 & 25.71 \\
\hline 3040 & 28.79 & 24.80 & 3040 & 29.12 & 25.29 & 3040 & 29.18 & 25.74 \\
\hline 3050 & 28.78 & 24.83 & 3050 & 29.13 & 25.31 & 3050 & 29.18 & 25.76 \\
\hline 3060 & 28.80 & 24.85 & 3060 & 29.13 & 25.32 & 3060 & 29.19 & 25.76 \\
\hline 3070 & 28.79 & 24.86 & 3070 & 29.13 & 25.33 & 3070 & 29.20 & 25.79 \\
\hline 3080 & 28.80 & 24.87 & 3080 & 29.15 & 25.36 & 3080 & 29.21 & 25.81 \\
\hline 3090 & 28.81 & 24.89 & 3090 & 29.15 & 25.37 & 3090 & 29.22 & 25.82 \\
\hline 3100 & 28.83 & 24.91 & 3100 & 29.16 & 25.39 & 3100 & 29.22 & 25.86 \\
\hline 3110 & 28.83 & 24.94 & 3110 & 29.16 & 25.41 & 3110 & 29.24 & 25.87 \\
\hline 3120 & 28.84 & 24.96 & 3120 & 29.18 & 25.44 & 3120 & 29.24 & 25.90 \\
\hline 3130 & 28.84 & 24.97 & 3130 & 29.18 & 25.46 & 3130 & 29.25 & 25.91 \\
\hline 3140 & 28.85 & 24.98 & 3140 & 29.19 & 25.47 & 3140 & 29.25 & 25.94 \\
\hline 3150 & 28.88 & 25.00 & 3150 & 29.20 & 25.49 & 3150 & 29.27 & 25.96 \\
\hline 3160 & 28.87 & 25.01 & 3160 & 29.21 & 25.52 & 3160 & 29.28 & 25.98 \\
\hline 3170 & 28.88 & 25.03 & 3170 & 29.23 & 25.53 & 3170 & 29.28 & 26.00 \\
\hline 3180 & 28.89 & 25.05 & 3180 & 29.23 & 25.56 & 3180 & 29.30 & 26.03 \\
\hline 3190 & 28.90 & 25.06 & 3190 & 29.24 & 25.57 & 3190 & 29.31 & 26.05 \\
\hline 3200 & 28.91 & 25.09 & 3200 & 29.24 & 25.59 & 3200 & 29.32 & 26.06 \\
\hline 3210 & 28.92 & 25.10 & 3210 & 29.25 & 25.61 & 3210 & 29.33 & 26.08 \\
\hline 3220 & 28.93 & 25.11 & 3220 & 29.27 & 25.62 & 3220 & 29.32 & 26.12 \\
\hline 3230 & 28.94 & 25.14 & 3230 & 29.27 & 25.64 & 3230 & 29.34 & 26.14 \\
\hline 3240 & 28.95 & 25.15 & 3240 & 29.29 & 25.67 & 3240 & 29.34 & 26.15 \\
\hline 3250 & 28.96 & 25.17 & 3250 & 29.29 & 25.68 & 3250 & 29.34 & 26.17 \\
\hline 3260 & 28.97 & 25.18 & 3260 & 29.30 & 25.71 & 3260 & 29.36 & 26.19 \\
\hline 3270 & 28.97 & 25.21 & 3270 & 29.29 & 25.73 & 3270 & 29.37 & 26.22 \\
\hline 3280 & 28.98 & 25.23 & 3280 & 29.32 & 25.75 & 3280 & 29.38 & 26.25 \\
\hline 3290 & 29.00 & 25.26 & 3290 & 29.31 & 25.78 & 3290 & 29.39 & 26.26 \\
\hline 3300 & 29.00 & 25.26 & 3300 & 29.33 & 25.81 & 3300 & 29.40 & 26.29 \\
\hline 3310 & 29.00 & 25.28 & 3310 & 29.34 & 25.82 & 3310 & 29.41 & 26.31 \\
\hline 3320 & 29.01 & 25.31 & 3320 & 29.35 & 25.84 & 3320 & 29.40 & 26.33 \\
\hline 3330 & 29.04 & 25.33 & 3330 & 29.35 & 25.87 & 3330 & 29.41 & 26.37 \\
\hline 3340 & 29.04 & 25.34 & 3340 & 29.37 & 25.89 & 3340 & 29.43 & 26.39 \\
\hline 3350 & 29.04 & 25.36 & 3350 & 29.38 & 25.91 & 3350 & 29.43 & 26.40 \\
\hline 3360 & 29.05 & 25.38 & 3360 & 29.38 & 25.94 & 3360 & 29.43 & 26.43 \\
\hline 3370 & 29.06 & 25.40 & 3370 & 29.39 & 25.95 & 3370 & 29.45 & 26.45 \\
\hline 3380 & 29.06 & 25.42 & 3380 & 29.39 & 25.98 & 3380 & 29.46 & 26.48 \\
\hline 3390 & 29.08 & 25.45 & 3390 & 29.42 & 26.01 & 3390 & 29.47 & 26.51 \\
\hline 3400 & 29.08 & 25.45 & 3400 & 29.42 & 26.03 & 3400 & 29.48 & 26.53 \\
\hline 3410 & 29.10 & 25.47 & 3410 & 29.42 & 26.05 & 3410 & 29.48 & 26.56 \\
\hline 3420 & 29.09 & 25.50 & 3420 & 29.42 & 26.07 & 3420 & 29.50 & 26.59 \\
\hline 3430 & 29.11 & 25.52 & 3430 & 29.43 & 26.09 & 3430 & 29.51 & 26.62 \\
\hline 3440 & 29.10 & 25.53 & 3440 & 29.45 & 26.12 & 3440 & 29.53 & 26.65 \\
\hline 3450 & 29.13 & 25.55 & 3450 & 29.45 & 26.14 & 3450 & 29.51 & 26.66 \\
\hline
\end{tabular}




\begin{tabular}{|c|c|c|c|c|c|c|c|c|}
\hline 3460 & 29.14 & 25.58 & 3460 & 29.47 & 26.17 & 3460 & 29.52 & 26.69 \\
\hline 3470 & 29.14 & 25.60 & 3470 & 29.47 & 26.21 & 3470 & 29.53 & 26.71 \\
\hline 3480 & 29.15 & 25.62 & 3480 & 29.48 & 26.21 & 3480 & 29.55 & 26.75 \\
\hline 3490 & 29.16 & 25.64 & 3490 & 29.49 & 26.25 & 3490 & 29.56 & 26.76 \\
\hline 3500 & 29.17 & 25.67 & 3500 & 29.51 & 26.27 & 3500 & 29.55 & 26.79 \\
\hline 3510 & 29.18 & 25.69 & 3510 & 29.52 & 26.30 & 3510 & 29.58 & 26.83 \\
\hline 3520 & 29.18 & 25.71 & 3520 & 29.52 & 26.32 & 3520 & 29.58 & 26.86 \\
\hline 3530 & 29.20 & 25.74 & 3530 & 29.53 & 26.35 & 3530 & 29.60 & 26.89 \\
\hline 3540 & 29.20 & 25.76 & 3540 & 29.53 & 26.38 & 3540 & 29.60 & 26.89 \\
\hline 3550 & 29.21 & 25.79 & 3550 & 29.54 & 26.40 & 3550 & 29.60 & 26.93 \\
\hline 3560 & 29.22 & 25.80 & 3560 & 29.54 & 26.41 & 3560 & 29.62 & 26.97 \\
\hline 3570 & 29.23 & 25.83 & 3570 & 29.57 & 26.45 & 3570 & 29.62 & 27.00 \\
\hline 3580 & 29.22 & 25.85 & 3580 & 29.57 & 26.47 & 3580 & 29.63 & 27.03 \\
\hline 3590 & 29.25 & 25.87 & 3590 & 29.58 & 26.50 & 3590 & 29.64 & 27.05 \\
\hline 3600 & 29.24 & 25.88 & 3600 & 29.59 & 26.54 & 3600 & 29.64 & 27.07 \\
\hline 3610 & 29.26 & 25.91 & 3610 & 29.60 & 26.56 & 3610 & 29.66 & 27.10 \\
\hline 3620 & 29.27 & 25.93 & 3620 & 29.60 & 26.57 & 3620 & 29.67 & 27.13 \\
\hline 3630 & 29.28 & 25.95 & 3630 & 29.62 & 26.61 & 3630 & 29.69 & 27.16 \\
\hline 3640 & 29.28 & 25.98 & 3640 & 29.62 & 26.64 & 3640 & 29.69 & 27.19 \\
\hline 3650 & 29.30 & 26.02 & 3650 & 29.62 & 26.66 & 3650 & 29.70 & 27.23 \\
\hline 3660 & 29.30 & 26.02 & 3660 & 29.64 & 26.69 & 3660 & 29.70 & 27.25 \\
\hline 3670 & 29.32 & 26.06 & 3670 & 29.65 & 26.72 & 3670 & 29.72 & 27.28 \\
\hline 3680 & 29.33 & 26.08 & 3680 & 29.65 & 26.74 & 3680 & 29.72 & 27.31 \\
\hline 3690 & 29.33 & 26.11 & 3690 & 29.67 & 26.77 & 3690 & 29.73 & 27.34 \\
\hline 3700 & 29.34 & 26.13 & 3700 & 29.67 & 26.80 & 3700 & 29.73 & 27.37 \\
\hline 3710 & 29.35 & 26.15 & 3710 & 29.67 & 26.82 & 3710 & 29.75 & 27.40 \\
\hline 3720 & 29.36 & 26.18 & 3720 & 29.69 & 26.85 & 3720 & 29.76 & 27.44 \\
\hline 3730 & 29.37 & 26.21 & 3730 & 29.70 & 26.89 & 3730 & 29.76 & 27.46 \\
\hline 3740 & 29.37 & 26.23 & 3740 & 29.70 & 26.91 & 3740 & 29.78 & 27.49 \\
\hline 3750 & 29.38 & 26.27 & 3750 & 29.71 & 26.93 & 3750 & 29.78 & 27.50 \\
\hline 3760 & 29.39 & 26.28 & 3760 & 29.71 & 26.96 & 3760 & 29.80 & 27.54 \\
\hline 3770 & 29.40 & 26.32 & 3770 & 29.73 & 27.00 & 3770 & 29.79 & 27.58 \\
\hline 3780 & 29.40 & 26.32 & 3780 & 29.73 & 27.02 & 3780 & 29.81 & 27.60 \\
\hline 3790 & 29.41 & 26.36 & 3790 & 29.74 & 27.06 & 3790 & 29.84 & 27.64 \\
\hline 3800 & 29.41 & 26.38 & 3800 & 29.75 & 27.08 & 3800 & 29.82 & 27.66 \\
\hline 3810 & 29.43 & 26.40 & 3810 & 29.75 & 27.10 & 3810 & 29.84 & 27.70 \\
\hline 3820 & 29.44 & 26.43 & 3820 & 29.76 & 27.13 & 3820 & 29.85 & 27.71 \\
\hline 3830 & 29.46 & 26.47 & 3830 & 29.77 & 27.17 & 3830 & 29.86 & 27.75 \\
\hline 3840 & 29.45 & 26.49 & 3840 & 29.80 & 27.21 & 3840 & 29.86 & 27.79 \\
\hline 3850 & 29.48 & 26.52 & 3850 & 29.79 & 27.23 & 3850 & 29.88 & 27.82 \\
\hline 3860 & 29.48 & 26.54 & 3860 & 29.80 & 27.25 & 3860 & 29.88 & 27.86 \\
\hline 3870 & 29.48 & 26.56 & 3870 & 29.82 & 27.29 & 3870 & 29.90 & 27.87 \\
\hline 3880 & 29.50 & 26.60 & 3880 & 29.83 & 27.31 & 3880 & 29.90 & 27.90 \\
\hline 3890 & 29.51 & 26.63 & 3890 & 29.83 & 27.35 & 3890 & 29.92 & 27.95 \\
\hline
\end{tabular}




\begin{tabular}{|c|c|c|c|c|c|c|c|c|}
\hline 3900 & 29.51 & 26.64 & 3900 & 29.84 & 27.37 & 3900 & 29.92 & 27.96 \\
\hline 3910 & 29.53 & 26.68 & 3910 & 29.86 & 27.41 & 3910 & 29.93 & 27.99 \\
\hline 3920 & 29.54 & 26.72 & 3920 & 29.86 & 27.43 & 3920 & 29.93 & 28.03 \\
\hline 3930 & 29.53 & 26.74 & 3930 & 29.87 & 27.47 & 3930 & 29.95 & 28.06 \\
\hline 3940 & 29.55 & 26.77 & 3940 & 29.88 & 27.49 & 3940 & 29.97 & 28.08 \\
\hline 3950 & 29.55 & 26.80 & 3950 & 29.88 & 27.53 & 3950 & 29.97 & 28.11 \\
\hline 3960 & 29.56 & 26.83 & 3960 & 29.90 & 27.56 & 3960 & 29.99 & 28.16 \\
\hline 3970 & 29.58 & 26.85 & 3970 & 29.90 & 27.59 & 3970 & 29.99 & 28.17 \\
\hline 3980 & 29.59 & 26.88 & 3980 & 29.91 & 27.62 & 3980 & 30.01 & 28.20 \\
\hline 3990 & 29.60 & 26.90 & 3990 & 29.92 & 27.66 & 3990 & 30.02 & 28.23 \\
\hline 4000 & 29.61 & 26.94 & 4000 & 29.93 & 27.69 & 4000 & 30.02 & 28.26 \\
\hline 4010 & 29.61 & 26.97 & 4010 & 29.95 & 27.72 & 4010 & 30.03 & 28.29 \\
\hline 4020 & 29.62 & 27.00 & 4020 & 29.95 & 27.74 & 4020 & 30.05 & 28.32 \\
\hline 4030 & 29.63 & 27.04 & 4030 & 29.96 & 27.78 & 4030 & 30.04 & 28.34 \\
\hline 4040 & 29.63 & 27.06 & 4040 & 29.96 & 27.81 & 4040 & 30.06 & 28.38 \\
\hline 4050 & 29.65 & 27.09 & 4050 & 29.98 & 27.83 & 4050 & 30.07 & 28.41 \\
\hline 4060 & 29.65 & 27.12 & 4060 & 29.99 & 27.85 & 4060 & 30.07 & 28.42 \\
\hline 4070 & 29.67 & 27.15 & 4070 & 29.99 & 27.88 & 4070 & 30.09 & 28.45 \\
\hline 4080 & 29.67 & 27.18 & 4080 & 30.00 & 27.92 & 4080 & 30.09 & 28.47 \\
\hline 4090 & 29.69 & 27.21 & 4090 & 30.02 & 27.97 & 4090 & 30.11 & 28.51 \\
\hline 4100 & 29.70 & 27.24 & 4100 & 30.01 & 27.99 & 4100 & 30.12 & 28.54 \\
\hline 4110 & 29.71 & 27.28 & 4110 & 30.02 & 27.99 & 4110 & 30.13 & 28.57 \\
\hline 4120 & 29.71 & 27.30 & 4120 & 30.03 & 28.04 & 4120 & 30.15 & 28.60 \\
\hline 4130 & 29.71 & 27.32 & 4130 & 30.05 & 28.07 & 4130 & 30.14 & 28.62 \\
\hline 4140 & 29.72 & 27.37 & 4140 & 30.06 & 28.10 & 4140 & 30.15 & 28.65 \\
\hline 4150 & 29.74 & 27.39 & 4150 & 30.06 & 28.13 & 4150 & 30.17 & 28.68 \\
\hline 4160 & 29.75 & 27.42 & 4160 & 30.07 & 28.16 & 4160 & 30.17 & 28.70 \\
\hline 4170 & 29.76 & 27.45 & 4170 & 30.08 & 28.19 & 4170 & 30.18 & 28.73 \\
\hline 4180 & 29.77 & 27.47 & 4180 & 30.08 & 28.21 & 4180 & 30.18 & 28.75 \\
\hline 4190 & 29.77 & 27.51 & 4190 & 30.09 & 28.24 & 4190 & 30.19 & 28.78 \\
\hline 4200 & 29.79 & 27.53 & 4200 & 30.11 & 28.27 & 4200 & 30.20 & 28.81 \\
\hline 4210 & 29.79 & 27.58 & 4210 & 30.12 & 28.31 & 4210 & 30.21 & 28.82 \\
\hline 4220 & 29.81 & 27.60 & 4220 & 30.11 & 28.32 & 4220 & 30.22 & 28.85 \\
\hline 4230 & 29.81 & 27.63 & 4230 & 30.13 & 28.37 & 4230 & 30.22 & 28.87 \\
\hline 4240 & 29.83 & 27.65 & 4240 & 30.14 & 28.39 & 4240 & 30.23 & 28.90 \\
\hline 4250 & 29.83 & 27.69 & 4250 & 30.14 & 28.42 & 4250 & 30.24 & 28.92 \\
\hline 4260 & 29.85 & 27.72 & 4260 & 30.16 & 28.46 & 4260 & 30.26 & 28.94 \\
\hline 4270 & 29.85 & 27.75 & 4270 & 30.17 & 28.49 & 4270 & 30.25 & 28.97 \\
\hline 4280 & 29.87 & 27.79 & 4280 & 30.18 & 28.52 & 4280 & 30.27 & 28.99 \\
\hline 4290 & 29.88 & 27.82 & 4290 & 30.18 & 28.55 & 4290 & 30.29 & 29.03 \\
\hline 4300 & 29.87 & 27.83 & 4300 & 30.20 & 28.57 & 4300 & 30.30 & 29.04 \\
\hline 4310 & 29.88 & 27.85 & 4310 & 30.20 & 28.60 & 4310 & 30.32 & 29.09 \\
\hline 4320 & 29.90 & 27.90 & 4320 & 30.21 & 28.62 & 4320 & 30.31 & 29.09 \\
\hline 4330 & 29.92 & 27.92 & 4330 & 30.22 & 28.65 & 4330 & 30.31 & 29.11 \\
\hline
\end{tabular}




\begin{tabular}{|c|c|c|c|c|c|c|c|c|}
\hline 4340 & 29.92 & 27.94 & 4340 & 30.23 & 28.67 & 4340 & 30.32 & 29.15 \\
\hline 4350 & 29.93 & 27.98 & 4350 & 30.25 & 28.71 & 4350 & 30.35 & 29.16 \\
\hline 4360 & 29.95 & 28.02 & 4360 & 30.26 & 28.72 & 4360 & 30.35 & 29.18 \\
\hline 4370 & 29.94 & 28.04 & 4370 & 30.26 & 28.76 & 4370 & 30.36 & 29.21 \\
\hline 4380 & 29.95 & 28.07 & 4380 & 30.27 & 28.78 & 4380 & 30.37 & 29.23 \\
\hline 4390 & 29.98 & 28.09 & 4390 & 30.27 & 28.81 & 4390 & 30.37 & 29.24 \\
\hline 4400 & 29.99 & 28.12 & 4400 & 30.29 & 28.84 & 4400 & 30.38 & 29.27 \\
\hline 4410 & 30.00 & 28.16 & 4410 & 30.30 & 28.86 & 4410 & 30.40 & 29.31 \\
\hline 4420 & 30.01 & 28.18 & 4420 & 30.31 & 28.89 & 4420 & 30.40 & 29.32 \\
\hline 4430 & 30.00 & 28.22 & 4430 & 30.31 & 28.92 & 4430 & 30.41 & 29.35 \\
\hline 4440 & 30.02 & 28.24 & 4440 & 30.32 & 28.93 & & & \\
\hline 4450 & 30.03 & 28.26 & 4450 & 30.32 & 28.95 & & & \\
\hline 4460 & 30.04 & 28.31 & 4460 & 30.33 & 28.99 & & & \\
\hline 4470 & 30.05 & 28.32 & 4470 & 30.35 & 29.00 & & & \\
\hline 4480 & 30.06 & 28.35 & & & & & & \\
\hline 4490 & 30.07 & 28.37 & & & & & & \\
\hline 4500 & 30.07 & 28.40 & & & & & & \\
\hline 4510 & 30.09 & 28.45 & & & & & & \\
\hline 4520 & 30.10 & 28.46 & & & & & & \\
\hline 4530 & 30.12 & 28.49 & & & & & & \\
\hline 4540 & 30.12 & 28.51 & & & & & & \\
\hline 4550 & 30.13 & 28.53 & & & & & & \\
\hline 4560 & 30.13 & 28.57 & & & & & & \\
\hline 4570 & 30.15 & 28.60 & & & & & & \\
\hline 4580 & 30.16 & 28.62 & & & & & & \\
\hline 4590 & 30.16 & 28.65 & & & & & & \\
\hline 4600 & 30.17 & 28.69 & & & & & & \\
\hline 4610 & 30.18 & 28.70 & & & & & & \\
\hline 4620 & 30.21 & 28.73 & & & & & & \\
\hline 4630 & 30.20 & 28.77 & & & & & & \\
\hline 4640 & 30.21 & 28.77 & & & & & & \\
\hline 4650 & 30.24 & 28.82 & & & & & & \\
\hline 4660 & 30.24 & 28.84 & & & & & & \\
\hline 4670 & 30.24 & 28.87 & & & & & & \\
\hline 4680 & 30.27 & 28.89 & & & & & & \\
\hline 4690 & 30.26 & 28.91 & & & & & & \\
\hline 4700 & 30.27 & 28.93 & & & & & & \\
\hline 4710 & 30.28 & 28.96 & & & & & & \\
\hline 4720 & 30.30 & 28.99 & & & & & & \\
\hline 4730 & 30.29 & 29.01 & & & & & & \\
\hline
\end{tabular}

